Universidad de Lima

Facultad de Ingeniería Industrial

Carrera de Ingeniería Industrial

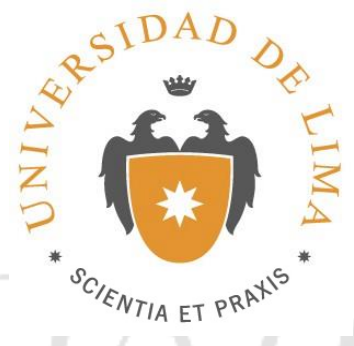

\title{
ESTUDIO DE PREFACTIBILIDAD PARA LA INSTALACIÓN DE UNA PLANTA DE ELABORACIÓN DE UN COMPLEMENTO ALIMENTICIO EN POLVO A BASE DE HARINA DE SANGRE DE POLLO Y CACAO.
}

Trabajo de investigación para optar el Título Profesional de Ingeniero Industrial

\author{
Renzo Renato Urrelo Costa \\ Código 20101142
}

Asesor

Elizabeth Liliana Herrera Vásquez

Lima - Perú

Setiembre de 2016 


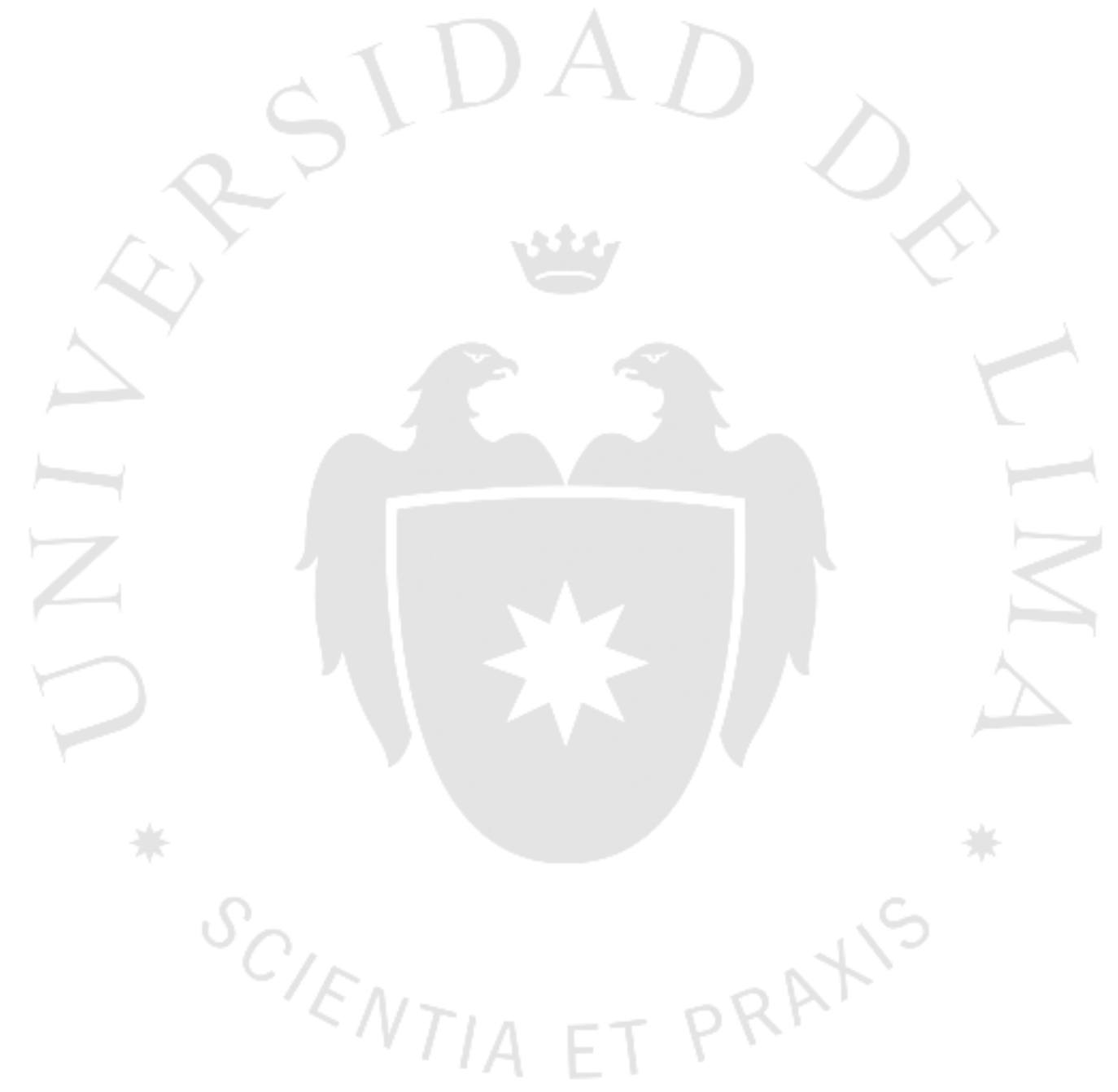




\section{ESTUDIO DE PREFACTIBILIDAD PARA LA}

INSTALACIÓN DE UNA PLANTA DE ELABORACIÓN DE UN COMPLEMENTO

\section{ALIMENTICIO EN POLVO A BASE DE HARINA DE SANGRE DE POLLO Y CACAO.}




\section{TABLA DE CONTENIDO}

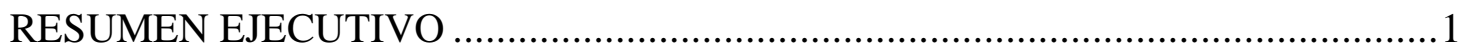

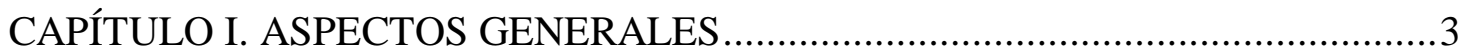

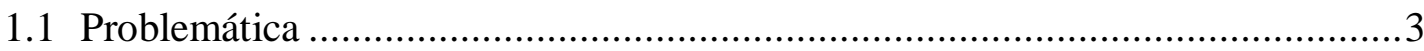

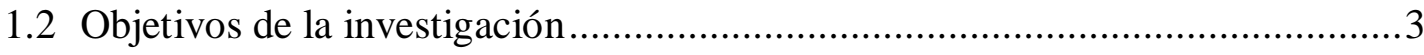

1.3 Alcance y limitaciones de la investigación.....................................................4

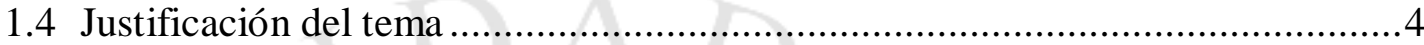

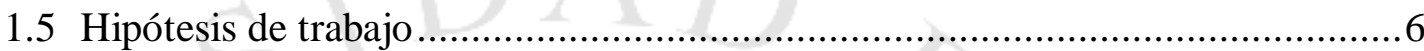

1.6 Marco referencial de la investigación ..........................................................6

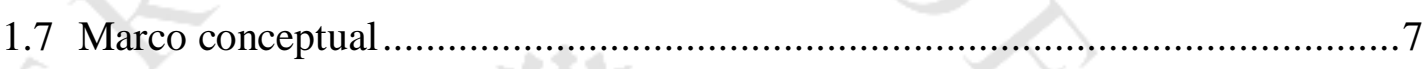

CAPÍTULO II. ESTUDIO DE MERCADO …................................................. 9

2.1 Aspectos generales del estudio de mercado .............................................

2.1.1Definición comercial del producto .....................................................9

2.1.2Principales características del producto ............................................ 10

2.1.2.1Usos y características del producto .................................................... 10

2.1.2.2Bienes sustitutos y complementarios ............................................ 10

2.1.3Determinación del área geográfica que abarcará el estudio ...................11

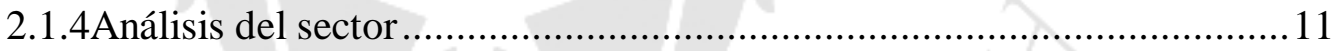

2.1.5Determinación de la metodología que se empleará en la

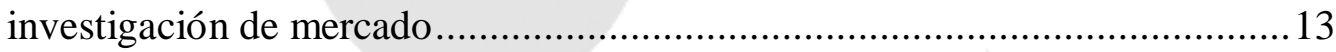

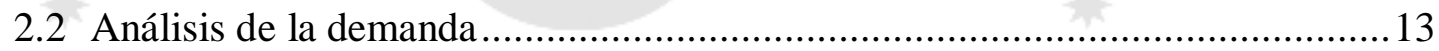

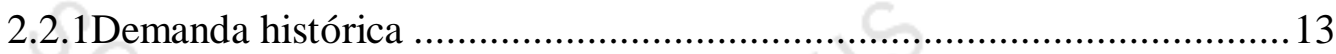

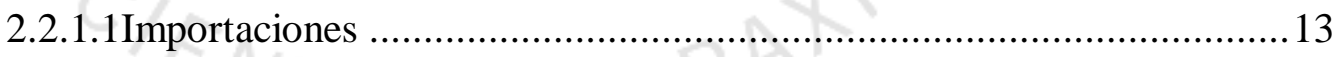

2.2.1.2Producción nacional ................................................................. 14

2.2.1.3Demanda interna aparente (DIA) ............................................... 14

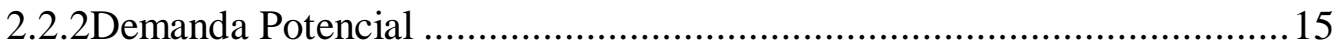

2.2.2.1Patrones de consumo: incremento poblacional, consumo per

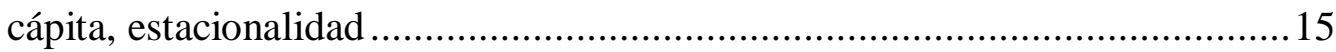

2.2.2.2Determinación de la demanda potencial .......................................... 17

2.2.3Demanda mediante fuentes primarias ................................................ 18

2.2.3.1Diseño y aplicación de encuestas u otras técnicas ............................ 18

2.2.3.2Determinación de la demanda ....................................................22 
2.2.4Proyección de la demanda

2.2.5Consideraciones sobre la vida útil del proyecto ................................23

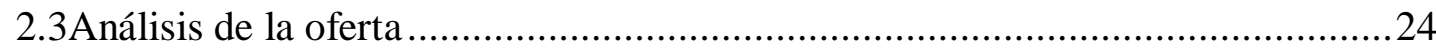

2.3.1Empresas productoras, importadoras y comercializadoras ....................2 24

2.3.2Competidores actuales y potenciales …...........................................24

2.4Determinación de la demanda para el proyecto ...........................................25

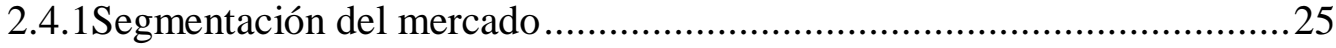

2.4.2Selección del mercado meta ...............................................................26

2.4.3Demanda específica para el proyecto.................................................28

2.5Definición de la estrategia de comercialización...............................................29

2.5.1Políticas de comercialización y distribución ......................................229

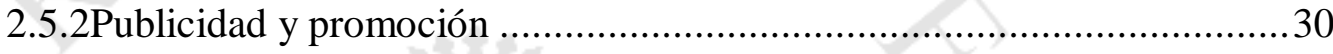

2.5.3Análisis de precios ..................................................................... 31

2.5.3.1Tendencia histórica de los precios ................................................. 31

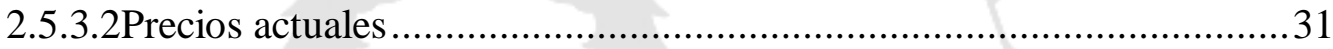

2.6Análisis de disponibilidad de los insumos principales .................................... 31

2.6.1Características principales de la materia prima ....................................31

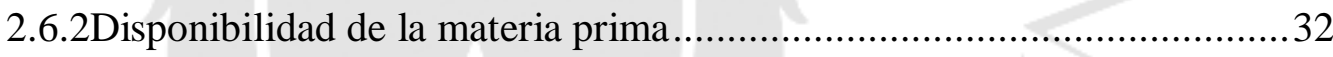

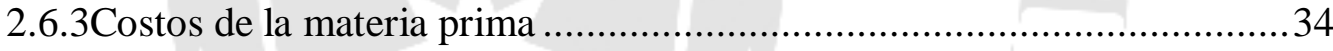

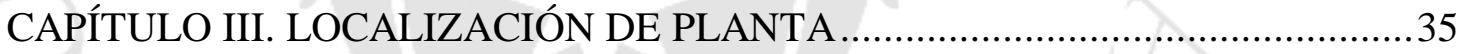

3.1 Identificación y análisis detallado de los factores de localización.......................35

3.2 Identificación y descripción de las alternativas de localización .........................36

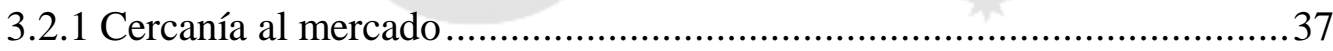

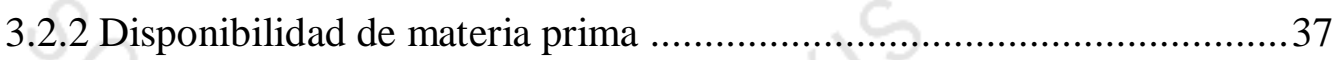

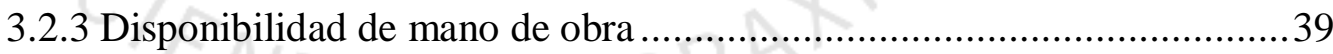

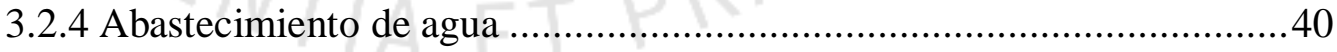

3.2.5 Disponibilidad de energía eléctrica.................................................4 41

3.3 Evaluación y selección de localización.................................................44

3.3.1 Evaluación y selección de macro localización ......................................44

3.3.2 Evaluación y selección de micro localización......................................45

3.3.2.1Disponibilidad de terrenos......................................46

3.3.2.2 Costo e terrenos................................................47

3.3.2.3Rutas de Acceso................................................. 48

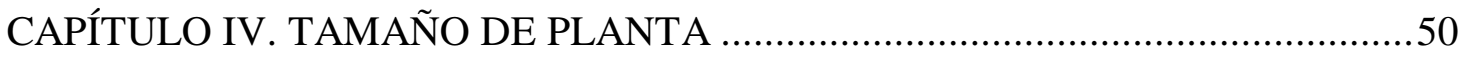


4.1 Relación tamaño-mercado .50

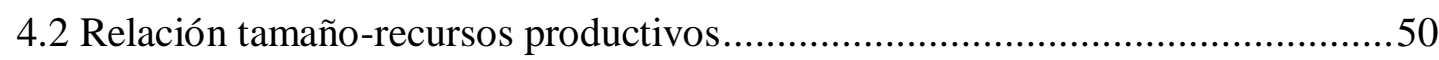

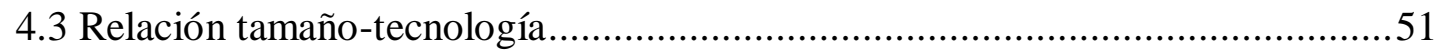

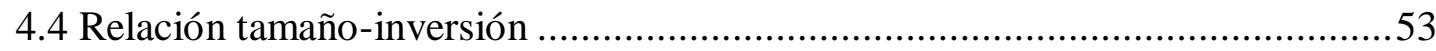

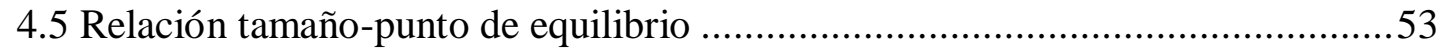

4.6 Selección del tamaño de planta ................................................................56

CAPÍTULO V. INGENIERÍA DEL PROYECTO................................................57

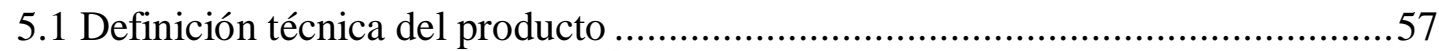

5.1.1 Especificaciones técnicas del producto ..............................................57

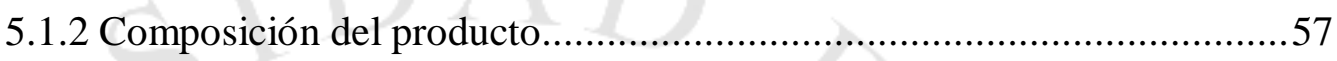

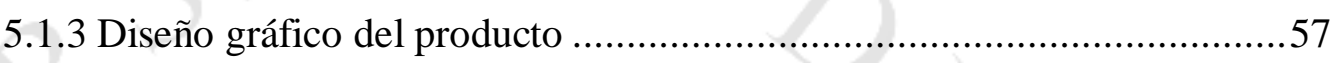

5.1.4 Regulaciones técnicas del producto ............................................58

5.2 Tecnologías existentes y procesos de producción............................................59

5.2.1 Naturaleza de la tecnología requerida ...........................................59

5.2.1.1 Descripción de la tecnología existente ............................................59

5.2.1.2 Selección de la tecnología ......................................................60

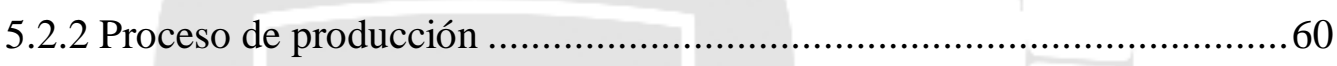

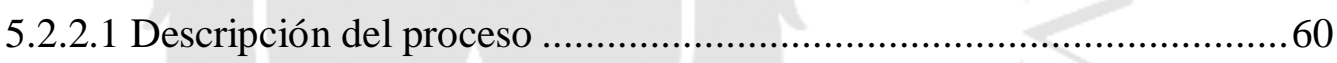

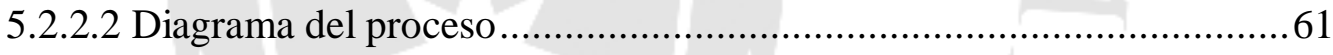

5.2.2.3 Balance de materia: Diagrama de bloques .......................................63

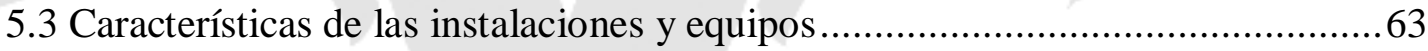

5.3.1 Selección de la maquinaria y equipos ...............................................63

5.3.2 Especificaciones de la maquinaria ................................................64

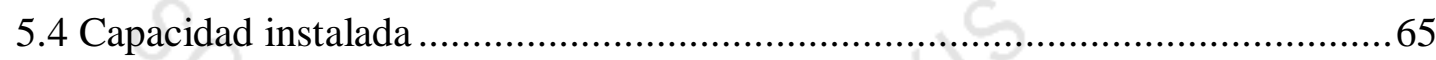

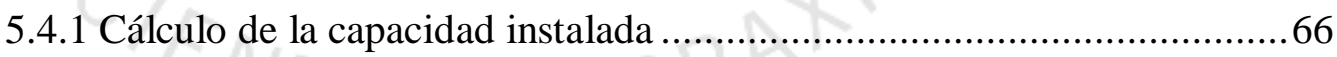

5.4.2 Cálculo detallado del número de máquinas requerido ..........................66

5.5 Aseguramiento de la calidad e inocuidad del producto ..................................69

5.5.1 Calidad de la materia prima, de los insumos, del proceso y del producto

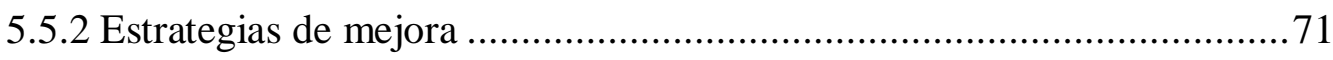

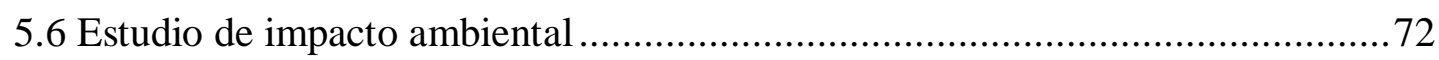

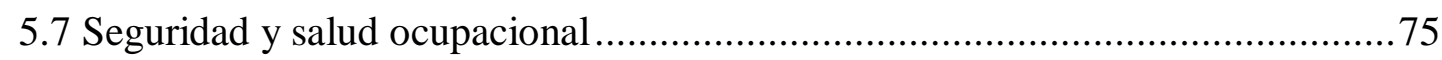

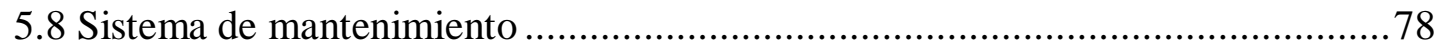

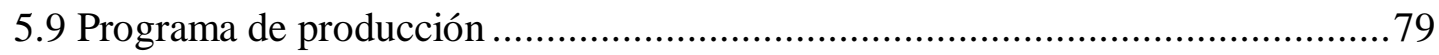


5.9.1 Factores para la programación de la producción

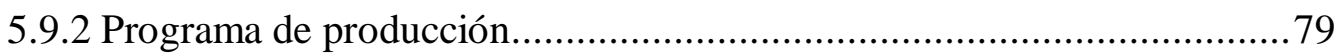

5.10 Requerimiento de insumos, servicios y personal ....................................... 81

5.10.1 Materia prima, insumos y otros materiales …................................. 81

5.10.2 Servicios: energía eléctrica, agua, vapor, combustible, etc..................83

5.10.3 Determinación del número de operarios y trabajadores indirectos........84

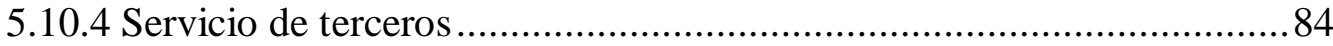

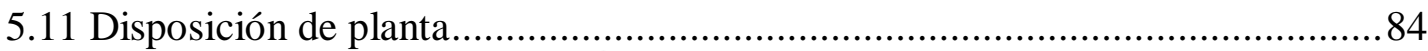

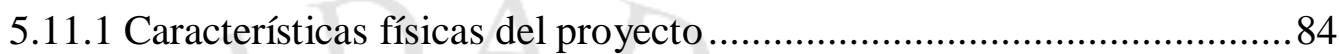

5.11.2 Determinación de las zonas físicas requeridas ..................................86

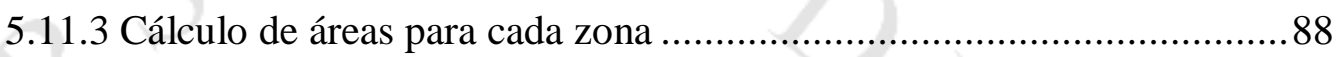

5.11.4 Dispositivos de seguridad industrial y señalización ............................96

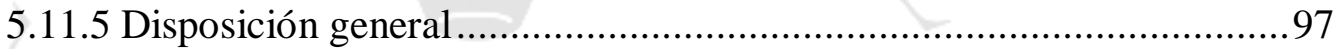

5.11.6 Disposición de detalle .............................................................. 102

5.12 Cronograma de implementación del proyecto ............................................ 103

CAPÍTULO VI. ORGANIZACIÓN Y ADMINISTRACIÓN .................................... 104

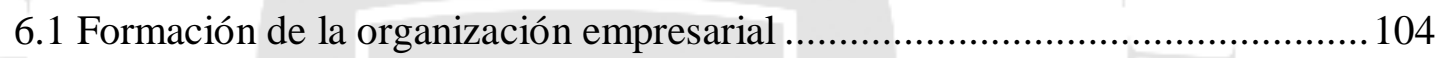

6.2Requerimiento de personal directivo, administrativo y de servicios................. 104

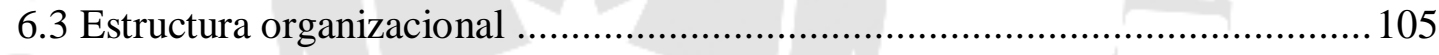

CAPÍTULO VII. ASPECTOS ECONÓMICOS Y FINANCIEROS ....................... 106

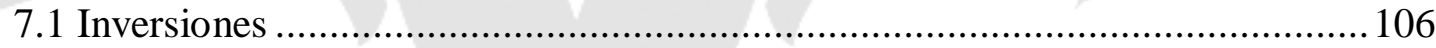

7.1.1 Estimación de las inversiones de largo plazo (tangibles e

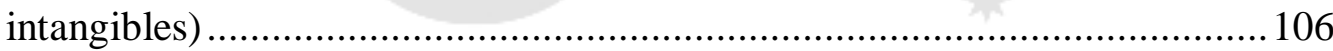

7.1.2 Estimación de las inversiones de corto plazo (Capital de trabajo) ........107

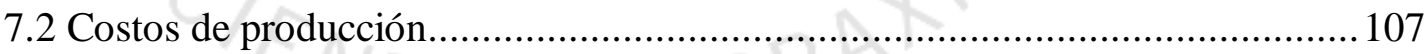

7.2.1 Costos de las materias primas......................................................... 107

7.2.2Costos de la mano de obra directa ............................................... 108

7.2.3 Costo indirecto de fabricación (materiales indirectos, mano de obra indirecta y costos generales de planta) ...................................................... 108

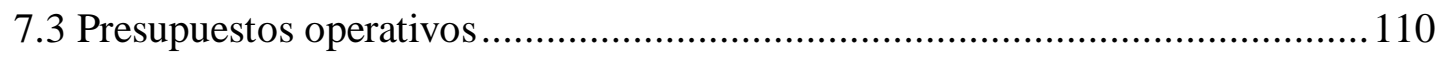

7.3.1 Presupuesto de ingreso por ventas ................................................. 110

7.3.2 Presupuesto operativo de costos ................................................. 110

7.3.3 Presupuesto operativo de gastos .................................................. 113

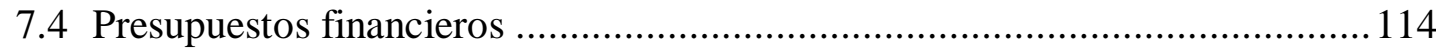


7.4.1 Presupuesto de servicio de deuda 114

7.4.2 Presupuesto de estado de resultados 116

7.4.3 Presupuesto de estado de situación financiera 117

7.4.4 Presupuesto de caja de corto plazo 117

7.5 Flujo de fondos netos 119

7.5.1 Flujo de fondos económicos 119

7.5.2 Flujo de fondos financieros 119

CAPÍTULO VIII. EVALUACIÓN ECONÓMICA Y FINANCIERA DEL PROYECTO

8.1 Evaluación económica: VAN, TIR, B/C, PR 120

8.2 Evaluación financiera: VAN, TIR, B/C, PR 120

8.3 Análisis de ratios (liquidez, solvencia, rentabilidad) e indicadores económicos y financieros del proyecto 120

8.4 Análisis de sensibilidad del proyecto 123

CAPÍTULO IX. EVALUACIÓN SOCIAL DEL PROYECTO 124

9.1 Identificación de las zonas y comunidades de influencia del proyecto 124

9.2 Análisis de indicadores sociales (valor agregado, densidad de capital, intensidad de capital) 124

CONCLUSIONES 126

RECOMENDACIONES 127

FUENTES DE INFORMACION. 128

BIBLIOGRAFÍA 130 


\section{INDICE DE TABLAS}

Tabla 2.1 Importación de complementos alimenticios en Kilogramos ........................ 13

Tabla 2.2 Estimación de la demanda interna aparente en Kilogramos ........................15

Tabla 2.3 Proyección de la Demanda Interna Aparente para el periodo

2014-2018

Tabla 2.4 Principales empresas importadoras bajo las partidas arancelarias 2106101900 y 2106907900

Tabla 2.5 Determinación de la demanda del proyecto en unidades

Tabla 2.6 Tablas actuales de las principales marcas

Tabla 2.7 Principales productores de pollo a nivel nacional .....................................33

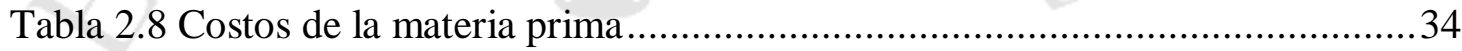

Tabla 3.1 Distancias de capitales departamental a Lima ...........................................37

Tabla 3.2 Calificación de factor cercanía de mercado .................................................37

Tabla 3.3 Calificación del factor disponibilidad de materia prima..............................39

Tabla 3.4 Disponibilidad de mano de obra por departamento..................................39

Tabla 3.5 Calificación del factor disponibilidad de mano de obra ............................40

Tabla 3.6 Calificación de factor abastecimiento de agua.........................................40

Tabla 3.7 Tarifa por el servicio de agua potable de categoría industrialpor ciudad .....41

Tabla 3.8 Calificación de factor abastecimiento de agua.........................................41

Tabla 3.9 Potencia y producción de energía eléctrica en el departamento de

Lima

Tabla 3.10 Potencia y producción de energía eléctrica en el departamento de Ucayali

Tabla 3.11 Potencia y producción de energía eléctrica en el departamento de San

Martin..... .43

Tabla 3.12 Tarifas BT5B por departamento .43

Tabla 3.13 Calificación del factor abastecimiento de energía eléctrica .44

Tabla 3.14 Tabla de enfrentamiento de factores.................................................... 45

Tabla 3.15 Tabla de Ranking de factores ...............................................................45

Tabla 3.16 Calificación del factor disponibilidad de terreno ..................................47

Tabla 3.17 Costos de terreno por distrito ............................................................47 
Tabla 3.18 Calificación del factor costo de terrenos 47

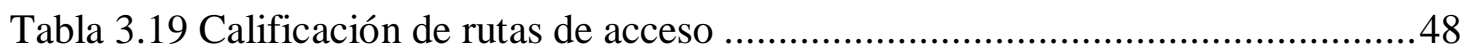

Tabla 3.20 Tabla de enfrentamiento de factores.................................................49

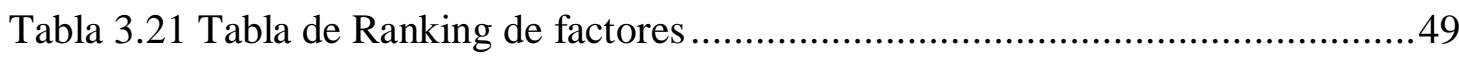

Tabla 4.1: Proyección de la demanda de complemento alimenticio hasta 2018 ..........50

Tabla 4.2 Capacidad de las máquinas en kilogramos por hora ................................52

Tabla 4.3 Costos fijos de depreciación de la maquinaria ........................................54

Tabla 4.4 Costos fijos de sueldos y salarios ............................................................54

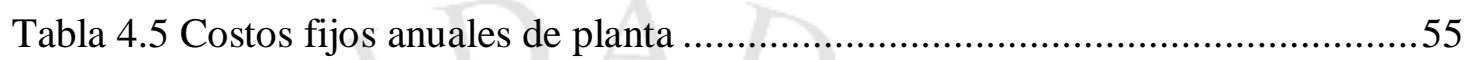

Tabla 4.6 Costos variable unitario de Complemento vitamínico ...............................55

Tabla 4.7 Precio variable unitario de Complemento vitamínico ..............................56

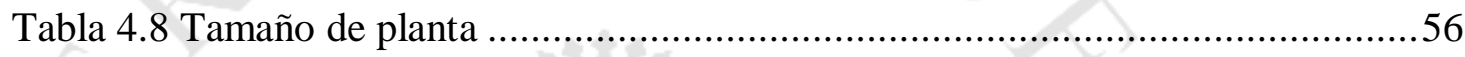

Tabla 5.1 Frasco del complemento vitamínico...................................................57

Tabla 5.2 Especificaciones técnicas por cada máquina ........................................64

Tabla 5.3 Continuación especificaciones técnicas por cada máquina .......................65

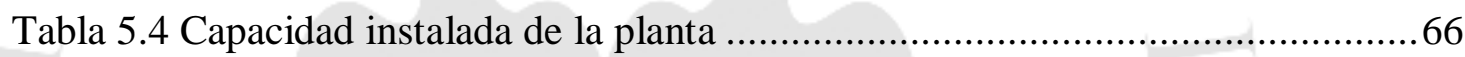

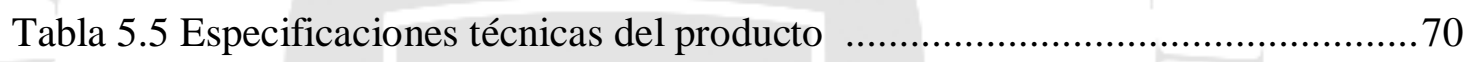

Tabla 5.6 Identificación de aspectos e impactos ambientales ................................. 73

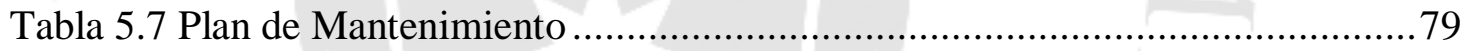

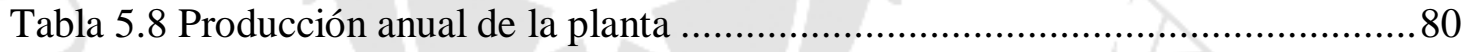

Tabla 5.9 Utilización de la capacidad de planta .................................................... 81

Tabla 5.10 Requerimientos del factor material .................................................. 82

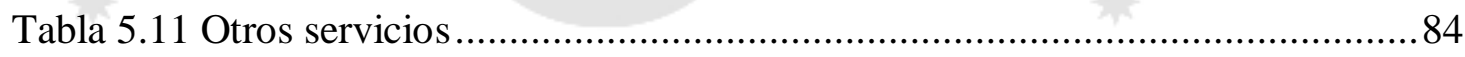

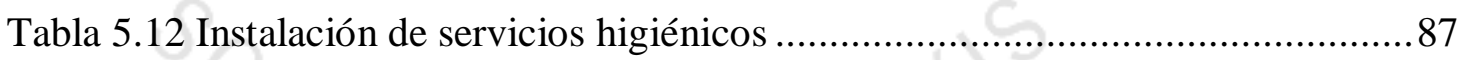

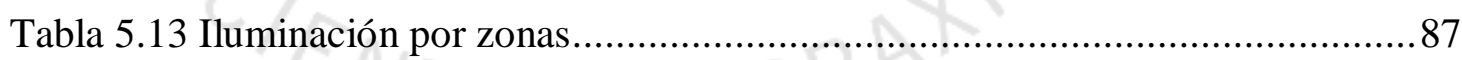

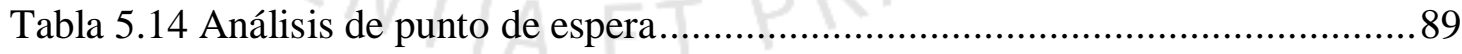

Tabla 5.15 Análisis de punto de espera para Guerchet .........................................90

Tabla 5.16 Requerimiento semanal de materiales al año 5 ...................................92

Tabla 5.17 Requerimiento de parihuelas para almacén de Materia Prima al año 5

Tabla 5.18 Requerimiento de parihuelas para almacén de Productos Terminados

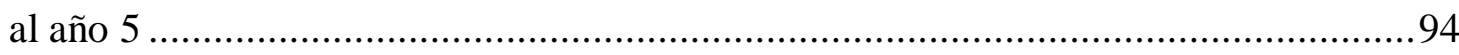

Tabla 5.19 Determinación de los espacios administrativos ......................................95

Tabla 5.20 Selección de tipo de extintor ....................................................................96 


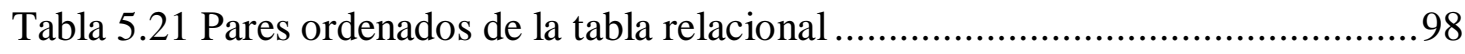

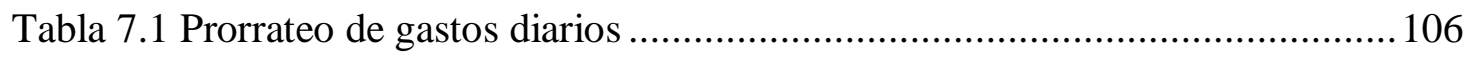

Tabla 7.2 Costos de Materias primas e insumos.................................................... 107

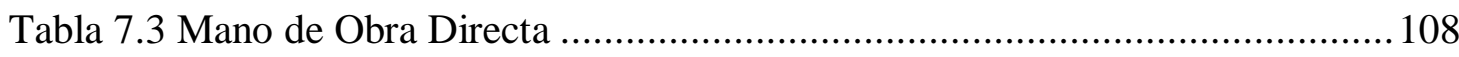

Tabla 7.4 Costos de los materiales indirectos de fabricación...................................108

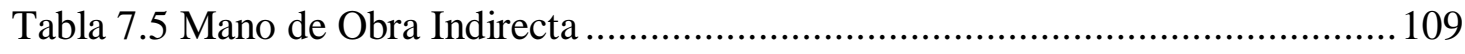

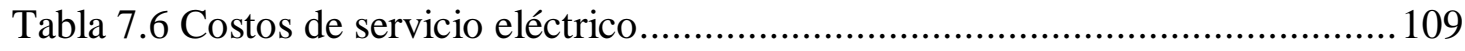

Tabla 7.7 Costos de servicio de Agua Potable ......................................................... 110

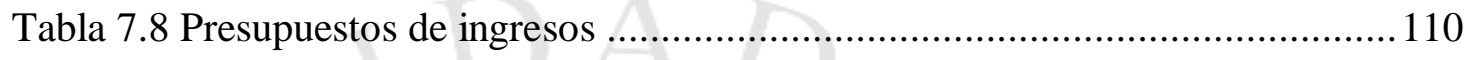

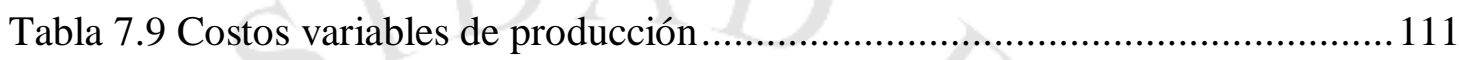

Tabla 7.10 Presupuesto operativo de costos de materia prima .................................111

Tabla 7.11 Depreciación de activos fijos tangibles en producción.............................112

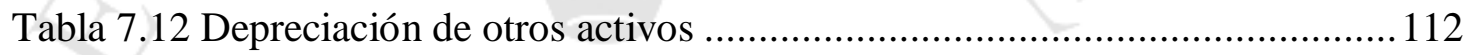

Tabla 7.13 Presupuesto operativo de gastos de ventas ....................................... 113

Tabla 7.14 Presupuesto operativo de gastos administrativos ................................ 113

Tabla 7.15 Depreciación de activos fijos tangibles en oficina .............................. 114

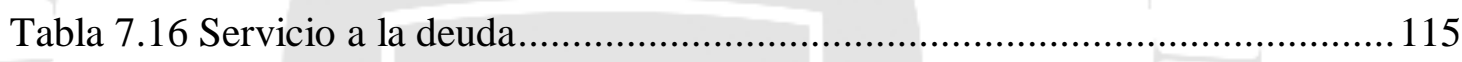

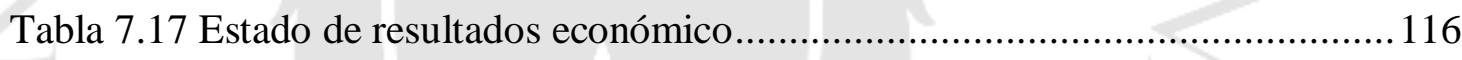

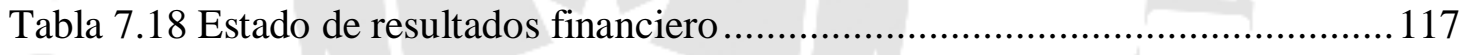

Tabla 7.19 Presupuesto de corto plazo o flujo de tesorería ...................................... 118

Tabla 7.20 Flujo de fondos económicos del proyecto ............................................ 119

Tabla 7.21 Flujo de fondos financieros del proyecto........................................ 119

Tabla 8.1 Evaluación económica del proyecto .................................................. 120

Tabla 8.2 Evaluación financiera del proyecto .................................................. 120

Tabla 8.3 Balance general al 5 año de operación ................................................ 121

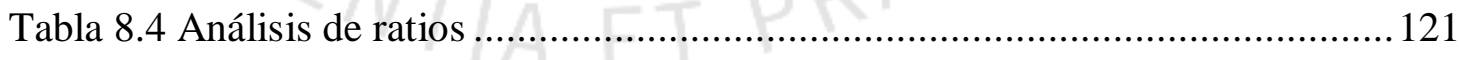

Tabla 8.5 Análisis de sensibilidad por cambio en el volumen ............................... 123

Tabla 8.6 Análisis de sensibilidad por cambio en el precio ................................... 123

Tabla 9.1 Valor agregado del proyecto ......................................................... 124 


\section{ÍNDICE DE FIGURAS}

Figura 1.1 Demanda histórica del mercado de vitaminas y suplementos diarios

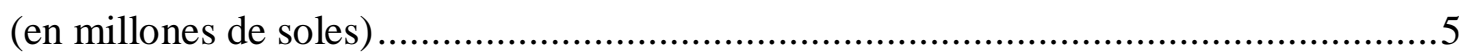

Figura 1.2 Penetración de productos de consumo individual .................................5

Figura 2.1 Presentación referencial del producto ...............................................

Figura 2.2 Lealtad a la marca de complementos alimenticios por NSE................ 16

Figura 2.3 Lugares frecuentes de compra por NSE ....................................... 16

Figura 2.4 Consumo per cápita del mercado de vitaminas y suplementos

diarios en soles ............................................................. 17

Figura 2.5 ¿Lleva un estilo de vida saludable?.................................................. 18

Figura 2.6 ¿De qué forma le gusta consumir los alimentos nutritivos envasados? ..... 19

Figura 2.7 ¿Con qué frecuencia consume alimentos nutritivos envasados? .............. 19

Figura 2.8 ¿Qué es lo primero que se fija en el producto? ......................................20

Figura 2.9 ¿Le gustaría consumir un alimento nutritivo envasado natural a base

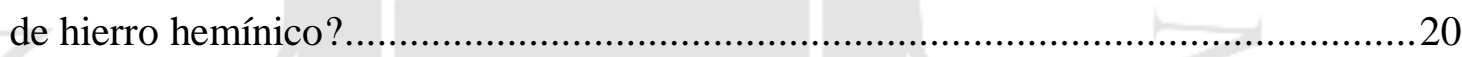

Figura 2.10 ¿Cuál es el precio que estaría dispuesto a pagar? ................................21

Figura 2.11 ¿En qué lugares preferiría comprar el producto? ................................21

Figura 2.12 Estimación del factor de determinación ............................................22

Figura 2.13 Marcas de complementos alimenticios más consumidos ......................25

Figura 2.14 Información geográfica de Lima Metropolitana ................................26

Figura 2.15 Población nacional y número de hogares .........................................27

Figura 2.16 Distribución de Lima Metropolitana por distrito .................................28

Figura 2.17 Composición de alimentos en porciones de 100 gramos........................32

Figura 3.1 Participación de la producción nacional de pollo Enero-Agosto 2013 ........38

Figura 5.1 Frasco del complemento vitamínico ..................................................58

Figura 5.2 Diagrama de operaciones del proceso ................................................62

Figura 5.3 Diagrama de bloques del proceso .................................................. 63

Figura 5.4 Circulo de Deming. Sistema de mejora continua....................................69

Figura 5.5 Peligros y determinación de puntos críticos de control del proceso ............71

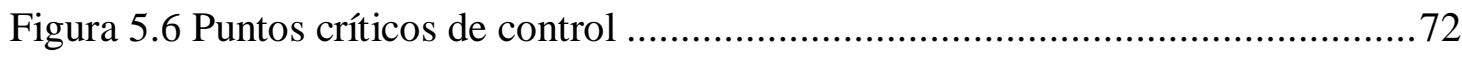

Figura 5.7 Matriz de Identificación y evaluación de impactos ambientales ................ 71 
Figura 5.8 Identificación de peligros y evaluación de riesgos del proceso productivo

Figura 5.9 Continuación de Identificación de peligros y evaluación de riesgos del proceso productivo 86

Figura 5.10 Producción mensual del proyecto en unidades 81

Figura 5.11 Planificación de los requerimientos de materiales al año 5 en kilogramos .83

Figura 5.12 Cálculo de superficies por el método de Guerchet. 91

Figura 5.13 Señales de obligación . 97

Figura 5.14 Leyenda para la tabla y diagrama relacional de actividades .99

Figura 5.15 Tabla relacional de actividades .99

Figura 5.16 Diagrama relacional de actividades 100

Figura 5.17 Diagrama relacional de espacios 101

Figura 6.1 Organigrama 105 


\section{INDICE DE ANEXOS}

Anexo01: Encuestas

.133

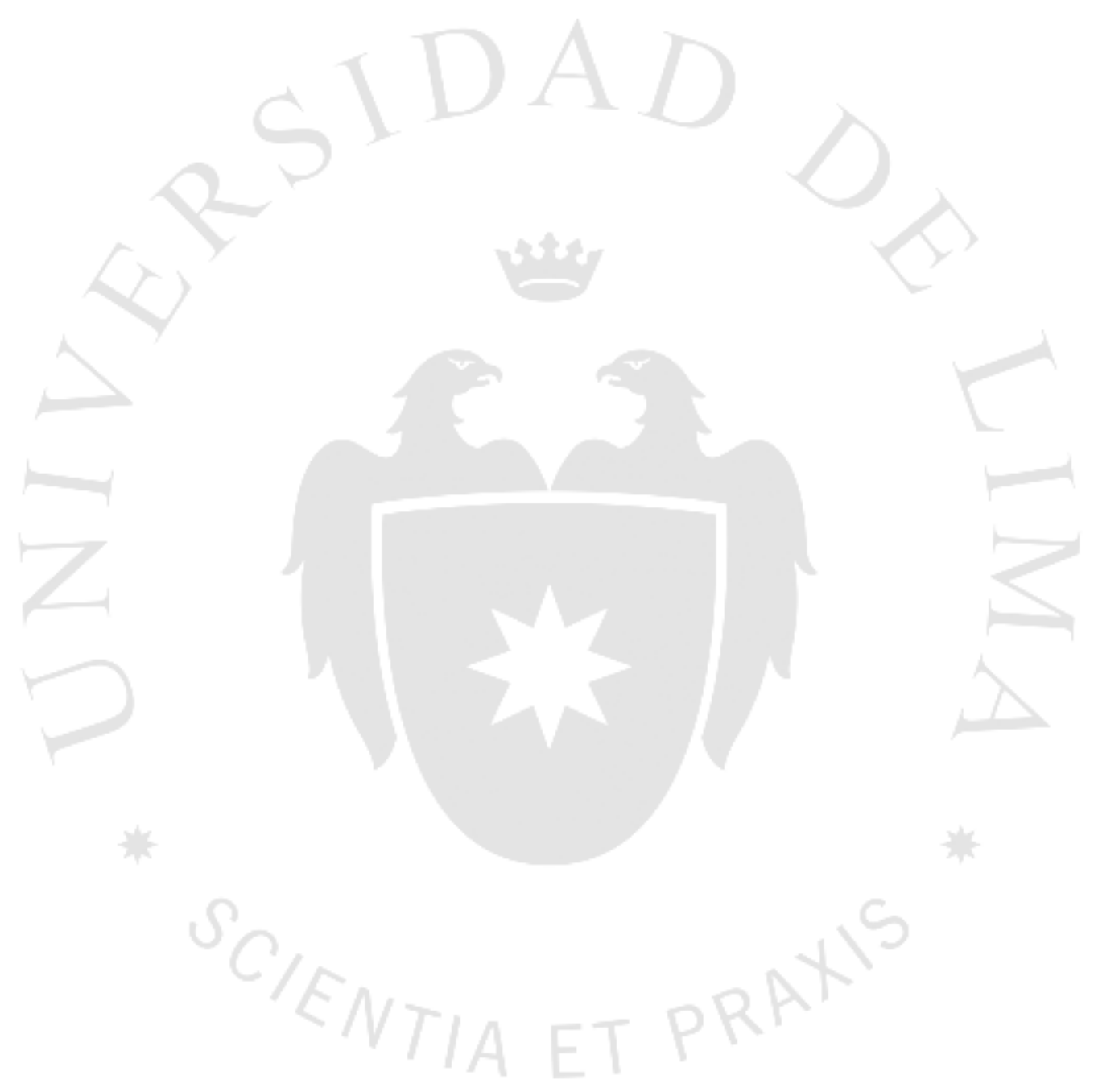




\section{RESUMEN EJECUTIVO}

El proyecto consiste en la elaboración de un complemento alimenticio a base de harina de sangre de pollo y cacao en polvo, con la finalidad de ayudar a mejorar la alimentación de las personas, dado los altos niveles de desnutrición existentes en el país. Se propone el desarrollo de este producto utilizando la harina de sangre de pollo debido a su alto contenido de hierro en comparación con otros alimentos, lo que representa un factor diferencial y novedoso.

El proyecto enfocará la venta en el segmento C y D de la ciudad de Lima, por ser los de mayores necesidades nutricionales y que presentan una alta incidencia de desnutrición.

El producto se venderá en frascos de vidrio de 250 gramos a un precio de S/. 8,00 soles, este será soluble en líquidos, pudiéndose consumir con leche o en otras preparaciones. La comercialización se realizará a través de cadenas de supermercados y boticas.

Para iniciar el proyecto se requerirá una inversión de S/. 528.901 soles, los cuales el $60 \%$ será aporte propio y el resto serán financiados por un tercero. El proyecto presenta una VAN de S/. 290.167,3 soles y una TIR de 49,21\% 


\section{SUMMARY}

The project involves the creation of a food supplement based on chicken blood flour and cocoa powder to help feed people, given the existing high levels of malnutrition. The development of the product is based in chicken blood flour for its high iron content compared with other, which represents a new differential factor.

The project will be focusing on sales in the C and D segments of Lima, because they have greater nutritional needs and which have a high indicence of malnutrition.

The product will sell in glass jars of 250 grams of flour at a price of $\mathrm{S} / .8 .00$ soles, this is dissolved in water or porridge to eat. Sales are made through supermarkets and drugstores.

To start the Project is required an investment of S/. 528.901 soles, which $60 \%$ of contribution will be own and the rest will be financed by a third party. The project has a VAN of S/. 290.167,3 soles and a TIR of $49.21 \%$ 


\section{CAPÍTULO I. ASPECTOS GENERALES}

\subsection{Problemática}

La anemia es una enfermedad por la cual la sangre tiene menos glóbulos rojos de lo normal o estos no contienen suficiente hemoglobina (proteína que contiene gran contenido de hierro), generando que no se llegue a recibir suficiente sangre rica en oxígeno en el cuerpo, causando cansancio, mareos, dolores de cabeza, entre otros síntomas.

En nuestro país la anemia afecta a más del $50 \%$ de los niños en edad preescolar, al $42 \%$ de madres gestantes y al $40 \%$ de las mujeres en edad fértil, lo cual son cifras significativas e impactantes, si lo que se busca es tener un país más productivo y con ideas de desarrollo económicas y sociales ${ }^{1}$ ya que como se puede ver, esta enfermedad afecta a una gran parte de la futura población económicamente activa del país.

\subsection{Objetivos de la investigación}

\section{Objetivo general}

Determinar la viabilidad de mercado, tecnológica, económica y financiera para la instalación de una planta de un complemento alimenticio en polvo a base de harina de sangre de pollo y cacao.

\section{Objetivos específicos}

- Evaluar la viabilidad técnica del proyecto.

- Realizar un estudio de mercado para determinar si el consumo del complemento alimenticio tendrá aceptación por parte de los consumidores.

- Identificar y evaluar a las empresas que actualmente comercializan este tipo de productos con el fin de generar diferenciación. 


\subsection{Alcance y limitaciones de la investigación}

\section{Alcance}

El proyecto tiene como alcance determinar la viabilidad para la instalación de una planta productora de un complemento alimenticio en polvo a base de sangre de pollo y cacao.

Los aspectos fundamentales que comprende la investigación están referidos al estudio de la viabilidad técnica, económica y social.

\section{Limitaciones}

\section{Tiempo}

Para poder obtener una mayor muestra y con ello que el resultado sea más representativo, se requeriría de mucho mayor tiempo para poder elaborar las encuestas.

\section{Recursos financieros}

La falta de recursos impide obtener información a la cual sólo se puede acceder por medio de su compra.

\section{Información desactualizada o sin acceso.}

Dada las características de la investigación, se encontrará con información que no esté actualizada y reporte información de varios años atrás, asimismo no se podrá acceder a ciertas bases de datos por tener la necesidad de contar con ciertas licencias.

\subsection{Justificación del tema}

\section{Técnica}

Es técnicamente viable la elaboración del producto ya que existe la tecnología necesaria para su producción y además ésta se usa en el mercado nacional. El proceso consiste en primer lugar en hacer una inspección de los insumos (pesado e inspección de calidad) que garantizará la calidad del producto final. Una vez que se hizo la prueba de calidad, la sangre de pollo pasa por un proceso de cocción y deshidratación, luego se procede a la molienda y finalmente pasa por un proceso de tamizado, obteniendo como resultado harina de sangre con un alto contenido de hierro. Asimismo, los granos de cacao pasan por un proceso de lavado, molienda y tamizado para lo obtención de harina de cacao. Se eligió el cacao porque este le 
dará un sabor agradable al momento que se mezcle con algún líquido como el agua, leche o algún jugo, así como por sus propiedades antioxidantes y energéticas. Finalmente las harinas se mezclan y se envasan en frascos estériles para su almacenamiento y posterior venta.

\section{Económica}

El proyecto es viable económicamente ya que el mercado de vitaminas y suplementos diarios se encuentra en crecimiento como se muestra en el siguiente Tabla de la base de datos Euromonitor ${ }^{2}$ :

\section{Figura 1.1}

\section{Demanda histórica del mercado de vitaminas y suplementos diarios (en millones de} soles)

\begin{tabular}{|c|c|c|c|c|c|c|c|}
\hline Change View & $\nabla$ & $2009 \nabla$ & $2010 \nabla$ & $2011 \nabla$ & $2012 \nabla$ & $2013 \nabla$ & $2014 \nabla$ \\
\hline \multicolumn{8}{|l|}{ Peru } \\
\hline 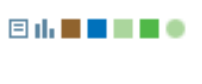 & $\begin{array}{l}\text { Vitamins and Dietary } \\
\text { Supplements }\end{array}$ & 426.7 & 477.6 & 617.7 & 694.2 & 786.6 & 855.8 \\
\hline
\end{tabular}

무잉

Fuente: Euromonitor Internacional, 2014

Por otra parte, el consumo individual del mercado peruano indica que los suplementos y/o complementos alimenticios son un producto de baja penetración lo que implica que existe mercado por explorar y por aprovechar en pro del proyecto, como lo muestra el siguiente Tabla en donde se puede observar que hay mercado por cubrir en los sectores B, C, D y E.

\section{Figura 1.2}

\section{Penetración de productos de consumo individual}

\begin{tabular}{|l|c|c|c|c|c|c|c|}
\hline \multirow{2}{*}{ Productos } & $\mathbf{2 0 1 0}$ & $\mathbf{2 0 1 1}$ & \multicolumn{5}{c|}{ Nivel Socioeconómico (\%) } \\
\cline { 5 - 10 } & $\mathbf{( \% )}$ & $\mathbf{( \% )}$ & $\mathbf{A}$ & $\mathbf{B}$ & $\mathbf{C}$ & $\mathbf{D}$ & E \\
\hline Agua con gas & 10 & $\mathbf{1 2}$ & 21 & 22 & 10 & 8 & 11 \\
\hline Yogurt light & 8 & 10 & 29 & 13 & 12 & 6 & 4 \\
\hline Mates / té adelgazante & 12 & $\mathbf{9}$ & 29 & 13 & 13 & 1 & 2 \\
\hline $\begin{array}{l}\text { Suplemento / complemento } \\
\text { vitamínico }\end{array}$ & 7 & $\mathbf{9}$ & 43 & 7 & 8 & 7 & 2 \\
\hline Bebidas energizantes & 9 & $\mathbf{8}$ & 26 & 11 & 5 & 6 & 1 \\
\hline Te embotellado & - & $\mathbf{8}$ & 13 & 20 & 5 & 3 & 2 \\
\hline
\end{tabular}

Fuente: Ipsos Apoyo, 2011

\footnotetext{
${ }^{2}$ Sistema de información que provee inteligencia comercial, investigaciones de mercado y data de industrias.
} 


\section{Social}

La instalación de una planta de elaboración de un complemento alimenticio a base de harina de sangre de pollo y cacao es viable socialmente ya que este producto permitirá al pueblo peruano combatir problemas alimenticios como la anemia y la desnutrición y así tener una sociedad sana, con buen rendimiento físico y mental para el estudio, trabajo u otras actividades que se realicen a diario y que contribuya al desarrollo del país.

Además, se crearán nuevos puestos de trabajo que hará que las condiciones de vida de estas personas mejoren y que existan nuevos consumidores en el mercado nacional y así lograr que éste siga creciendo.

\subsection{Hipótesis de trabajo}

La instalación de una planta de complemento alimenticio en polvo a base de harina de sangre de pollo y cacao es factible, pues existe un mercado potencial que aceptaría el producto y además es tecnológica, económica y financieramente viable.

\subsection{Marco referencial de la investigación}

\section{Marco referencial}

Sánchez Honorio, Enrique Raúl. Estudio preliminar para la instalación de una planta procesadora de suplementos proteicos a base de quinua, kiwicha y tarwi. Universidad de Lima. Lima, Perú. 2011. Código 07338 (SEM).

Se empleará el presente seminario para tomar como referencia la estimación de la demanda y la proyección de la oferta para el estudio.

Cottle Gray, Jeffrey Michael; Rodriguez Paiva Gonzales, Renzo. Estudio preliminar para la instalación de una planta de producción de un sustituto alimenticio en base a ingredientes naturales. Universidad de Lima. Lima, Perú. 2010. Código 07112 (SEM).

Se empleará el presente seminario para tomar como referencia el estudio de mercado y así poder determinar a los posibles consumidores del producto. 
Aguirre Caro, Sergio. Estudio preliminar para la instalación de una planta productora de suplemento proteico a base de agua de cola de pescado en comprimidos. Universidad de Lima. Lima, Perú. 2010. Código 07083 (SEM).

Se empleará el presente seminario para tomar como referencia la maquinaria empleada en la elaboración del suplemento proteico ya que existe cierta maquinaria que también servirá para emplearse en el proyecto.

Guevara, Zagaceta Zaida. Costo y efectividad de la ingesta de sangre de pollo en el tratamiento de anemia ferropénica en estudiantes de la EAP. de la facultad de obstetricia de la facultad de medicina de la UNMSM. Universidad Nacional Mayor de San Marcos. Lima, Perú. 2006.

Se empleará como estadística e información relevante acerca de los resultados la ingesta de la sangre de pollo en las personas.

Galarza Martel, Ronny Raúl O. Calidad nutricional de un producto extruido forticado con dos niveles de hierro proveniente de harina de sangre bovina. Universidad Nacional Mayor de San Marcos. Lima, Perú. 2011.

Se empleará como referente en el uso de harina de sangre para la elaboración de un producto para consumo humano.

\subsection{Marco conceptual}

- Hierro: Es un mineral que se encuentra en cada célula del cuerpo y se considera por este motivo esencial. El cuerpo humano necesita hierro para producir la hemoglobina que es la proteína responsable de transportar el oxígeno a todo el organismo.

- Hemoglobina: Proteína de la sangre que transporta el oxígeno desde los órganos respiratorios hasta los tejidos.

- Suplemento vitamínico: Son productos elaborados de una mezcla de vitaminas y minerales que ayudan al cuerpo a recuperar la carencia de estas.

- Complemento alimenticio: Fuente concentrada de nutrientes u otras sustancias alimenticias que tienen un efecto nutricional sobre el cuerpo y que se pueden usar cuando la dieta no cumple con los requerimientos que el cuerpo necesita. 
- Vitaminas: Son sustancias esenciales que el cuerpo necesita para crecer y desarrollarse normalmente.

- Anemia: Empobrecimiento de la sangre por disminución de su cantidad (glóbulos rojos), como ocurre después de las hemorragias, o por enfermedades, ya hereditarias, ya adquiridas, que disminuyen la cantidad de glóbulos rojos.

- Hierro hemínico: Hierro que proviene de los animales.

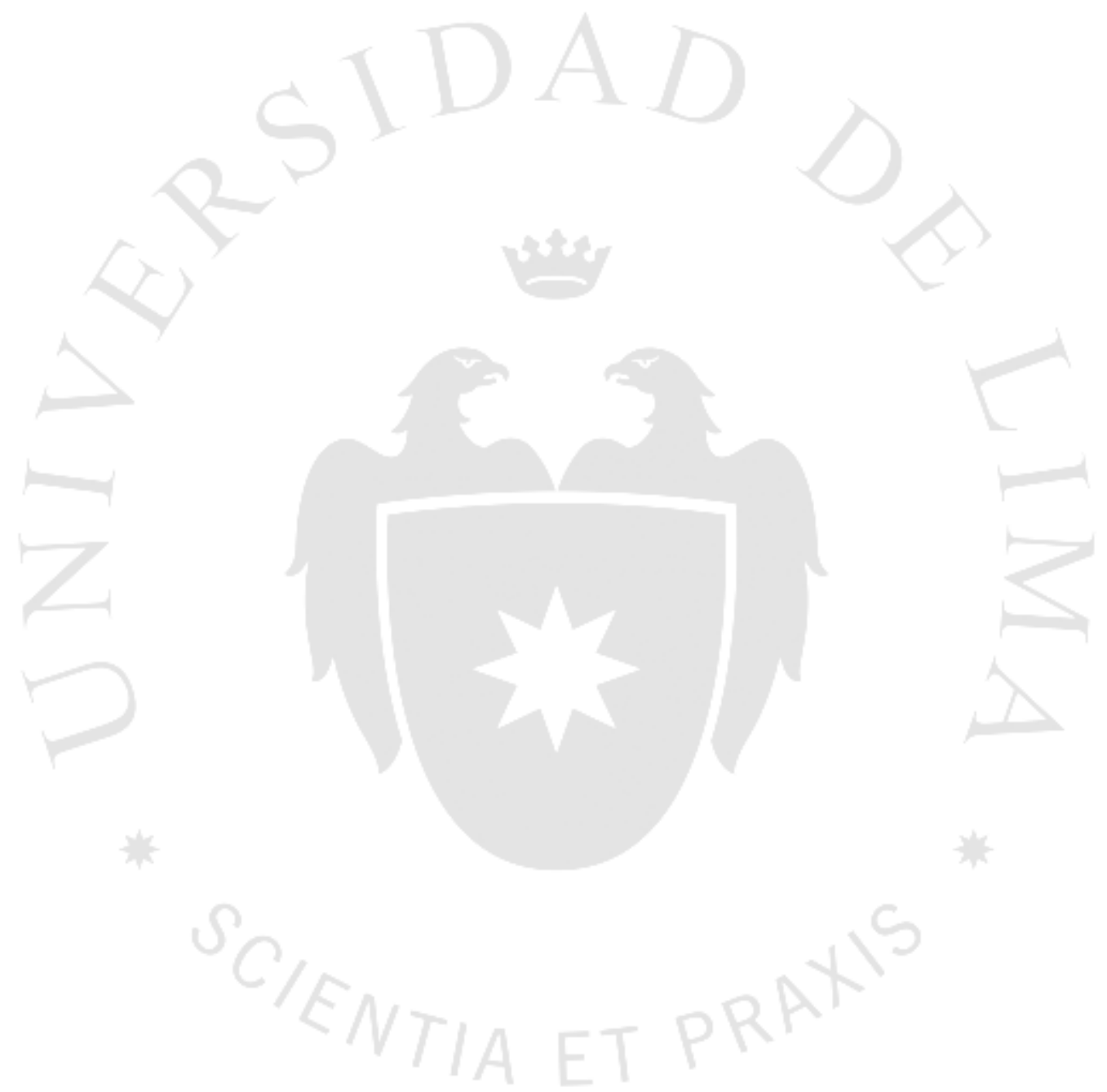




\section{CAPÍTULO II. ESTUDIO DE MERCADO}

\subsection{Aspectos generales del estudio de mercado}

\subsubsection{Definición comercial del producto}

\section{Producto básico}

El producto a desarrollar es un complemento alimenticio con alto contenido de hierro, necesario para una buena alimentación y con ello combatir la desnutrición y la anemia. Además posee un elevado porcentaje de proteína.

\section{Producto real}

El complemento alimenticio en polvo será a base de harina de sangre de pollo y cacao lo que a diferencia de otros productos contendrá un mayor nivel de hierro en su composición. El producto se venderá en la presentación de frasco de 250 gramos y adicionalmente se le añadirá otras vitaminas necesarias para el mejor desarrollo del organismo como lo son el fósforo y magnesio.

La presentación del producto será en polvo y para su consumo se puede mezclar con alguna bebida (agua, jugo, leche) e incluso mazamorras. La comercialización se hará en frascos de vidrio, con tapa rosca, además tendrá la información nutricional en la etiqueta donde también se podrá apreciar el nombre de la marca y la fecha de vencimiento.

\section{Figura 2.1}

\section{Presentación referencial del producto}

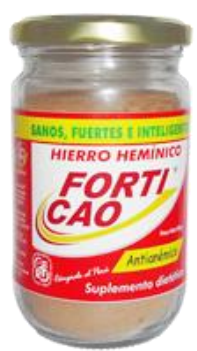

Fuente: naturalnutrition.com.pe. s.f 


\section{Producto aumentado}

Se brindará un servicio de atención al cliente en el cual se atenderá las quejas y consultas de los clientes a través de un call center (centro de llamadas), para así estar en un continuo proceso de mejora y brindarle al cliente la mayor satisfacción.

\subsubsection{Principales características del producto}

\subsubsection{Usos y características del producto}

El producto a elaborar es un complemento alimenticio en polvo que para su consumo se recomienda mezclar una cucharadita del producto con alguna bebida, avena o mazamorra. Se recomienda que en primer lugar se disuelva el producto en alguna bebida caliente y mezclar bien hasta que se halla disuelto por completo y después si se desea se le puede agregar agua fría.

Entre las principales propiedades del producto se encuentra que al contener un alto nivel de hierro, este producto ayuda a combatir la anemia y otras deficiencias como el cansancio excesivo de las personas ya que el hierro ayuda a mejorar la circulación de la sangre en el organismo.

Otra propiedad del producto es que no genera estreñimiento ya que al contener cacao, este permite la estimulación y flujo del sistema digestivo y de los intestinos. Adicionalmente al ser un producto elaborado naturalmente sin preservantes o saborizantes, lo vuelve apto para el consumo del público en general.

Finalmente, los aditivos minerales que se añadirán al producto como el fósforo y el magnesio (ojo vitamina $\mathrm{C}$ evaluar), ayudaran a mejorar el metabolismo celular, la formación de los tejidos musculares, tener un mejor mantenimiento de los huesos y mantener el correcto funcionamiento del organismo.

\subsubsection{Bienes sustitutos y complementarios}

Entre los productos sustitutos se pueden encontrar:

- Barras proteicas.

- Batidos energéticos. 
- Complementos alimenticios a base de sangre de bovino.

- Suplementos vitamínicos en polvo.

- Vitaminas en pastillas y tabletas.

Entre estos productos, la mayor amenaza vendría a estar constituida por las vitaminas en pastillas o tabletas ya que son prácticas de consumir (ingiriendo la pastilla o tableta vía oral acompañado de alguna bebida, sin necesidad de preparación) y al poder encontrarse en distintos supermercados o boticas son de fácil acceso para el público.

Dado que el producto a elaborar es un complemento alimenticio en polvo, los bienes complementarios con los cuales el producto tendría relación son:

- Jugos

- Agua

- Leche

- Avena

\subsubsection{Determinación del área geográfica que abarcará el estudio}

Para definir el área geográfica del proyecto se tomó como prioridad la ubicación del mercado. Se consideró realizar el estudio en el área de Lima metropolitana ya que ésta, como se verá más adelante resultó ser el lugar idóneo luego del análisis de Ranking de factores,, además abarca un gran porcentaje de la población nacional, aproximadamente el 31,6\% que vendría a ser 9.740.410 habitantes ${ }^{3}$.

\subsubsection{Análisis del sector}

A continuación se realizará un estudio de los factores que afectan al sector bajo el análisis de las 5 fuerzas de Michael Porter:

\section{Amenazas de ingresos}

La amenaza de ingreso es medio alta ya que dentro de una economía de escalas existe la posibilidad de crear diferenciación frente a los productos que ya se venden en el mercado. Para el caso del complemento alimenticio en polvo a base de sangre de pollo y cacao puede

\footnotetext{
${ }^{3}$ Ipsos Marketing. Estadística Poblacional 2014
} 
ser una oportunidad de diferenciación el hecho que este sea un producto que se va a elaborar de forma natural.

\section{Presión de productos sustitutos}

Los principales productos sustitutos son los suplementos vitamínicos en tableta que también brindan la opción de mejorar el estado de salud de las personas. Estos productos son productos más elaborados, muchas veces con mayor publicidad, con producciones de escala y se pueden encontrar en las cadenas de boticas, farmacias y supermercados. El hecho que estos productos se encuentren a rápida disposición del mercado y fáciles de ingerir hace que la presión de los productos sustitutos sea alta.

\section{Poder de negociación de los compradores}

El complemento alimenticio a base de harina de sangre de pollo y cacao va orientado a las personas que quieran mejorar su estado nutricional y de salud, por lo que si la venta es directa con el cliente en un local establecido por el proyecto, el poder de negociación de estos es baja ya que se tendrán que adecuar al precio establecido y los volúmenes de venta por comprador serían bajos.

Sin embargo, si la venta se desea realizar por medio de cadenas de boticas o farmacias donde los volúmenes de venta son mayores, el poder de negociación de estos será alto ya que ellos tratarán de negociar el precio para poder colocar el producto en sus instalaciones.

\section{Poder de negociación de los proveedores}

El poder de negociación de los proveedores en este caso es bajo ya que existe un variado grupo de comerciantes que puedan vender los insumos principales para el proyecto, ya sea el cacao o la sangre de pollo y cambiar de proveedor no representaría un mayor costo para los intereses del proyecto.

\section{Intensidad de la rivalidad entre los competidores existentes}

La rivalidad entre los competidores de este sector sería baja ya que existe solo 1 empresa en el Perú que ofrece un producto con características similares desde hace ya más de 20 años, pero que a pesar de ello no ha llegado a ser muy reconocida por el público. No 
obstante, productos en polvo como el Nesquik, Milo o Kiwigen representarían una competencia alta ya que su finalidad también en la de apoyar la alimentación de las personas.

\subsubsection{Determinación de la metodología que se empleará en la investigación de mercado}

En su primera instancia la investigación será exploratoria, ya que se recurrirá a información secundaria para obtener información como las importaciones, exportaciones y la producción, para luego pasar a una segunda etapa de la investigación por medio de la elaboración de encuestas y así poder obtener información de primera mano para realizar un análisis más profundo de los resultados.

\subsection{Análisis de la demanda}

\subsubsection{Demanda histórica}

En el mercado actual, no existen complementos alimenticios a base de harina de sangre de pollo y cacao, por ello para la obtención de la información de la demanda histórica se recurrirá a los datos del mercado de complementos alimenticios ya existentes.

\subsubsection{Importaciones}

En base a la información histórica de Aduanas, a continuación se presenta el Tabla 2.1 con las importaciones bajo las partidas arancelarias: 2106101900 (preparaciones alimenticias diversas-los demás) y 2106907900 (demás complementos alimenticios):

Tabla 2.1

Importación de complementos alimenticios en Kilogramos

\begin{tabular}{|c|c|c|c|}
\cline { 2 - 4 } \multicolumn{1}{c|}{} & \multicolumn{2}{c|}{ Partidas Arancelarias } & Total \\
\hline Año & 2106907900 & 2106101900 & 1.455 .874 \\
\hline 2008 & 1.329 .754 & 126.120 & 1.537 .980 \\
\hline 2009 & 1.420 .074 & 117.906 & 2.666 .111 \\
\hline 2010 & 2.580 .924 & 85.187 & 2.627 .940 \\
\hline 2011 & 2.468 .851 & 159.089 & 4.066 .927 \\
\hline 2012 & 3.821 .738 & 245.189 & 2.705 .689 \\
\hline 2013 & 2.330 .689 & 375.000 & \\
\hline
\end{tabular}

Fuente: Datatrade.2014

Elaboración propia 
Como se puede observar de la información obtenida, las importaciones totales de complementos alimenticios han venido en aumento desde el 2008 hasta el 2012, notándose un incremento anormal para el año 2012, sin embargo se ve una regularización de las importaciones para el periodo 2013.

\subsubsection{Producción nacional}

En la actualidad, la producción de complementos alimenticios viene dado por empresas como Incasur y uno de sus productos estrella, Kiwigen, que tiene una capacidad de planta de 2.000 TM (en el 2012 se invirtió en una nueva planta y su producción creció en 7\%), sin embargo no se cuenta con los niveles de producción únicamente de los productos que son complementos alimenticios. No obstante, al ser una de las principales marcas de esta empresa (Chocolate sol del cuzco y Kiwigen), podríamos estimar que la producción de Kiwigen podría ser del $40 \%$ de la producción total asumiendo que el $60 \%$ restante se emplean en su mayoría para la producción de los chocolates Sol del Cusco, sin embargo, en Agosto del 2014, el gerente de marketing de Incasur sostiene que al cerrar el año deben estar registrando un 10\% de crecimiento en sus ventas, por lo que podríamos esperar que la producción también se

eleve y que se mantenga en ese ritmo de crecimiento. Para el proyecto se asumirá que el crecimiento de la producción será el mismo al que se refiere el crecimiento de ventas, es decir, un crecimiento anual de $10 \%$.

Adicionalmente, otra empresa que produce complementos alimenticios a nivel nacional es Waala, que tiene una producción mensual de 6.000 unidades, lo que representaría la elaboración de 72.000 unidades al año (cada frasco de 80 gramos); sin embargo la empresa espera pronto alcanzar un nivel de producción anual de 120.000 unidades.

Para el caso de las exportaciones, la empresa Incasur exporta a Bolivia 5 mil cajas de 360 gramos (1.8 TM) desde el 2010, ya que antes solo exportaba la mitad de esta cantidad. Asimismo, para el 2013 se proyectaba que un 20\% de la producción nacional iría destinado a países como Chile, España, EE.UU, entre otros y también exportar próximamente a Venezuela y Centroamérica.

\subsubsection{Demanda interna aparente (DIA)}

Para determinar la demanda, se utilizará la ecuación de la Demanda Interna Aparente: 


\section{$\mathrm{DIA}=\mathrm{P}+\mathrm{I}-\mathrm{E}$}

Dónde:

P: Producción nacional

I: Importaciones

E: Exportaciones

Tabla 2.2

Estimación de la demanda interna aparente en Kilogramos

\begin{tabular}{|c|c|c|c|c|}
\hline Año & $\begin{array}{c}\text { Importaciones de } \\
\text { Complementos } \\
\text { Alimenticios (Kg) }\end{array}$ & $\begin{array}{c}\text { Producción } \\
\text { Complementos } \\
\text { alimenticios (Kg) }\end{array}$ & $\begin{array}{c}\text { Exportación de } \\
\text { Complementos } \\
\text { alimenticios (Kg) }\end{array}$ & DIA (Kg) \\
\hline 2008 & 1.455 .874 & 753.424 & 900 & 2.208 .398 \\
\hline 2009 & 1.537 .980 & 753.424 & 900 & 2.290 .504 \\
\hline 2010 & 2.666 .111 & 753.424 & 1.800 & 3.417 .735 \\
\hline 2011 & 2.627 .940 & 753.424 & 1.800 & 3.379 .564 \\
\hline 2012 & 4.066 .927 & 753.424 & 1.800 & 4.818 .551 \\
\hline 2013 & 2.705 .689 & 805.760 & 1.800 & 3.509 .649 \\
\hline
\end{tabular}

Fuente: Datatrade, Expreso, Agencia agraria de noticias. 2014

Elaboración propia

\subsubsection{Demanda Potencial}

\subsubsection{Patrones de consumo: incremento poblacional, consumo per cápita, estacionalidad}

En Lima metropolitana, el consumo de complementos alimenticios tiene un $65 \%$ de lealtad a la marca, es decir que el consumidor va a buscar el producto deseado a otro lugar si no lo encuentra en donde se encuentra, por lo que resulta importante establecer un plan de posicionamiento en la mente del consumidor para poder crear así esta lealtad y tener un mayor número de consumidores. 


\section{Figura 2.2}

\section{Lealtad a la marca de complementos alimenticios por NSE}

\begin{tabular}{|r|c|c|c|c|c|c|}
\hline & \multicolumn{5}{|c|}{ NSE } \\
\hline Lealtad a la marca & $\begin{array}{c}\text { TOTAL } \\
2011 \\
\%\end{array}$ & $\begin{array}{c}\text { A } \\
\%\end{array}$ & $\begin{array}{c}\text { B } \\
\%\end{array}$ & $\begin{array}{c}\text { C } \\
\%\end{array}$ & $\begin{array}{c}\text { D } \\
\%\end{array}$ & $\begin{array}{c}\text { E } \\
\%\end{array}$ \\
\hline Lealtad a la marca & 65 & 61 & 37 & 84 & 51 & 100 \\
\hline Compra otra marca & 29 & 39 & 63 & 16 & 24 & - \\
\hline Base & 42 & $15^{*}$ & $5^{*}$ & $12^{*}$ & $8^{*}$ & $2^{*}$ \\
\hline
\end{tabular}

Fuente: Ipsos Apoyo, 2011

Asimismo, al analizar el lugar favorito de compra podemos observar que las personas prefieren los supermercados y farmacias que tienen casi el $82 \%$ de frecuencia de compra, por ello se optaría por vender los productos mediante estos canales.

\section{Figura 2.3}

Lugares frecuentes de compra por NSE

\begin{tabular}{|c|c|c|c|c|c|c|}
\hline \multirow[b]{2}{*}{$\begin{array}{l}\text { Lugar de compra más } \\
\text { frecuente }\end{array}$} & \multirow{2}{*}{$\begin{array}{c}\text { TOTAL } \\
2011 \\
\%\end{array}$} & \multicolumn{5}{|c|}{ NSE } \\
\hline & & $\begin{array}{l}\text { A } \\
\%\end{array}$ & $\begin{array}{l}\text { B } \\
\%\end{array}$ & $\begin{array}{l}\mathrm{C} \\
\%\end{array}$ & $\begin{array}{l}\mathbf{D} \\
\%\end{array}$ & $\begin{array}{l}\mathbf{E} \\
\%\end{array}$ \\
\hline Supermercado & 49 & 58 & 68 & 29 & 60 & 53 \\
\hline Farmacia & 33 & 33 & 32 & 40 & 27 & - \\
\hline Bodega & 9 & 2 & - & 20 & - & 47 \\
\hline Mercado & 4 & 2 & - & 5 & 6 & - \\
\hline Panadería & 1 & 5 & - & - & - & - \\
\hline Base & 58 & $25^{\star}$ & $5^{*}$ & $15^{*}$ & $11^{*}$ & $2^{*}$ \\
\hline
\end{tabular}

Fuente: Ipsos Apoyo, 2011

No existe una estacionalidad marcada para el consumo de complementos alimenticios, sin embargo, se considerará que para la época de invierno debería de haber un mayor consumo de estos complementos debido a que es el periodo en la que las bajas temperaturas y la humedad causan mayores enfermedades y por ende surge la necesidad de contar con una mejor alimentación. 


\subsubsection{Determinación de la demanda potencial}

El consumo per cápita peruano del mercado de vitaminas y suplementos diarios ha venido creciendo desde el 2008 a una tasa de casi 16\%, incluso igualando la línea de grandes países como México.

\section{Figura 2.4}

Consumo per cápita del mercado de vitaminas y suplementos diarios (en soles)

\begin{tabular}{|c|c|c|c|c|c|c|c|}
\hline \multirow{2}{*}{\multicolumn{8}{|c|}{$\begin{array}{l}\text { Change View } \\
\text { Vitamins and Dietary Supplements }\end{array}$}} \\
\hline & & & & & & & \\
\hline 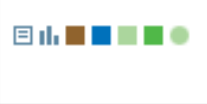 & $\begin{array}{l}\text { Argentina - ARS Per } \\
\text { Capita }\end{array}$ & 2.2 & 2.5 & 3.0 & 3.5 & 4.0 & 4.7 \\
\hline 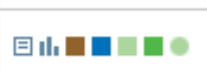 & Chile - CLP Per Capita & 7.5 & 7.2 & 7.7 & 7.9 & 8.2 & 8.8 \\
\hline 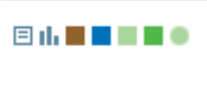 & $\begin{array}{l}\text { Colombia - COP Per } \\
\text { Capita }\end{array}$ & 9.6 & 10.3 & 10.6 & 11.0 & 11.2 & 11.5 \\
\hline 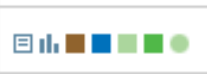 & Mexico - MXN Per Capita & 20.6 & 22.0 & 23.2 & 26.6 & 28.8 & 29.7 \\
\hline 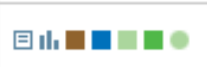 & Peru - PEN Per Capita & 14.7 & 16.3 & 20.9 & 23.1 & 25.9 & 27.8 \\
\hline
\end{tabular}

Fuente: Euromonitor, 2014

Elaboración propia

Si mantenemos esa línea de crecimiento, podríamos estimar que para el 2015, el consumo per cápita peruano seria 31,6 soles, por lo que podríamos establecer una demanda potencial en soles, ya que no se cuenta con la cantidad total en Kilogramos que produce el mercado de vitaminas y suplementos diarios.

Población peruana: 30.814 .175 habitantes $^{4}$

$$
\text { Demanda Potencial }=30.814 .175 \text { hab } \times 31,6 \frac{\mathrm{S} /}{\mathrm{hab}}
$$

Demanda Potencial (millones de soles) $=973,7 \mathrm{~S} /$.

La demanda potencial sería igual a 973.7 millones de soles, superando al valor de la figura 1.1 para el año 2014 de 855.8 en 117.9 millones de soles.

\footnotetext{
${ }^{4}$ Fuente: Ipsos Apoyo. IGM Estadística poblacional 2014
} 


\subsubsection{Demanda mediante fuentes primarias}

\subsubsection{Diseño y aplicación de encuestas u otras técnicas}

En una encuesta (ver Anexos) realizada a 30 personas se obtuvieron los siguientes datos:

- La pregunta 1 “CConsume alimentos nutritivos envasados?”, era una pregunta filtro ya que si la respuesta era negativa la encuesta se daba por concluida.

- Para la pregunta 2 "¿Lleva un estilo de vida saludable?”, 11 personas indicaron que si llevaban un estilo de vida saludable, mientras que 19 personas a pesar de consumir complementos vitamínicos, no lo hace.

\section{Figura 2.5}

¿Lleva un estilo de vida saludable?

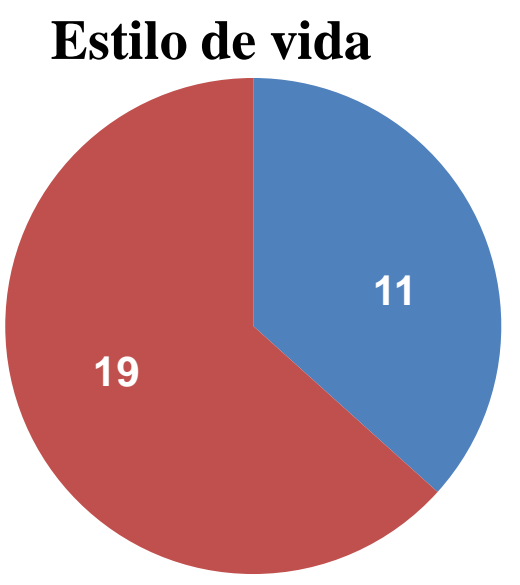

Saludable No Saludable

Elaboración propia

- Para la pregunta 3 “¿De qué forma le gusta consumir los alimentos nutritivos envasados?", 12 personas indicaron que prefieren hacerlo mediante tabletas ya que son bastante prácticas y 18 indicaron que prefieren hacerlo mediante la disolución del complemento en polvo en alguna bebita. 


\section{Figura 2.6}

¿De qué forma le gusta consumir los alimentos nutritivos envasados?

\section{Modalidad de consumo}

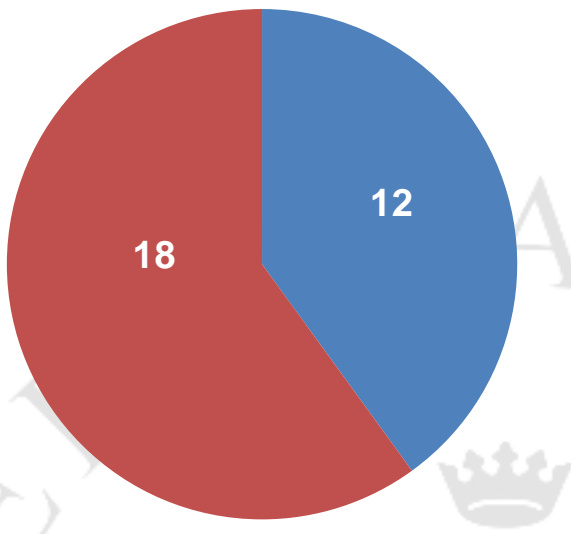

Tableta Polvo Gel $\square$ Otro

Elaboración propia

- Para la pregunta 4 “¿Con qué frecuencia consume alimentos nutritivos envasados?”, 26 personas indicaron que tenían un consumo diario y controlado mientras que 4 personas indicaron que lo consumían de 2 a 3 veces por semana.

\section{Figura 2.7}

¿Con qué frecuencia consume alimentos nutritivos envasados?

\section{Frecuencia de consumo}

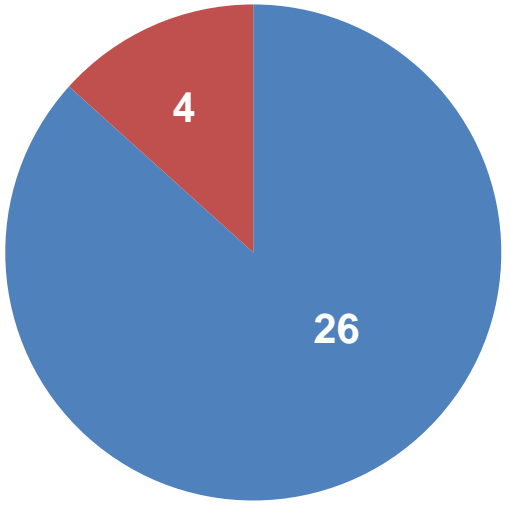

$$
\begin{array}{ll}
\text { Diario } & 2 \text { a } 3 \text { veces por semana } \\
\text { Una vez por semana } & \text { Otro }
\end{array}
$$


- Para la pregunta 5 “¿Qué es lo primero que se fija en el producto?”, El 73\% de los encuestados ( 22 personas) señalo que el precio era el primer factor en el que se fijaba, mientras que los restantes indicaron que se fijan en la calidad

\section{Figura 2.8}

¿Qué es lo primero que se fija en el producto?

\section{Lo primero que ve del producto}

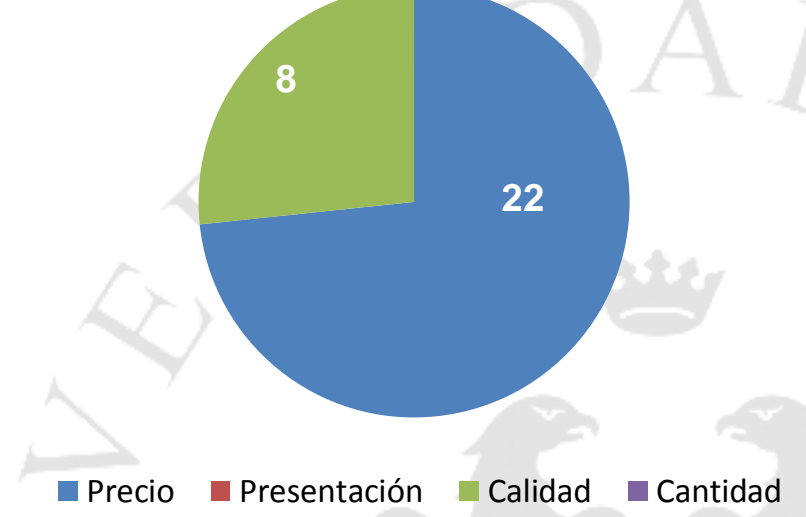

Elaboración propia

- Para la pregunta 6 "¿Le gustaría consumir un alimento nutritivo envasado natural a base de hierro hemínico?", El 50\% (15 personas) indicaron que si les gustaría consumir este producto, 6 señalaron que no les gustaría y hubo 9 indecisos.

\section{Figura 2.9}

¿Le gustaría consumir un alimento nutritivo envasado natural a base de hierro hemínico?

¿Consumiría el producto?

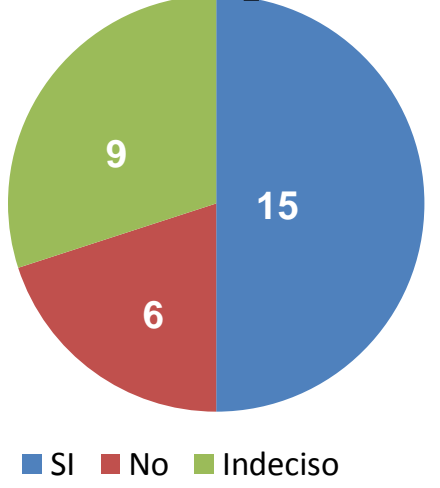


- Para la pregunta 7 “¿Cuál es el precio que estaría dispuesto a pagar?”, En su gran mayoría eligieron un precio entre 5 a 10 soles ( 28 de 30 entrevistados) y 2 personas eligieron entre 10 a 15 soles.

\section{Figura 2.10}

¿Cuál es el precio que estaría dispuesto a pagar?

\section{Precio dispuesto a pagar}

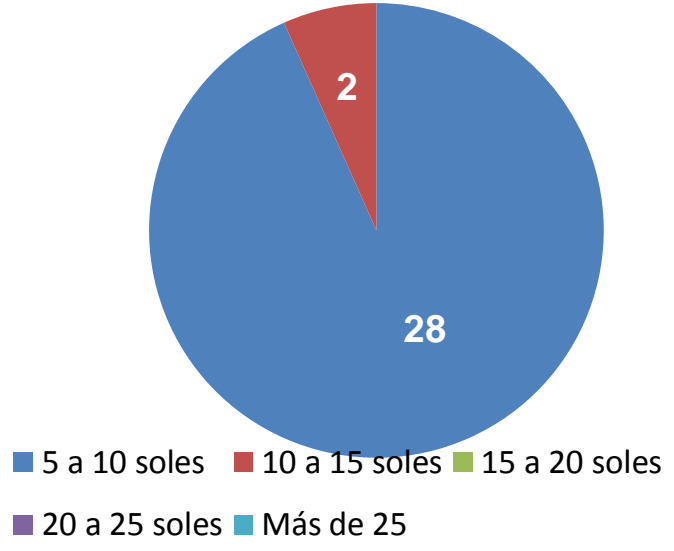

Elaboración propia

- Para la pregunta 8 “En qué lugares preferiría comprar el producto?”, El $60 \%$ de los encuestados (18 personas) señalo como lugar favorito de compra a los supermercados mientras que 12 personas eligieron a las bodegas.

\section{Figura 2.11}

¿En qué lugares preferiría comprar el producto?

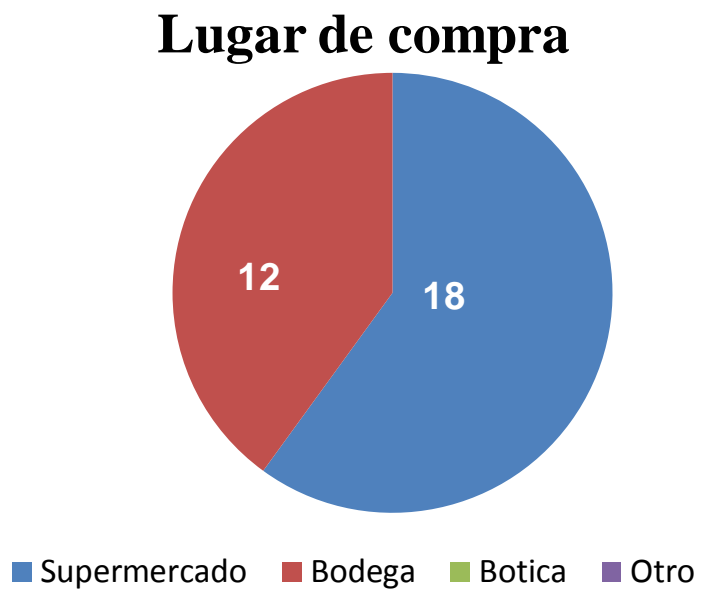

Elaboración propia 


\subsubsection{Determinación de la demanda}

De la figura 2.9 se obtuvo que un 50\% de la población objetivo estaría dispuesto a consumir el producto ofrecido.

\subsubsection{Proyección de la demanda}

Para la proyección de la demanda, se hará uso de la información del Tabla 2.2 para analizar el modelo por el cual se rige, por lo que se hará el cálculo del coeficiente de determinación $\left(\mathrm{R}^{2}\right)$ para evaluar cómo se comporta la variable.

Para el caso de la producción nacional se asumirá que durante la proyección de la demanda se mantendrá un crecimiento desde el año 2013, de la misma manera se hará el cálculo para las exportaciones. Se asumirá que la producción ira creciendo anualmente un $10 \%$ por lo explicado anteriormente y se espera que se venga produciendo de una manera similar en los próximos años.

Para el caso de las importaciones, se puede apreciar que presenta una variabilidad por lo que es necesario hacer el cálculo del factor de determinación para predecir cómo se dará en el futuro. Sin embargo al darse un pico anormal en el año 2012, este valor se excluirá del cálculo ya que hará que la dispersión sea mayor a lo que realmente debería ser:

\section{Figura 2.12}

\section{Estimación del factor de determinación}

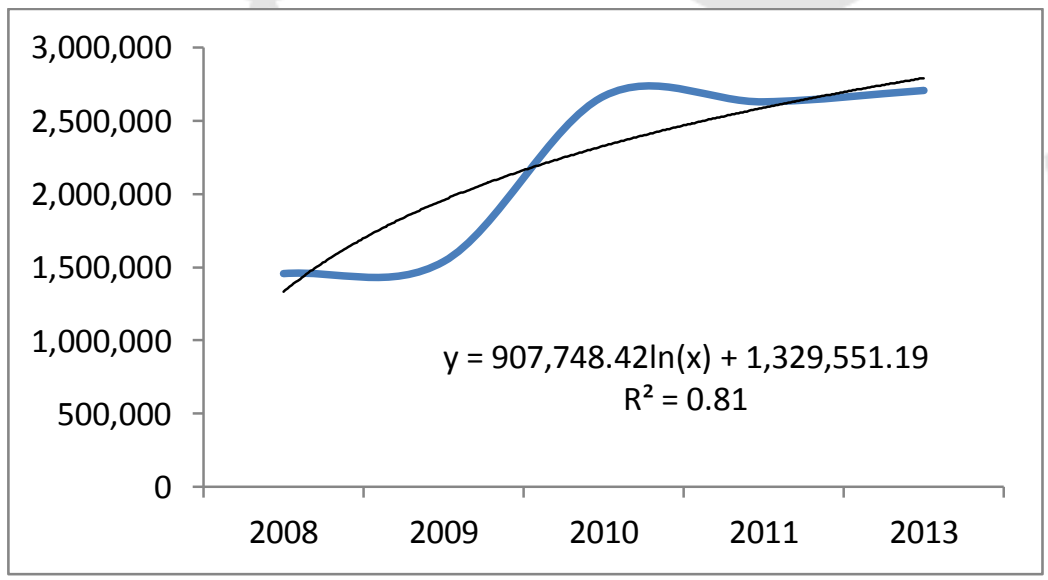

Elaboración propia 
Con un factor de $\mathrm{R}^{2}$ de casi 0.81 se puede establecer el factor de correlación $\mathrm{R}$ siendo igual a 0.90 , lo que quiere decir que la cantidad de importaciones y el paso de los años tienen una correlación fuerte. Así, con la ecuación que establece el modelo, podemos proyectar las importaciones para los próximos años. Para este proyecto se considerará un periodo de 5 años en los cuales se estima el proyecto pueda demostrar que es viable, por ello todas las evaluaciones y cálculos se harán para el periodo comprendido entre el 2014-2018.

\section{Tabla 2.3}

Proyección de la Demanda Interna Aparente para el periodo 2014-2018

\begin{tabular}{|c|c|c|c|c|}
\hline Año & $\begin{array}{c}\text { Importaciones de } \\
\text { Complementos } \\
\text { Alimenticios (Kg) }\end{array}$ & $\begin{array}{c}\text { Producción } \\
\text { Complementos } \\
\text { alimenticios (Kg) }\end{array}$ & $\begin{array}{c}\text { Exportación de } \\
\text { Complementos } \\
\text { alimenticios (Kg) }\end{array}$ & $\begin{array}{c}\text { DIA de } \\
\text { Complementos } \\
\text { alimenticios } \\
\text { (Kg) }\end{array}$ \\
\hline 2014 & 1.329 .551 & 886.336 & 179.067 & 2.036 .820 \\
\hline 2015 & 1.958 .741 & 974.970 & 196.794 & 2.736 .917 \\
\hline 2016 & 2.326 .793 & 1.072 .467 & 216.293 & 3.182 .966 \\
\hline 2017 & 2.587 .930 & 1.179 .713 & 237.743 & 3.529 .901 \\
\hline 2018 & 2.790 .484 & 1.297 .685 & 261.337 & 3.826 .832 \\
\hline
\end{tabular}

Elaboración propia

\subsubsection{Consideraciones sobre la vida útil del proyecto}

Para la vida útil del proyecto se considerará que el producto no demorará mucho en entrar al mercado ya que el tema de los complementos alimenticios no es un tema nuevo en el país y por el contrario se está dando con fuerza, es por ello que la duración del proyecto será de 5 años.

Asimismo, se considerará que las maquinarias tendrán una depreciación lineal, es decir, se depreciarán un $20 \%$ anual. 


\subsection{Análisis de la oferta}

\subsubsection{Empresas productoras, importadoras y comercializadoras}

De la información que se obtuvo para el punto 2.2 se obtiene que las 5 principales empresas que importan bajo las partidas arancelarias anteriormente mencionadas son:

\section{Tabla 2.4}

Principales empresas importadoras bajo las partidas arancelarias 2106101900 y 2106907900

\begin{tabular}{|l|c|c|}
\hline \multicolumn{1}{|c|}{ Razón Social } & RUC & $\begin{array}{c}\text { Peso } \\
\text { Neto(kg) }\end{array}$ \\
\hline ABBOTT LABORATORIOS SA & 20100096936 & 5.162 .628 \\
\hline OMNILIFE PERU SAC & 20290314799 & 2.428 .166 \\
\hline BAKELS PERU SAC & 20102179898 & 2.054 .112 \\
\hline HERBALIFE PERU SRL & 20512759778 & 1.247 .889 \\
\hline ALICORP S.AA & 20100055237 & 708.900 \\
\hline
\end{tabular}

Fuente: Datatrade, 2014

Elaboración propia

Dentro de las empresas productoras a nivel nacional se encuentra la empresa Waala, que por medio de su producto Forticao, empezó su venta en la provincia de San Martín (Tarapoto) y ahora se ha extendido a nivel nacional, viene ofreciendo este producto en cadenas de boticas como lo es el caso de Inkafarma. Asimismo, la empresa Incasur se ha consolidado en el mercado peruano con productos como Sol del Cusco y Kiwigen, llegando a captar un gran número del mercado nacional.

No obstante, en los mercados surgen también los pequeños comerciantes que venden productos como la maca y kiwicha, que también son muy consumidos por la población limeña.

\subsubsection{Competidores actuales y potenciales}

El principal competidor es el producto Forticao, sin embargo, también se considerará a los complementos alimenticios ya que su principal función es la de brindar el soporte alimenticio para mantener buena salud. 
Todas estas organizaciones tratan de captar la mayor cantidad de mercado por medio de publicidad haciendo creer al cliente que el producto es eficaz, por ello emplean diferentes estrategias para llegar a dicha finalidad.

Dentro de este rubro de los complementos alimenticios, se puede observar que Kiwigen de la empresa Incasur es la que tiene mayor preferencia por los consumidores, sin embargo Ensure de la empresa Abbott Laboratories ha registrado un crecimiento de $11 \%$ en lo que respecta al periodo 2010-2011.

\section{Figura 2.13}

\section{Marcas de complementos alimenticios más consumidos}

\begin{tabular}{|l|c|c|c|c|c|c|c|}
\hline $\begin{array}{l}\text { Marca más utilizada en } \\
\text { los últimos tres meses }\end{array}$ & $\begin{array}{c}\text { TOTAL TOTAL } \\
\%\end{array}$ & $\begin{array}{c}\mathbf{2 0 1 1} \\
\%\end{array}$ & $\begin{array}{c}\text { A } \\
\%\end{array}$ & $\begin{array}{c}\text { B } \\
\%\end{array}$ & $\begin{array}{c}\text { C } \\
\%\end{array}$ & $\begin{array}{c}\text { D } \\
\%\end{array}$ & $\begin{array}{c}\text { E } \\
\%\end{array}$ \\
\hline Kiwigen & 49 & 46 & 51 & 46 & 41 & 44 & 47 \\
\hline Ensure & 5 & 16 & 12 & - & 26 & 9 & 53 \\
\hline Sustagen & 8 & 13 & - & - & 23 & 18 & 53 \\
\hline Pediasure & 9 & 10 & 5 & 41 & - & 7 & 47 \\
\hline Protiban & 3 & 3 & - & - & 10 & - & - \\
\hline GNC & - & 1 & 5 & - & - & - & - \\
\hline & & 68 & 34 & $6^{\star}$ & $15^{\star}$ & $11^{\star}$ & $2^{\star}$ \\
\hline
\end{tabular}

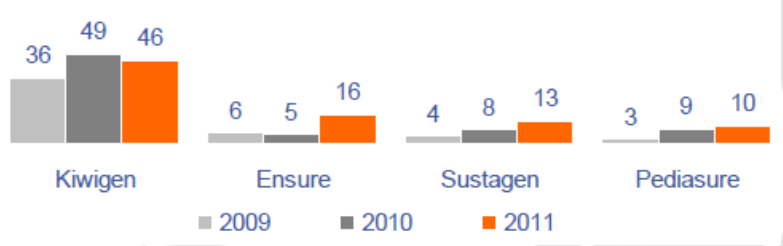

Fuente: Ipsos Apoyo, 2011

Adicionalmente, se puede observar que las demás marcas también registraron un crecimiento en el mercado, lo que podría dar a entender que mayor cantidad de personas están consumiendo este tipo de productos y es muy probable que esta tendencia se mantenga.

\subsection{Determinación de la demanda para el proyecto}

\subsubsection{Segmentación del mercado}

La segmentación del mercado de consumidores se hará en base a la segmentación propuesta por Philip Kotler y Gary Armstrong. 
Según la segmentación geográfica se escogió la ciudad de Lima Metropolitana porque abarca la mayor cantidad de personas en relación al resto del país (31.6 \%) y es la que presenta mayor desarrollo.

Según la segmentación demográfica no se hará distinción por raza, religión, sexo o edad ya que la idea es brindar un beneficio al mayor número de personas.

Según la segmentación Psicográfica se escogieron los niveles económicos C y D por ser los que representan menores posibilidades de acceder a mayores beneficios y representan mayores niveles de anemia y desnutrición.

A continuación se muestra las diferencias existentes entre las zonas geográficas en Lima Metropolitana donde se puede apreciar la zona predominante por cada zona, así como su ingreso promedio familiar mensual:

\section{Figura 2.14}

\section{Información geográfica de Lima Metropolitana}

\begin{tabular}{|c|c|c|c|c|c|c|c|}
\hline & Total & Lima Norte & Lima Este & Lima Centro & Lima Moderna & Lima Sur & Callao \\
\hline Total de habitantes & $9^{\prime} 362,385$ & $2^{\prime} 295,561$ & $2^{*} 186,720$ & 889,594 & 12291,878 & $1,731,133$ & 967.498 \\
\hline Distrito con mayor población & $\begin{array}{l}\text { S. Juan de } \\
\text { Lurigancho }\end{array}$ & $\begin{array}{c}\text { San Martin de } \\
\text { Porres }\end{array}$ & $\begin{array}{l}\text { S. Juan de } \\
\text { Lurigancho }\end{array}$ & Lima (Cercado) & $\begin{array}{l}\text { Santiago de } \\
\text { Surco }\end{array}$ & Villa El Salvador & Callao \\
\hline NSE predominantes & NSE C & NSE C y D & NSE D y C & NSE C y B & NSE B y A & NSE C y D & NSE D y C \\
\hline Cantidad de negocios & 312,770 & 72,349 & 60,543 & 64,510 & 38,078 & 53,429 & 23.861 \\
\hline $\begin{array}{l}\text { Ingreso prom. familiar mensual } \\
\text { bruto }\end{array}$ & S/.1,857 & $\mathrm{S} / .1,164$ & $\mathrm{~S} / 1,096$ & S/.1,631 & $\mathrm{S} / .4,671$ & $\mathrm{~S} / .1,189$ & $\mathrm{~S} / .1,012$ \\
\hline $\begin{array}{l}\text { Ingreso mínimo requerido por el } \\
\text { hogar }\end{array}$ & $\mathrm{S} / .2,174$ & S/.1,796 & S/.1,624 & $\mathrm{S} / .2,552$ & $\mathrm{~S} / .4,324$ & S/.1.704 & $\mathrm{S} / .1,640$ \\
\hline Tenencia de deudas & $41 \%$ & $43 \%$ & $34 \%$ & $33 \%$ & $54 \%$ & $38 \%$ & $41 \%$ \\
\hline
\end{tabular}

Fuente: Ipsos Apoyo, 2015

\subsubsection{Selección del mercado meta}

El mercado objetivo del proyecto será Lima Metropolitana, específicamente los distritos de Comas y San Juan de Lurigancho, que son distritos populosos y representan una población creciente que necesita una buena alimentación para su mejor desarrollo. 


\section{Figura 2.15}

\section{Población nacional y número de hogares}

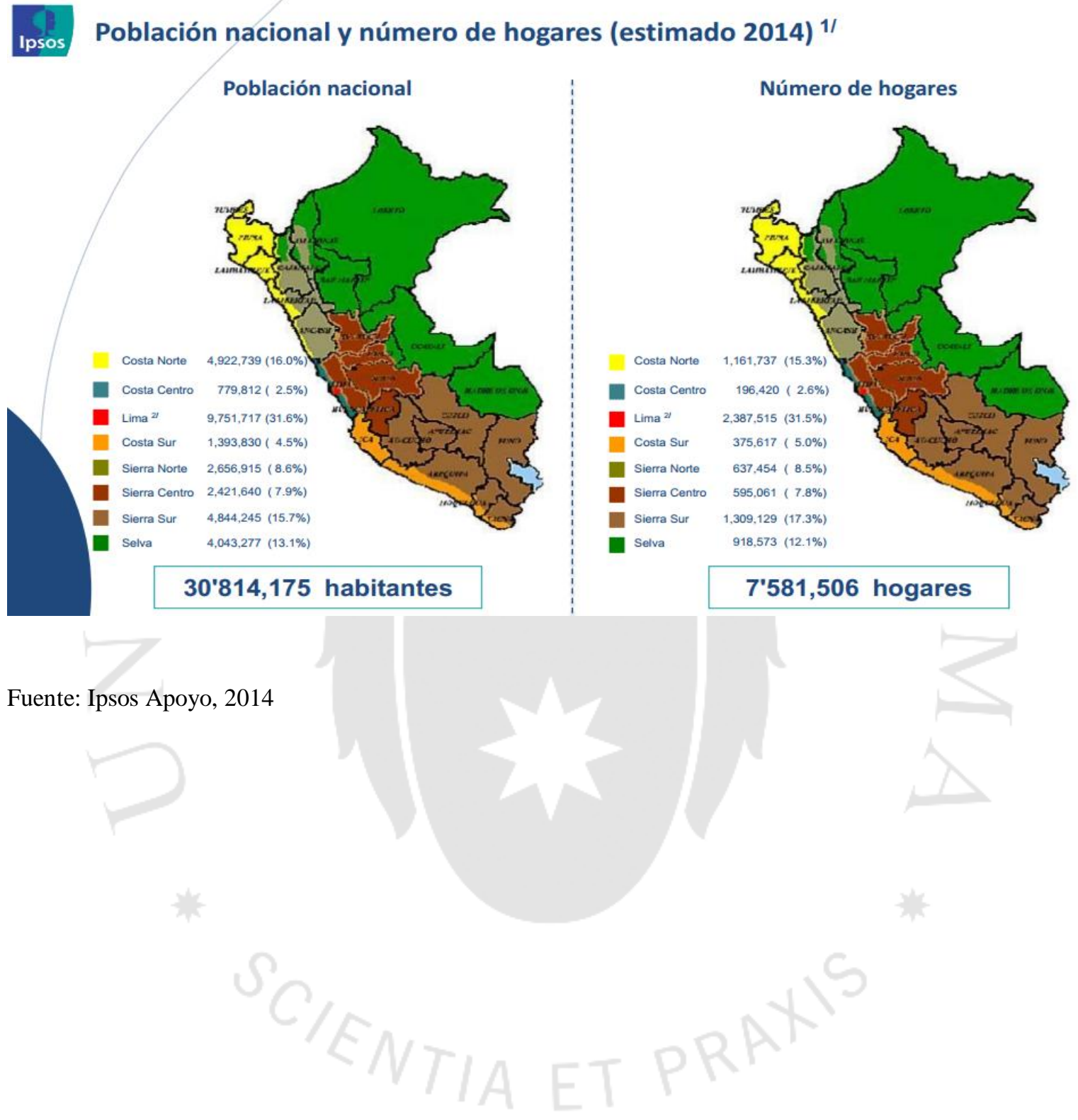




\section{Figura 2.16}

\section{Distribución de Lima Metropolitana por distrito}

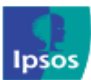

Distribución de la población por zonas geográficas
(estimado 2014)

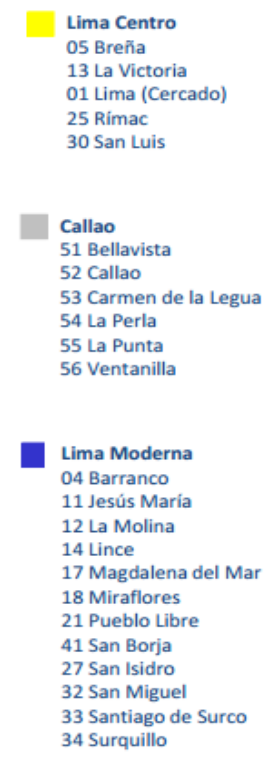

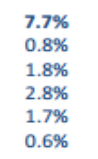

$10.2 \%$
$0.7 \%$
$4.2 \%$
$0.4 \%$
$0.6 \%$
$0.0 \%$
$4.2 \%$

$\mathbf{1 3 . 0 \%}$
$0.3 \%$
$0.7 \%$
$1.7 \%$
$0.5 \%$
$0.6 \%$
$0.9 \%$
$0.8 \%$
$1.1 \%$
$0.6 \%$
$1.4 \%$
$3.5 \%$
$0.9 \%$

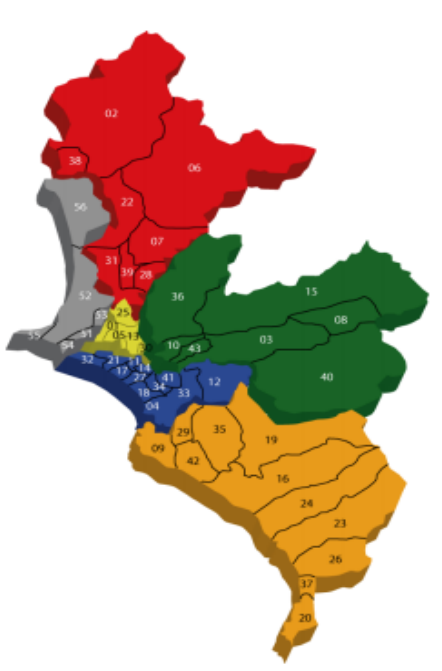

Lima Norte 02 Ancón 06 Carabayllo 07 Comas

28 Independencia

39 Los Olivos

22 Puente Piedra

31 San Martín de Porres

38 Santa Rosa

Lima Este

03 Ate

08 Chaclacayo

40 Cieneguilla

10 El Agustino

15 Lurigancho

36 San Juan de Lurigancho

43 Santa Anita

Lima Sur

09 Chorrillos

16 Lurín

19 Pachacamac

24 Punta Hermosa

23 Punta Negra

26 San Bartolo

29 San Juan de Miraflores

37 Santa María del Mar

42 Villa El Salvader

35 Villa María del Triunfo

Fuente: Estimaciones y proyecciones de la población al 30 de Junio del 2014 - INEI. Población total ajustada Censo 2007. Elaboración: Ipsos Perú $1 /$ No incluye la población rural, 11129 habitantes, según definición INEI 2007.

Fuente: Ipsos Apoyo, 2014

De la figura 2.16 se puede apreciar que Comas y San Juan de Lurigancho representan el 16.4\% de la población limeña.

\subsubsection{Demanda específica para el proyecto}

Para determinar la demanda para el presente proyecto se utilizará la demanda proyectada hallada en el Tabla 2.3, que es la demanda interna aparente (DIA), de la cual se determinó que el mercado meta serán los distritos de Comas y San Juan de Lurigancho, que representan el 16.4\% de Lima Metropolitana.

Asimismo, por medio de la encuesta realizada al mercado meta se obtuvo que del total de encuestados (30) el 50\% tendría la intención de compra del producto, por lo que también se considerará en el cálculo de la demanda del proyecto. 
Para el cálculo de la demanda se aplicará el siguiente cálculo para cada uno de los años del proyecto tomando en consideración que la participación de Lima Metropolitana, la participación de los distritos y la intención de compra se mantendrán constantes en el tiempo:

$\begin{gathered}\text { Demanda Proyec. } \\ \text { Añ } o X\end{gathered}=$ DIA AñoXX $x \begin{gathered}\text { Partic. Lima } \\ \text { Metropolitna (\%) }\end{gathered}{ }^{x} \begin{gathered}\text { Segmentación } \\ \text { pordistrito (\%) }\end{gathered} x_{\text {compra (\%) }}^{\text {Intención de }}$

A continuación se presenta la demanda proyectada hasta el año 2018 en unidades de producto de 250 gramos:

Tabla 2.5

Determinación de la demanda del proyecto en unidades

\begin{tabular}{|c|c|c|c|c|c|}
\hline Año & $\begin{array}{c}\text { Demanda } \\
\text { Proyectada } \\
\text { (Kg) }\end{array}$ & $\begin{array}{c}\text { Lima } \\
\text { Metropolitana } \\
\mathbf{3 1 . 6 \%}(\mathbf{K g})\end{array}$ & $\begin{array}{c}\text { Comas y SJL } \\
\mathbf{1 6 . 4 \%}(\mathbf{K g})\end{array}$ & $\begin{array}{c}\text { Encuesta } \\
\mathbf{5 0 \%}(\mathbf{K g})\end{array}$ & $\begin{array}{c}\text { Demanda } \\
\text { del } \\
\text { Proyecto } \\
\text { (Unidades) }\end{array}$ \\
\hline $\mathbf{2 0 1 4}$ & 2.036 .820 & 643.635 & 105.556 & 52.778 & 211.112 \\
\hline $\mathbf{2 0 1 5}$ & 2.736 .917 & 864.866 & 141.838 & 70.919 & 283.676 \\
\hline $\mathbf{2 0 1 6}$ & 3.182 .966 & 1.005 .817 & 164.954 & 82.477 & 329.908 \\
\hline $\mathbf{2 0 1 7}$ & 3.529 .901 & 1.115 .449 & 182.934 & 91.467 & 365.867 \\
\hline $\mathbf{2 0 1 8}$ & 3.826 .832 & 1.209 .279 & 198.322 & 99.161 & 396.643 \\
\hline
\end{tabular}

Elaboración propia

\subsection{Definición de la estrategia de comercialización}

\subsubsection{Políticas de comercialización y distribución}

Para aplicar una estrategia de posicionamiento, se buscará colocar al producto como natural, de buena calidad, inocuo y con altos beneficios para la salud - nutritivo, teniendo en cuenta el sector de la población que intenta llevar un estilo de vida saludable y entienda la importancia de mantenerse sano.

Al mismo tiempo, se buscará promocionar el producto dando a conocer su sabor, usos, y beneficios - propiedades nutricionales. En un primer momento, se dará a conocer el 
producto mediante degustaciones y entrega de volantes de información, posteriormente se podría considerar realizar ofertas como descuentos para promocionar e incrementar su venta. Las políticas de ventas de la empresa se dividirán en:

Precios: Los precios de ingreso al mercado serán más bajos respecto a la competencia para generar el interés del público.

Ventas: La venta del producto será principalmente a través del canal minorista en bodegas, cadenas de boticas y farmacias, asimismo se incursionará en los supermercados ya que según el análisis de los patrones de consumo, las personas prefirieron estos establecimientos para realizar sus compras. No obstante, también se podría realizar la venta en un local propio establecido para el proyecto.

Formas de pago: La empresa solo aceptará pagos en efectivo, pagos a crédito y pagos por adelantado. Para la cobranza y el pago a proveedores se tratará que sea $70 \%$ el mismo mes y $30 \%$ para el siguiente.

La distribución será a cargo de un servicio tercerizado que pueda llevar el producto de la planta a los puntos de venta mencionados anteriormente, este tendrá que llegar a tiempo o en el peor de los casos sin mucho tiempo de demora. Los camiones llevarán cajas de 24 unidades, y al ser este un producto de vidrio se tendrá que tener un especial cuidado en el transporte por la fragilidad que tiene el producto.

\subsubsection{Publicidad y promoción}

La publicidad del producto se hará en los mismos puntos de venta donde se realizaran las degustaciones al público, para que puedan comprobar su calidad de este y a la vez se les explicará sobre sus propiedades, beneficios y su forma de consumo. Además, se brindará información sobre el producto a través de volantes y afiches, en donde se describan las cualidades del producto ofrecido.

Otro medio de publicidad será a través de redes sociales como Facebook o Twitter, ya que actualmente la mayoría de personas emplea estos medios para buscar información.

Adicionalmente, como parte de la promoción, durante el proyecto se establecerán ofertas como el 2x1 para incentivar la venta del producto. 


\subsubsection{Análisis de precios}

\subsubsection{Tendencia histórica de los precios}

No se cuenta con una tendencia histórica de precios de cada uno de los productos, por lo que considerara solamente la del producto Forticao, que en el año 1999 comenzó la venta de su producto a un precio de S/. 10,00 nuevos soles, unos años más tarde el precio se elevó a S/. 30,00 nuevos soles y actualmente se comercializa a un precio de S/. 36,00 nuevos soles.

\subsubsection{Precios actuales}

A continuación se presenta una lista de los principales productos en el mercado peruano y sus precios actuales:

\section{Tabla 2.6}

Tablas actuales de las principales marcas

\begin{tabular}{|c|c|c|}
\hline Marca & Presentación & Precio Actual (S/.) \\
\hline Forticao & Frasco por 80 gramos & 36,00 \\
\hline Kiwigen & Frasco por 400 gramos & 12,89 \\
\hline
\end{tabular}

Fuente: Natural Nutrition y Perufarma, 2015

Elaboración propia

Con la información del Tabla 2.6 se podría establecer, en primera instancia, que el precio de venta del producto esté en relación con el precio promedio de los demás, sin embargo, como se trata de ayudar a la complementación de la alimentación de las personas y que resulte atractivo en una primera instancia para el público, el precio del producto será de S/. 8,00 nuevos soles, ya que sería un precio introductorio.

\subsection{Análisis de disponibilidad de los insumos principales}

\subsubsection{Características principales de la materia prima}

Los insumos a utilizarse como materia prima son la sangre de pollo y el cacao. La sangre de pollo se obtiene del mismo animal una vez que este es sacrificado. Una de las características principales de este insumo es que a diferencia de otros contiene un alto nivel de hierro, como 
lo sostiene el nutricionista del Instituto Nacional de Salud (INS) Luis Aguilar Esenarro: "En 100 gramos de carne de pollo, el contenido de hierro es de 1,5 mg. Mientras que en la misma cantidad, la sangrecita cocida aporta $27,3 \mathrm{mg}$ hierro y el hígado de pollo aporta 8,5 mg",5, lo que hace posible que elaborar un producto a base de sangre de pollo resulte beneficioso para la salud.

\section{Figura 2.17}

Composición de alimentos en porciones de 100 gramos

\begin{tabular}{|c|c|c|c|c|c|c|c|}
\hline \multicolumn{8}{|c|}{ TABLAS PERUANAS DE COMPOSICIÓN DE ALIMENTOS } \\
\hline \multirow[t]{2}{*}{ ALIMENTO } & \multicolumn{7}{|c|}{ COMPOSICION POR 100 GRAMOS DE PORCION COMESTIBLE } \\
\hline & $\begin{array}{c}1 \\
\text { Energía } \\
\text { Kcal }\end{array}$ & \begin{tabular}{|c|}
3 \\
Proteína \\
$\mathrm{g}$
\end{tabular} & $\begin{array}{c}4 \\
\text { Grasa } \\
9\end{array}$ & $\begin{array}{c}5 \\
\text { Carbohidrato } \\
\end{array}$ & $\begin{array}{c}8 \\
\text { Calcio } \\
\text { mg }\end{array}$ & \begin{tabular}{|c|}
9 \\
Fósforo \\
mg
\end{tabular} & $\begin{array}{l}10 \\
\text { Hierro } \\
\text { mg }\end{array}$ \\
\hline \multicolumn{8}{|c|}{$\begin{array}{l}\text { III CARNES Y PREPARADOS } \\
\text { (continuación) } \\
\text { Conejo }\end{array}$} \\
\hline Carne, pulpa & 163 & 20.0 & 8.6 & 0.0 & 18 & 210 & 2.4 \\
\hline \multicolumn{8}{|l|}{ Cuy } \\
\hline $\begin{array}{l}\text { Carne, pulpa } \\
\text { Gallina: }\end{array}$ & 96 & 19.0 & 1.6 & & 29 & 258 & 1.9 \\
\hline Pechuga, pulpa & 108 & 19.2 & 2.9 & & 5 & 237 & 0.8 \\
\hline Pierna, pulpa & 120 & 20.6 & 3.6 & & 9 & 190 & 0.9 \\
\hline \multicolumn{8}{|l|}{ Pato: } \\
\hline Carne, pulpa & 326 & 16.0 & 28.6 & 0.0 & 15 & 188 & 1.8 \\
\hline \multicolumn{8}{|l|}{ Pollo } \\
\hline Carne, pulpa & 170 & 18.2 & 10.2 & 0.0 & 14 & 200 & 1.5 \\
\hline Corazón & 157 & 20.5 & 7.0 & 1.6 & 23 & 142 & 1.7 \\
\hline Sangre cocida & 69 & 16.0 & 0.1 & & 14 & 115 & 29.5 \\
\hline Sangre cruda & 65 & 15.0 & 0.1 & & 12 & 101 & 27.3 \\
\hline
\end{tabular}

Fuente: Sanchez, N. ,2000

El otro insumo a emplearse como materia prima es el cacao que dentro de sus principales características es que tiene propiedades antioxidantes y estimulantes, lo que genera en el organismo que este se sienta con mayor energía y evita así la muerte temprana de las células, asimismo ayuda a combatir el estreñimiento.

\subsubsection{Disponibilidad de la materia prima}

El recurso principal para el proyecto, como ya se mencionó anteriormente, es la sangre de pollo cuyo origen proviene del sacrificio de este animal. El Perú está considerado dentro de los 20 mayores países avícolas del mundo y no es para menos ya que en el año 2012 la producción avícola total alcanzo la cifra de 1,112 millones de toneladas métricas, siendo considerado el consumo per cápita a nivel nacional de $39 \mathrm{Kg}$ y en Lima metropolitana el

\footnotetext{
${ }^{5}$ http://www.ins.gob.pe/portal/noticias/noticia/0/989/la-sangrecita-economica-y-nutritiva
} 
consumo de $60 \mathrm{Kg}^{6}$. En el siguiente Tabla se puede apreciar los principales productores de pollo a nivel nacional:

Tabla 2.7

Principales productores de pollo a nivel nacional

\begin{tabular}{|c|c|}
\hline Productor & RUC \\
\hline San Fernando S.A & 20100154308 \\
\hline Avinka S.A & 20299982484 \\
\hline Redondos S.A & 20221084684 \\
\hline Rico Pollo S.A & 20121685435 \\
\hline
\end{tabular}

Fuente: Ministerio de Agricultura, 2014

Elaboración propia

La sangre de pollo se obtendría de un proveedor especializado, que en este caso podría ser San Fernando por su capacidad y su experiencia, además nos daría la garantía de calidad de la sangre de pollo por como alimentan a sus aves, sin embargo también se podría recurrir a otras empresas como Avinka o Redondos. Considerando que es un insumo altamente perecible, se tomará en cuenta en todo momento las Buenas Prácticas de Manipulación, a fin de asegurar su calidad, por ello el transporte hacia la sede del proyecto se hará a través de una cadena de frio que permita la conservación del insumo. Según un estudio realizado en la universidad de Zaragoza, por cada kilogramo de pollo se obtiene 60 mililitros de sangre, por ende si tomamos como ejemplo el mes de Mayo 2014 en el que se obtuvo 49 millones de pollos ${ }^{7}$, entonces considerando que cada pollo pese aproximadamente 2 kilos, se podría obtener aproximadamente 5,8 millones de litros de sangre

Asimismo, la producción de cacao en el Perú viene en expansión y a comparación del primer trimestre del 2013, el 2014 ha crecido un 22\% más. Durante el 2013, la producción nacional de cacao alcanzó las 62.973 toneladas siendo esta cultivada por aproximadamente 56.000 familias.

\footnotetext{
${ }^{6}$ Diario El Comercio. "El Perú se encuentra entre los 20 mayores productores avícolas del mundo”. (2013)

${ }^{7}$ El Comercio. http://elcomercio.pe/economia/peru/produccion-nacional-pollo-registro-maximo-historico-mayonoticia-1428307 (2014)
} 
Para el caso del cacao, para el año 2014 se esperaba que la producción interna de este grano sea de 75.500 TM superando en 20\% al año 2013, según la Dirección General de competitividad Agraria (DGCA) del Ministerio de Agricultura y Riego (MINAGRI), por lo que se puede esperar que para los próximos años la producción siga creciendo y no exista problema con la disponibilidad y en la adquisición del insumo.

\subsubsection{Costos de la materia prima}

A continuación se presenta el costo promedio al cual se puede adquirir los insumos principales:

\section{Tabla 2.8}

\section{Costos de la materia prima}

\begin{tabular}{|c|c|}
\hline Materia prima & Costo (S/.)/Kg \\
\hline Sangre de pollo & 3,00 \\
\hline Cacao & 8,00 \\
\hline
\end{tabular}

Elaboración propia 


\section{CAPÍTULO III. LOCALIZACIÓN DE PLANTA}

\subsection{Identificación y análisis detallado de los factores de localización}

Se considerarán para las posibles localizaciones los factores de cercanía al mercado, disponibilidad de materia prima, disponibilidad de mano de obra, abastecimiento de agua y disponibilidad de energía eléctrica. A continuación se detallará cada uno de los factores mencionados:

\section{Cercanía al mercado}

Este factor se considera relevante porque incurrirá en los gastos ligados a la distribución de los insumos, materiales y del producto. Teniendo en cuenta que la demanda objetivo se encuentra en Lima, es vital tratar de tener los menores tiempos posibles en lo que se refiere a transporte ya que la sangre de pollo es un insumo perecible.

\section{Disponibilidad de materia prima}

La disponibilidad de materia prima es el factor más importante ya que de este depende si existen suficientes insumos para llevar a cabo el proyecto. Las materias primas a emplear en el proyecto son la sangre de pollo y el cacao. Se determinó que la materia prima o insumo principal es la sangre de pollo. Es de vital importancia mantener la inocuidad del proceso, es por ello que se debe tener un cuidado muy especial con el transporte y manipuleo de la sangre de pollo por ser un insumo orgánico altamente perecible.

\section{Disponibilidad de la mano de obra}

La planta requiere ubicarse en un lugar donde se disponga de oferta laboral adecuada y con un nivel de conocimientos necesario para llevar acabo las actividades del proyecto.

\footnotetext{
Abastecimiento de agua

El proyecto debe contar con un nivel de servicio de agua que permita usar este recurso la mayor cantidad de tiempo posible, asimismo se debe contar con servicio de alcantarillado y una tarifa razonable a los intereses del proyecto.
} 


\section{Disponibilidad de energía eléctrica}

Para el buen funcionamiento de la planta, la energía eléctrica es bastante importante ya que las máquinas empleadas para la producción requerirán de una fuente continua que no genera paradas y por ende pérdidas, por lo tanto se necesita un abastecimiento constante, que brinde la potencia suficiente.

Las localizaciones a evaluar son:

\section{1) Lima}

Se consideró la ciudad de Lima ya que en esta se ubica el mercado objetivo al que va dirigido el producto, se tiene acceso a todos los servicios básicos y además acceso a la materia prima principal del producto que es la sangre de pollo.

\section{2) San Martín}

A pesar de la distancia a la que se encuentra del mercado objetivo, tiene un fácil acceso a una de las materias primas principales del producto que es la semilla del cacao.

\section{3) Ucayali}

Aunque se encuentra alejado del mercado objetivo, tiene un fácil acceso a una de las materias primas principales del producto que es la semilla del cacao.

A continuación se evaluará cada factor de forma aislada, para determinar la macro localización idónea.

\subsection{Identificación y descripción de las alternativas de localización}

Se calificará cada departamento (Lima, San Martín y Ucayali) en función a sus factores, haciendo uso de una escala de calificación para la importancia de estos, A continuación se muestra la escala:

Excelente (10)

Muy Bueno (8)

Bueno (6)

Regular (4)

Deficiente (2) 


\subsubsection{Cercanía al mercado}

Para este análisis se tendrá en cuenta las distancias por vías terrestres de las capitales departamentales y la ciudad de Lima, donde se encuentra la demanda del proyecto. Las distancias se muestran en el siguiente Tabla:

Tabla 3.1

Distancias de capitales departamental a Lima

\begin{tabular}{|c|c|c|l|}
\hline Departamento & Capital & $\begin{array}{c}\text { Distancia a } \\
\text { Lima KM }\end{array}$ & \multicolumn{1}{c|}{ Vías de Acceso } \\
\hline Ucayali & Pucallpa & $840 \mathrm{~km}$ & Ucayali-Huánuco-Pasco-Junín Lima \\
\hline San Martín & Moyobamba & $1.445 \mathrm{~km}$ & $\begin{array}{l}\text { San Martín-Amazonas-La libertad- } \\
\text { Ancash -Lima }\end{array}$ \\
\hline
\end{tabular}

Fuente: MINCETUR, 2014

Elaboración propia

En base a las distancias, se realizó la calificación por cada departamento que se muestra a continuación:

Tabla 3.2

Calificación de factor cercanía de mercado

\begin{tabular}{|l|c|c|c|}
\hline Departamento & Lima & San Martín & Ucayali \\
\hline Calificación & 10 & 4 & 2 \\
\hline
\end{tabular}

Elaboración propia

\subsubsection{Disponibilidad de materia prima}

A continuación se elaborará un análisis de las 2 materias primas para el proyecto:

\section{A. Sangre de pollo}

La materia principal se obtiene a través del proceso de sacrificio del pollo. Por cada kilogramo de pollo se obtiene 60 mililitros de sangre ${ }^{8}$, esto quiere decir que si un pollo pesa aproximadamente 2 kilos en promedio, se obtendría 0.12 litros de sangre.

\footnotetext{
${ }^{8}$ Universidad de Zaragoza. Comisión ética asesora para la experimentación animal
} 
El consumo de pollo en el Perú ha venido en crecimiento en estos últimos años, llegando a alcanzar un consumo per cápita de 39 Kilogramos en comparación con otros tipos de carnes como el chancho que tiene un consumo per cápita de 4,7 Kg. Según el Banco Central de Reserva del Perú (BCRP) en su análisis de la avicultura nacional y regional 2013 (periodo Enero a Agosto), la Costa concentra el 90\% de la producción nacional de este animal siendo Lima la principal zona productora con un 55\% del total, seguido largamente por la Libertad (19\%) y Arequipa (9\%).

Del estudio del BCRP, la producción de pollo durante ese periodo (Enero-Agosto 2013) fue de 393 millones de pollos, de los cuales, como ya se mencionó, Lima tiene un 55\% de la participación que vendría a ser aproximadamente 216,15 millones de pollos, San Martín tiene un $2 \%$ de la producción que es aproximadamente 7,86 millones, mientras que Ucayali se encuentra dentro del $7 \%$ correspondiente a otros departamentos, lo que hace pensar que su producción es menor a la de los otros 2 departamentos mencionados.

\section{Figura 3.1}

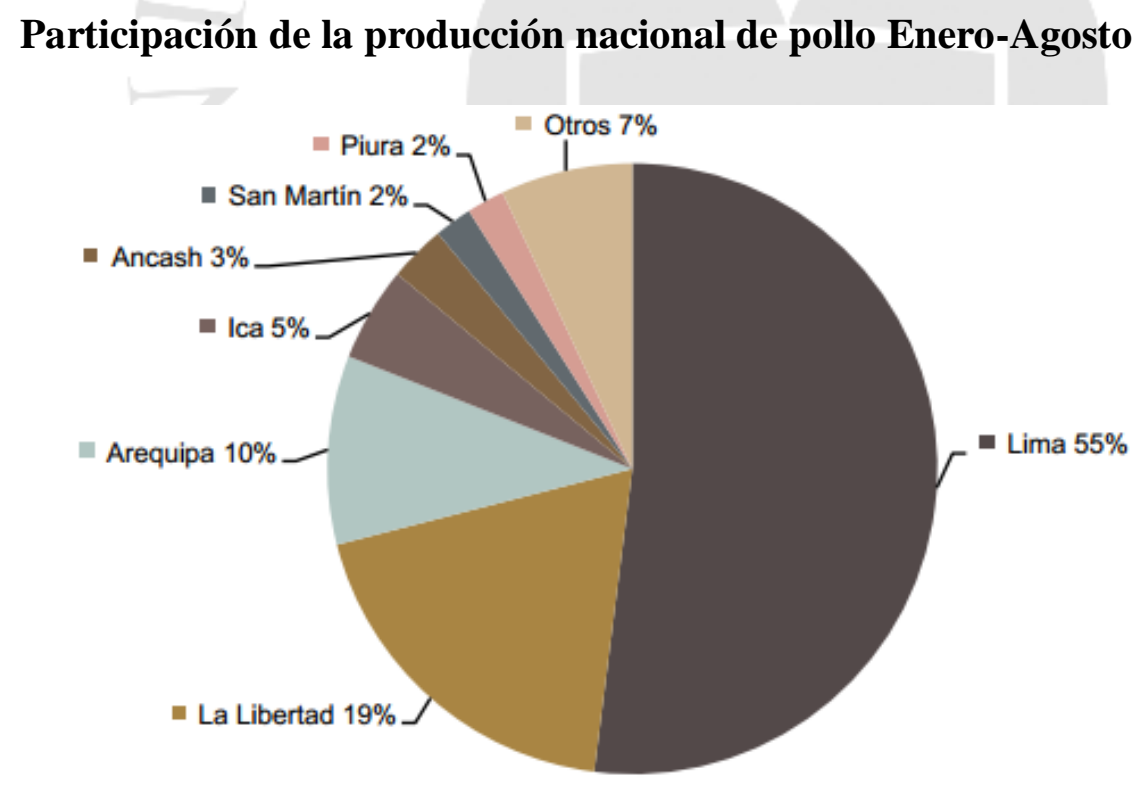

Fuente: Banco Central de Reserva del Perú (BCRP), 2013

Por lo tanto, el departamento que brinda mayores facilidades para obtener la sangre de pollo es Lima, seguido de San Martín y finalmente Ucayali.

\section{B. Cacao}

En el Perú, el departamento que produce mayor cantidad de cacao es San Martín con 18.764 toneladas métricas, Ucayali produce 1.032 toneladas métricas y Lima no produce una 
cantidad significante. Teniendo en cuenta estas consideraciones, San Martín es el departamento más importante en la producción de cacao.

Teniendo en cuenta la disponibilidad de materia prima y la importancia de la sangre de pollo por encima del cacao como insumo principal, se establece la siguiente calificación:

\section{Tabla 3.3}

Calificación del factor disponibilidad de materia prima

\begin{tabular}{|l|c|c|c|}
\hline Departamento & Lima & San Martín & Ucayali \\
\hline Calificación & 10 & 6 & 4 \\
\hline
\end{tabular}

Elaboración propia

\subsubsection{Disponibilidad de mano de obra}

A continuación se presenta una tabla con ciertos indicadores a tomar en cuenta para la elección de la mejor opción en cuanto a disponibilidad de mano de obra se refiere:

Tabla 3.4

Disponibilidad de mano de obra por departamento

\begin{tabular}{|l|c|c|c|}
\hline \multicolumn{1}{|c|}{ Indicadores } & Lima & San Martín & Ucayali \\
\hline $\begin{array}{l}\text { Población en edad para trabajar } \\
\text { (PET) (miles de personas) }\end{array}$ & $7.930,1$ & 572,0 & 333,0 \\
\hline $\begin{array}{l}\text { Población económicamente activa } \\
\text { (PEA) (miles de personas) }\end{array}$ & $5.628,4$ & 425,4 & 265,2 \\
\hline $\begin{array}{l}\text { Población económicamente activa } \\
\text { ocupada (miles de personas) }\end{array}$ & $5.353,8$ & 415,9 & 258,2 \\
\hline $\begin{array}{l}\text { Población económicamente activa } \\
\text { desocupada (miles de personas) }\end{array}$ & 267,4 & 9,5 & 7 \\
\hline $\begin{array}{l}\text { Ingreso promedio mensual } \\
\text { proveniente del trabajo }\end{array}$ & $1.470,2$ & 982,9 & $1.015,3$ \\
\hline
\end{tabular}

Fuente: INEI, 2014

Elaboración propia 
Como se puede apreciar en la tabla, el departamento con mayor disponibilidad de mano de obra es la ciudad de Lima, seguido por San Martín y finalmente el departamento de Ucayali. Sin embargo, un alto ingreso promedio mensual del trabajador podría afectar los intereses del proyecto en términos económicos, por lo que se considerará más importante el ingreso del trabajador mensual a la cantidad de PEA desocupada, ya que se espera que el proyecto no cuente con mucho personal.

Con las consideraciones mencionadas anteriormente, se establece la ponderación de la siguiente manera:

\section{Tabla 3.5}

Calificación del factor disponibilidad de mano de obra

\begin{tabular}{|l|c|c|c|}
\hline Departamento & Lima & San Martín & Ucayali \\
\hline Calificación & 4 & 8 & 6 \\
\hline
\end{tabular}

Elaboración propia

\subsubsection{Abastecimiento de agua}

Para analizar este factor adecuadamente se tendrá en cuenta la Cobertura de Agua Potable, Cobertura de Alcantarillado y la tarifa por el servicio de agua potable.

Tabla 3.6

Calificación de factor abastecimiento de agua

\begin{tabular}{|l|c|c|}
\cline { 2 - 3 } \multicolumn{1}{c|}{} & $\begin{array}{c}\text { Cobertura de } \\
\text { Agua Potable }\end{array}$ & $\begin{array}{c}\text { Cobertura de } \\
\text { Alcantarillado }\end{array}$ \\
\hline SEDAPAL S.A. (Lima) & $94,59 \%$ & $89,86 \%$ \\
\hline EMAPACOP S.A. (Ucayali) & $61,53 \%$ & $62,01 \%$ \\
\hline $\begin{array}{l}\text { EMAPA MOYOBAMBA } \\
\text { S.R.L.LTDA. (San Martín) }\end{array}$ & $85,61 \%$ & $64,79 \%$ \\
\hline
\end{tabular}

Fuente: SUNASS, 2013

Elaboración: Propia 
Tabla 3.7

Tarifa por el servicio de agua potable de categoría industrial por ciudad

\begin{tabular}{|c|c|c|c|c|}
\hline Empresa (Ciudad) & $\begin{array}{c}\text { Rango } \\
\left(\mathrm{m}^{3} / \mathrm{mes}\right)\end{array}$ & $\begin{array}{l}\text { Cargo fijo } \\
\text { (S/./mes) }\end{array}$ & $\begin{array}{l}\text { Volumen de } \\
\text { Agua potable } \\
\left(\mathrm{S} / . / \mathrm{m}^{3}\right)\end{array}$ & $\begin{array}{c}\text { Servicio de } \\
\text { Alcantarillado } \\
\left(\mathrm{S} / . / \mathrm{m}^{3}\right)\end{array}$ \\
\hline \multirow{2}{*}{ SEDAPAL S.A. (Lima) } & 0 a 1.000 & \multirow{2}{*}{4,74} & 4,1 & 1,789 \\
\hline & 1.001 a más & & 4,39 & 1,919 \\
\hline \multirow{2}{*}{ EMAPACOP S.A. (Ucayali) } & 0 a 50 & \multirow{2}{*}{1,362} & 2,81 & 1,26 \\
\hline & 50 a más & & 5,67 & 2,55 \\
\hline $\begin{array}{l}\text { EMAPA MOYOBAMBA } \\
\text { S.R.L.LTDA (San Martín) }\end{array}$ & 0 más & 1,752 & 2,7 & 0,755 \\
\hline
\end{tabular}

Fuente: SEDAPAL, EMAPACOP Y ENAPA MOYOBAMBA, 2014

Elaboración propia

Dado que el nivel de cobertura de agua potable y alcantarillado es mayor al $50 \%$ en las 3 localidades y por lo que se considera aceptable para el proyecto, se hará la calificación de cada departamento en base a las tarifas, que es lo que afecta la rentabilidad:

\section{Tabla 3.8}

Calificación de factor abastecimiento de agua

\begin{tabular}{|l|c|c|c|}
\hline Departamento & Lima & San Martín & Ucayali \\
\hline Calificación & 6 & 8 & 8 \\
\hline
\end{tabular}

Elaboración propia

\subsubsection{Disponibilidad de energía eléctrica}

Para analizar el abastecimiento de energía se presenta a continuación información sobre el tipo de energía (térmico o hidráulico), potencia y producción de energía de cada uno de los departamentos analizados.

\section{A. Departamento de Lima:}

Hay dos fuentes de energía eléctrica en el departamento de Lima; uno puede ser de origen térmico y el otro de origen hidráulico. 


\section{Tabla 3.9}

Potencia y producción de energía eléctrica en el departamento de Lima

\begin{tabular}{|l|c|c|}
\hline Tipo & Potencia total (MW) & Producción total (GW.h) \\
\hline Total & $3.089,2$ & $14.097,6$ \\
\hline Hidráulico $(\%)$ & 29 & 39 \\
\hline Térmico $(\%)$ & 71 & 61 \\
\hline
\end{tabular}

Fuente: Ministerio de Energía y Mina, 2014

Elaboración propia

\section{B. Departamento de Ucayali}

La energía existente en el departamento de Ucayali es térmica, por la poca fuerza que existe en la caída de agua de los ríos. En la siguiente tabla se puede observar la información obtenida del Ministerio de Energía y Minas (MINEM):

Tabla 3.10

Potencia y producción de energía eléctrica en el departamento de Ucayali

\begin{tabular}{|l|c|c|}
\hline Tipo & Potencia total (MW) & Producción total (GW.h) \\
\hline Total & 343 & 508,4 \\
\hline Hidráulico (\%) & -- & 1 \\
\hline Térmico (\%) & 100 & 99 \\
\hline
\end{tabular}

Fuente: Ministerio de Energía y Minas, 2014

Elaboración: Propia

\section{Departamento de San Martín}

La energía existente en el departamento de San Martin es en su mayoría hidráulica porque aprovecha más la fuerza de los ríos para la generación de electricidad que el uso de otros combustibles. 
Tabla 3.11

Potencia y producción de energía eléctrica en el departamento de San Martin

\begin{tabular}{|c|c|c|}
\hline Tipo & Potencia total (MW) & Producción total (GW.h) \\
\hline Total & 53,2 & 44,8 \\
\hline Hidráulico (\%) & 82 & 78 \\
\hline Térmico (\%) & 18 & 22 \\
\hline
\end{tabular}

Fuente: Ministerio de Energía y Minas, 2014

Elaboración: Propia

Con respecto a la tarifa se decidió trabajar con la BT5B (Baja tensión), no residencial, que es un suministro de baja tensión que es común en el uso de talleres y plantas con una demanda máxima mensual de $20 \mathrm{KW}$ en horas punta y de hasta $50 \mathrm{KW}$ en horas fuera de punta. A continuación se presenta la tabla con las tarifas de cargo fijo y por energía activa en cada departamento:

Tabla 3.12

Tarifas BT5B por departamento

\begin{tabular}{|c|c|c|}
\hline Departamento & $\begin{array}{r}\text { Cargo fijo } \\
\text { (S/./mes) }\end{array}$ & Cargo por Energía Activa (ctm S/./KW.h) \\
\hline Lima & 2,41 & 37,80 \\
\hline San Martín & 3,09 & 54,31 \\
\hline Ucayali & 3,09 & 48,57 \\
\hline
\end{tabular}

Fuente: OSINERGMIN, 2014

Elaboración propia

De las tablas mostradas, podemos concluir que Lima es quien podría brindar el mejor abastecimiento de energía eléctrica a una menor tarifa, seguido por Ucayali y por último San Martin, cuya potencia y producción total es bastante pequeña comparada con los otros departamentos. 
Tabla 3.13

Calificación del factor abastecimiento de energía eléctrica

\begin{tabular}{|l|c|c|c|}
\hline Departamento & Lima & San Martín & Ucayali \\
\hline Calificación & 10 & 2 & 4 \\
\hline
\end{tabular}

Elaboración propia

\subsection{Evaluación y selección de localización}

Se analizaran los departamentos de Lima, San Martín y Ucayali en función de los 5 factores previamente descritos.

\subsubsection{Evaluación y selección de macro localización}

Para elegir la macro localización de la planta se empleará la metodología de ranking de factores, la cual consiste en ponderar cada factor para posteriormente calificar cada localización en base a la ponderación de los factores.

En primer lugar, se elaborara una matriz de enfrentamientos para ponderar los factores, siguiendo los siguientes criterios:

-Se asignara el valor de 1 si un factor es más importante que otro.

-Se asignara el valor de 1 si ambos factores son de igual importancia.

-Se asignará el valor de 0 si un factor es menos importante que otro.

Dónde:

A: Cercanía de mercado

B: Disponibilidad de materia prima

C: Disponibilidad de mano de obra

D: Abastecimiento de agua

E: Disponibilidad de energía eléctrica. 
Tabla 3.14

Tabla de enfrentamiento de factores

\begin{tabular}{|c|c|c|c|c|c|c|c|}
\cline { 2 - 9 } \multicolumn{1}{c|}{} & A & B & C & D & E & Conteo & Pond. \\
\hline A & - & 1 & 1 & 1 & 0 & 3 & $23,08 \%$ \\
\hline B & 1 & - & 1 & 1 & 1 & 4 & $30,77 \%$ \\
\hline C & 0 & 1 & - & 0 & 1 & 2 & $15,38 \%$ \\
\hline D & 0 & 1 & 0 & - & 1 & 2 & $15,38 \%$ \\
\hline E & 0 & 1 & 0 & 1 & - & 2 & $15,38 \%$ \\
\hline
\end{tabular}

Elaboración propia

Con los resultados de la ponderación de factores de la tabla de enfrentamiento, se procede a elaborar un ranking de factores donde se calificará cada uno de los factores con la escala establecida al principio del capítulo.

Tabla 3.15

Tabla de Ranking de factores

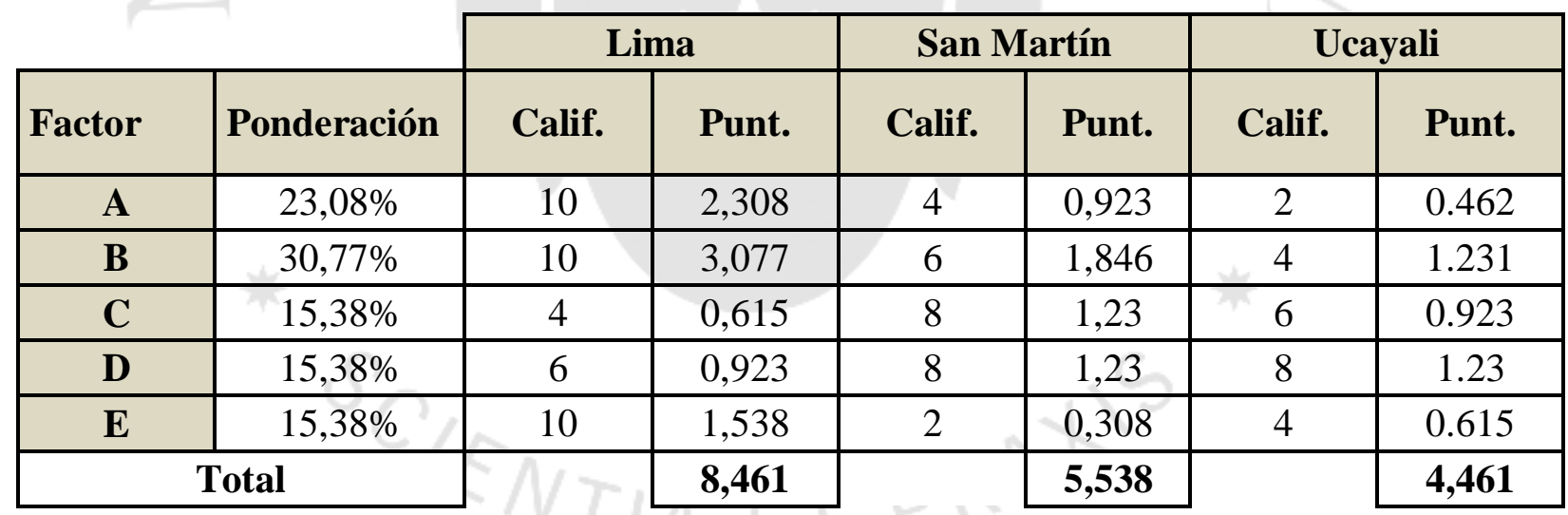

Elaboración propia

El análisis del ranking de factores da como ganador al departamento de Lima con una puntuación de 8.461 .

\subsubsection{Evaluación y selección de micro localización}

Luego que se determinó que la planta esté ubicada en Lima, se procede a realizar un análisis más detallado de las posibles alternativas de localización, para ello será importante considerar 
la disponibilidad de terrenos, los costos del terreno y para ello se eligió los siguientes 3 distritos por su actividad industrial:

- Ate

- Callao

- Lurín

Se hará uso de la misma escala de calificación usada en el punto anterior.

\subsubsection{Disponibilidad de terrenos}

Para el proyecto es importante considerar la disponibilidad de terrenos en alguna zona industrial de Lima y a continuación se realiza el análisis en los distritos mencionados:

\section{A. Ate}

Su ubicación y accesos hacen que Ate sea una zona muy atractiva para la actividad industrial; ya que cuenta con los servicios básicos que hacen que esta zona resulte atractiva para todo tipo de sector. En Ate se encuentran principalmente industrias livianas.

\section{B. Callao}

El Callao es una zona que por su ubicación cercana al aeropuerto y al puerto la mantiene como una zona industrial muy atractiva e importante. Puede albergar industrias tanto livianas como pesadas, de grandes y pequeñas dimensiones.

\section{Lurín}

Lurín ha tenido un importante desarrollo gracias a la autopista Panamericana Sur y además este distrito brinda la posibilidad de encontrar terrenos espaciosos de entre 30.000 a más metros cuadrados para plantas grandes, sin embargo no cuentan con los servicios completos de energía, agua y desagüe.

Se puede concluir que Ate y Callao tienen zonas industriales muy activas y atractivas y cuentan con todas las facilidades de los servicios básicos que permitirían un correcto funcionamiento de la planta; mientras que, Lurín es una zona industrial que aún le falta desarrollarse pues no cuenta con servicios básicos completos.

De acuerdo a las características mencionadas anteriormente por distrito, se concluye: 
Tabla 3.16

Calificación del factor disponibilidad de terreno

\begin{tabular}{|l|c|c|c|}
\hline Distritos & Ate & Callao & Lurín \\
\hline Calificación & 8 & 8 & 4 \\
\hline
\end{tabular}

Elaboración propia

\subsubsection{Costo de terrenos}

El costo de los terrenos por cada distrito también es un factor relevante ya que dentro de la misma capital, el costo de estos puede variar considerablemente y ello puede afectar en mayor o menor grado la inversión inicial del proyecto. A continuación se presenta una tabla con la información con el rango promedio del costo del metro cuadrado en cada uno de los distritos en estudio:

Tabla 3.17

Costos de terreno por distrito

\begin{tabular}{|c|c|}
\hline Zona & $\begin{array}{c}\text { Costos de Terreno } \\
(\mathrm{S} / . / \mathrm{m} 2)\end{array}$ \\
\hline Ate & $1.120-2.240$ \\
\hline Callao & $560-840$ \\
\hline Lurín & $336-504$ \\
\hline
\end{tabular}

Elaboración propia

Como se puede observar Lurín tiene un menor costo promedio de precios, pero ello se puede deber a que no cuenta con los servicios básicos completamente desarrollados.

Considerando el costo de los terrenos, se determina:

Tabla 3.18

Calificación del factor costo de terrenos

\begin{tabular}{|l|c|c|c|}
\hline Distritos & Ate & Callao & Lurín \\
\hline Calificación & 6 & 8 & 10 \\
\hline
\end{tabular}

Elaboración propia 


\subsubsection{Rutas de Acceso}

Este factor es relevante ya que sin este, la empresa no se podría abastecer de sus materias primas ni podría despachar sus productos. El transporte es un problema crítico en nuestro país en los últimos tiempos y ha venido mejorando año a año. La implementación de carreteras y pistas en algunos distritos de Lima ha sido notable, sin embargo; el país todavía no cuenta con el acceso adecuado.

Ate tiene fácil acceso a un gran número de distritos de la ciudad además de tener como carretera cercana e importante a la carretera central y la autopista Ramiro Prialé. Lurín, es un distrito que debido a su cercanía a la Panamericana sur se encuentra aledaño muchos otros distritos del sur de Lima, también esta carretera brinda la facilidad de transporte ya que siempre está libre de caos vehicular. Para el caso del Callao, este distrito cuenta con rutas como lo son las carreteras Néstor Gambetta y Elmer Faucett., además de tener cercanía al puerto como al aeropuerto, los cuales serían convenientes si en un futuro se pensará en exportar los productos al extranjero.

Tomando en cuenta lo mencionado anteriormente, se llega a la conclusión:

Tabla 3.19

Calificación de rutas de acceso

\begin{tabular}{|l|c|c|c|}
\hline Distritos & Ate & Callao & Lurín \\
\hline Calificación & 8 & 10 & 8 \\
\hline
\end{tabular}

Elaboración propia

Una vez hecho el análisis de los factores se procede a hacer la tabla de enfrentamiento siguiendo el mismo criterio establecido para la Macrolocalización:

Dónde:
A: Disponibilidad de terrenos
B: Costo de terrenos
C: Rutas de acceso 
Tabla 3.20

Tabla de enfrentamiento de factores

\begin{tabular}{|c|c|c|c|c|c|}
\hline Factores & A & B & C & Conteo & Ponderación \\
\hline A & - & 1 & 1 & 2 & $50 \%$ \\
\hline B & 1 & - & 0 & 1 & $25 \%$ \\
\hline C & 0 & 1 & - & 1 & $25 \%$ \\
\hline \multicolumn{7}{r|}{} & 4 & $100 \%$ \\
\hline
\end{tabular}

Elaboración propia

Con la ponderación de los factores, se procede a elaborar el ranking de factores para determinar cuál será el lugar idóneo para la instalación de la planta.

Tabla 3.21

Tabla de Ranking de factores

\begin{tabular}{|c|c|c|c|c|c|c|c|}
\hline \multicolumn{2}{|c|}{ be } & \multicolumn{2}{|c|}{ Ate } & \multicolumn{2}{|c|}{ Callao } & \multicolumn{2}{|c|}{ Lurín } \\
\hline Factor & Ponderación & Calif. & Punt. & Calif. & Punt. & Calif. & Punt. \\
\hline $\mathbf{A}$ & $50,00 \%$ & 8 & 4 & 8 & 4 & 4 & 2 \\
\hline B & $25,00 \%$ & 6 & 1,5 & 8 & 2 & 10 & 2.5 \\
\hline $\mathrm{C}$ & $25,00 \%$ & 8 & 2 & 10 & 2,5 & 8 & 2 \\
\hline \multicolumn{2}{|c|}{ Total } & 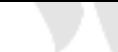 & 7,5 & & 8,5 & & 6,5 \\
\hline
\end{tabular}

Elaboración propia

Luego de haber realizado los cálculos correspondientes, se obtuvo que el lugar idóneo para la instalación de la planta sea el Callao. 


\section{CAPÍTULO IV. TAMAÑO DE PLANTA}

\subsection{Relación tamaño-mercado}

Este factor está limitado por la demanda proyectada que el proyecto abarcará, la cual fue calculada en el capítulo 2. El tamaño del proyecto se sustenta en que el tamaño del mercado actualmente es superior a la porción de la demanda que piensa abastecer, por lo que el proyecto se puede realizar. A continuación de muestra la demanda del proyecto para los próximos 5 años

\section{Tabla 4.1}

Proyección de la demanda de complemento alimenticio hasta 2018

\begin{tabular}{|c|c|}
\hline Año & $\begin{array}{c}\text { Demanda del } \\
\text { proyecto }(\mathbf{k g})\end{array}$ \\
\hline $\mathbf{2 0 1 4}$ & 52.778 \\
\hline $\mathbf{2 0 1 5}$ & 70.919 \\
\hline $\mathbf{2 0 1 6}$ & 82.477 \\
\hline $\mathbf{2 0 1 7}$ & 91.467 \\
\hline $\mathbf{2 0 1 8}$ & 99.161 \\
\hline
\end{tabular}

Elaboración propia

\subsection{Relación tamaño-recursos productivos}

Este factor está determinado por la disponibilidad de los recursos o materias primas que se usarán en la producción del complemento proteico. Para el proyecto se requiere de dos materias primas principales las cuales son sangre de pollo y semilla de cacao.

Según un informe hecho por la empresa Equilibrium Clasificadora de Riesgo S.A a la empresa San Fernando, la producción avícola ${ }^{9}$ a nivel nacional para el año 2013 fue de 1.466,6 miles de toneladas métricas, siendo la producción de pollos más del $80 \%$ del total, es decir aproximadamente 1.173,3 miles toneladas métricas de carne de pollo. Para calcular la

\footnotetext{
${ }^{9}$ Incluye carne de gallina, pato, pollo y pavo.
} 
cantidad de insumo que existe en el mercado tomaremos como referencia la producción nacional anteriormente calculada y a través del factor de conversión $(1 \mathrm{Kg}$ de pollo $=60$ mililitros de sangre de pollo) podremos hallar la cantidad de sangre disponible:

Cantidad de sangre disp.

$$
=1.173 .280 \mathrm{TM} \times 1000 \frac{\mathrm{Kg}}{1 \mathrm{TM}} \times 60 \frac{\text { mililitros }}{\mathrm{Kg}} \times \frac{1 \mathrm{~L}}{1000 \text { mililitros }}
$$

\section{Cantidad de sangre disponible $=70.396 .800$ Litros}

Para la sangre de pollo, se puede contar con aproximadamente $70.397 \mathrm{~m}^{3}$ a nivel nacional para la adquisición de este insumo y así poder elaborar el producto. Debido a la gran cantidad de litros de sangre, se podría considerar que este primer insumo no sería una limitante para el tamaño de planta. Asimismo, si consideramos sólo la compra en Lima, esa cantidad vendría a representar el $51 \%{ }^{10}$ de la producción nacional, es decir $35.902 \mathrm{~m}^{3}$ de sangre, lo que igualmente representaría un número significativo y no limitante.

Para el caso del cacao, la producción nacional del 2013, como se mencionó en el punto 2.6.2, fue de 62.973 toneladas, debido a la cantidad que se cultiva tampoco se consideraría a este insumo como una limitante para definir el tamaño de planta.

\subsection{Relación tamaño-tecnología}

La tecnología viene a ser el conjunto de procesos, equipos y maquinarias que forman parte del proceso productivo y que en muchas ocasiones determina o limita la capacidad de producción en una planta. Es por ello que resulta muy importante saber elegir la tecnología a emplear ya que ésta debe poder adaptarse a los cambios en los niveles de producción.

Para el análisis del tamaño de planta por tecnología, se analizará el proceso que genera una demora en la producción o lo que se conoce como cuello de botella. Para que se realice un mejor análisis de las capacidades de las máquinas se uniformizará las unidades a kilogramos por hora $(\mathrm{Kg} / \mathrm{h})$, por ello que se empleará la densidad de la sangre de pollo $(1,0081 \mathrm{~g} / \mathrm{ml})$ para realizar algunas conversiones.

\footnotetext{
${ }^{10}$ Equilibrium. "La mayor parte de la producción tuvo lugar en la región costa del país, repitiendo la concentración mostrada en años anteriores, principalmente en los departamentos de Lima (51,9\%), La Libertad $(19.8 \%)$ y Arequipa (10.2\%)."
} 
Dado que se requiere una menor cantidad del insumo sangre de pollo, las máquinas por donde pase este insumo tendrán una menor capacidad para no tener mucha capacidad ociosa.

A continuación, se presenta el Tabla con las capacidades de cada máquina:

\section{Tabla 4.2}

\section{Capacidad de las máquinas en kilogramos por hora}

\begin{tabular}{|c|c|}
\hline Máquina & $\begin{array}{c}\text { Capacidad } \\
(\mathrm{Kg} / \mathrm{h})\end{array}$ \\
\hline Lavadora & 40 \\
\hline Molino & 40 \\
\hline Mezcladora & 40 \\
\hline Tamizadora & 60 \\
\hline Horno & 10 \\
\hline Secadora & 5 \\
\hline
\end{tabular}

Elaboración: propia

A través de la tabla 4.2 se puede determinar que el cuello de botella es generado por la secadora, ya que es la que tiene la menor capacidad de procesamiento por hora. Sin embargo, a pesar que la secadora tiene menor capacidad de procesamiento, la mezcladora es la máquina que trabaja más y es la que determina el tamaño tecnológico con 410.800 unidades.

En la planta se trabajará un turno de 8 horas durante 7 días, con esta información y la capacidad de procesamiento del cuello de botella, se procede a calcular la capacidad máxima de procesamiento de la planta desde el punto de vista tecnológico de la siguiente manera:

$$
\begin{gathered}
\text { producción }=40 \frac{\mathrm{Kg}}{\mathrm{h}} \times \frac{1 \text { und }}{0,250 \mathrm{Kg}} \times \frac{8 \mathrm{~h}}{\text { día }} \times \frac{7 \text { día }}{\text { semana }} \times \frac{4,33 \text { semana }}{\text { mes }} \times \frac{12 \text { meses }}{a \tilde{n} o} \times 0.9412 \times 0.9375 \\
\text { producción }=410.800 \frac{\text { unidades }}{a \tilde{n} o}
\end{gathered}
$$

Con esta capacidad se logra cubrir la demanda estimada del proyecto los 5 primeros años de operación, por lo que no se consideraría a la tecnología como un factor limitante en el proyecto. 


\subsection{Relación tamaño-inversión}

Por lo descrito en el capítulo VII, el monto de la inversión para el proyecto es de S/. 528.091 soles, lo que no representa una limitante para el proyecto ya que se recurrirá a un financiamiento para solventar parte del monto (60\%).

\subsection{Relación tamaño-punto de equilibrio}

El punto de equilibrio permite calcular la cantidad mínima de producción requerida en la que no se generan ni ganancias ni pérdidas, a partir de este punto se empiezan a percibir utilidades. Para lo que nos valdremos de la siguiente fórmula:

$$
Q_{\min }=C F /(P V u-C V u)
$$

Dónde:

Q: Punto de Equilibrio

CF: Costos Fijos

PVu: Precio de venta unitario

$\mathrm{CVu}$ : Costo de venta unitario

\section{Costos Fijos:}

Estos costos son los que se establecen independientemente del volumen de producción, estos son los gastos de servicios (Luz, Agua, Teléfono), depreciación de maquinaria (5 años) y sueldos. 


\section{Tabla 4.3}

Costos fijos de depreciación de la maquinaria

\begin{tabular}{|l|c|c|c|c|}
\hline \multicolumn{1}{|c|}{ Equipos } & $\begin{array}{c}\text { Precio unitario } \\
(\mathbf{S} / .)\end{array}$ & Cantidad & Total(S/.) & $\begin{array}{c}\text { Depreciación } \\
\text { Anual(S/.) }\end{array}$ \\
\hline Lavadora & 4.170 & 1 & 4.170 & 834 \\
\hline Molino & 3.900 & 1 & 3.900 & 780 \\
\hline Mezcladora & 8.340 & 1 & 8.340 & 1.668 \\
\hline Tamizadora & 5.560 & 1 & 5.560 & 1.112 \\
\hline Secadora & 2.688 & 1 & 2.688 & 538 \\
\hline Horno & 5.560 & 1 & 5.560 & 1.112 \\
\hline Balanza & 840 & 1 & 840 & 168 \\
\hline Esterilizador & 1.350 & 1 & 1.350 & 270 \\
\hline Etiquetador & 750 & 1 & 750 & 150 \\
\hline \multicolumn{2}{|c|}{ Total } & & $\mathbf{3 4 . 3 0 8}$ & $\mathbf{6 . 6 3 2}$ \\
\hline
\end{tabular}

Elaboración propia

Tabla 4.4

Costos fijos de sueldos y salarios

\begin{tabular}{|l|c|c|c|c|}
\hline \multicolumn{1}{|c|}{ Personal } & Cantidad & $\begin{array}{c}\text { Sueldo } \\
\text { Unitario(S/.) }\end{array}$ & $\begin{array}{c}\text { Sueldo/Mes } \\
(\mathbf{S} / .)\end{array}$ & $\begin{array}{c}\text { Sueldo } \\
\text { Anual (S/.) }\end{array}$ \\
\hline Operarios & 7 & 900 & 6.300 & 94.500 \\
\hline Secretaria & 1 & 1.200 & 1.200 & 18.000 \\
\hline Jefe de Planta & 1 & 5.000 & 5.000 & 75.000 \\
\hline Gerente General & 1 & 8.000 & 8.000 & 120.000 \\
\hline Jefe Comercial & 1 & 5.000 & 5.000 & 75.000 \\
\hline Inspector Calidad & 1 & 3.000 & 3.000 & 45.000 \\
\hline \multicolumn{4}{|c|}{ Total } \\
\hline
\end{tabular}

Elaboración propia

Dentro de otros costos fijos encontramos:

- Pago por servicios públicos

- Pago por servicios privados. 


\section{Tabla 4.5}

\section{Costos fijos anuales de planta}

\begin{tabular}{|l|c|}
\hline \multicolumn{1}{|c|}{ Costos Fijos } & (S/.) \\
\hline Sueldos & 427.500 \\
\hline Depreciación & 6.632 \\
\hline Electricidad & 16.958 \\
\hline Agua & 1.085 \\
\hline Teléfono & 3.120 \\
\hline Internet & 2.300 \\
\hline TOTAL & $\mathbf{4 5 7 . 8 2 5}$ \\
\hline
\end{tabular}

Elaboración propia

\section{Costos Variables:}

Estos costos se conforman de la materia prima e insumos usados en la producción, ya que el sueldo de trabajadores y personal está incluido en los costos fijos. Para determinar dichos costos se ha calculado cuánto se necesita de sangre de pollo, cacao, magnesio, fosforó, frascos y etiquetado

Tabla 4.6

\section{Costos variable unitario de Complemento vitamínico}

\begin{tabular}{|l|c|}
\hline Costos variables & $\begin{array}{c}\text { S/./Complemento } \\
\text { Vitamínico }\end{array}$ \\
\hline Sangre de pollo & 0,05 \\
\hline Cacao & 1.80 \\
\hline Magnesio & 0,08 \\
\hline Fosforo & 0,11 \\
\hline Frasco & 0,57 \\
\hline Etiquetado & 0,27 \\
\hline TOTAL & $\mathbf{2 , 8 7}$ \\
\hline
\end{tabular}

Elaboración propia

El precio unitario incluido IGV: 
Tabla 4.7

Precio variable unitario de Complemento vitamínico

\begin{tabular}{|c|c|}
\hline $\begin{array}{c}\text { Precio de C. } \\
\text { Vitamínico }\end{array}$ & S/. \\
\hline Valor de venta & 8,0 \\
\hline
\end{tabular}

Elaboración propia

Aplicando la fórmula se obtuvo como resultado 89.200 unidades, por lo que el punto de equilibrio estaría por debajo de la demanda final de 396.643 unidades que debe cubrirse, concluyéndose que el proyecto si es factible.

\subsection{Selección del tamaño de planta}

A continuación, se presenta la tabla que resume la capacidad de planta por cada una de las opciones analizadas:

\section{Tabla 4.8}

\section{Tamaño de planta}

\begin{tabular}{|c|c|}
\hline $\begin{array}{c}\text { Relación Tamaño } \\
\text { de planta }\end{array}$ & $\begin{array}{c}\text { Capacidad } \\
\text { (Unidades) }\end{array}$ \\
\hline Mercado & 396.643 \\
\hline Recursos & No limitante \\
\hline Tecnología & 410.800 \\
\hline Inversión & No limitante \\
\hline Punto de equilibrio & 89.200 \\
\hline
\end{tabular}

Elaboración propia

Con la información de la tabla 4.8 , el proyecto decide como tamaño de planta a la capacidad establecida por el mercado al final del proyecto ya que ésta es menor a la capacidad que ofrece la tecnología y el proyecto considera innecesario producir más de lo que la demanda exige, por ello la capacidad de la planta procesadora de un complemento alimenticio a base de sangre de pollo y cacao será de 99.161 Kilogramos al año, es decir, 396.643 unidades. 


\section{CAPÍTULO V. INGENIERÍA DEL PROYECTO}

\subsection{Definición técnica del producto}

\subsubsection{Especificaciones técnicas del producto}

\begin{tabular}{|l|l|}
\hline Producto: & Complemento alimenticio \\
\hline Envase: & Frasco de vidrio (Figura 5.1) \\
\hline Etiqueta: & Etiqueta de plástico adherida al frasco \\
\hline Contenido neto: & 250 gramos \\
\hline Unidad de comercialización: & Planchas de 12 frascos \\
\hline Modo de consumo: & Mezclar con agua o mazamorra \\
\hline
\end{tabular}

\subsubsection{Composición del producto}

La composición del producto, la misma que deberá figurar en la etiqueta del envase será la siguiente para un valor referencial de 100 gramos:

\section{Tabla 5.1}

Frasco del complemento vitamínico

\begin{tabular}{|l|l|l|}
\hline \multirow{4}{*}{$\begin{array}{l}\text { Información } \\
\text { nutricional }\end{array}$} & Porción & 100 gramos \\
\cline { 2 - 3 } & Hierro & 30 gramos \\
\cline { 2 - 3 } & Fósforo & 3 gramos \\
\cline { 2 - 3 } Indicaciones & Magnesio & 3 gramos \\
\hline & Guardar en un lugar fresco y fuera del alcance de la luz del sol. \\
\cline { 2 - 2 } & Consumir antes de la fecha de vencimiento. \\
\cline { 2 - 2 } & Mantenerse fuera del alcance de los niños. \\
\hline
\end{tabular}

Elaboración propia

\subsubsection{Diseño gráfico del producto}

El envase que contendrá el producto será un frasco de vidrio oscuro, con tapa rosca para que se pueda abrir y cerrar fácilmente y tendrá una etiqueta adherida en la cual se señalará la 
información del punto 5.1.2, así mismo el número de Registro Sanitario y otra información exigida por la Autoridad Sanitaria para el caso de Alimentos Envasados.

A continuación se presenta un frasco del complemento alimenticio en polvo a base de sangre de pollo y cacao:

\section{Figura 5.1}

\section{Frasco del complemento vitamínico}
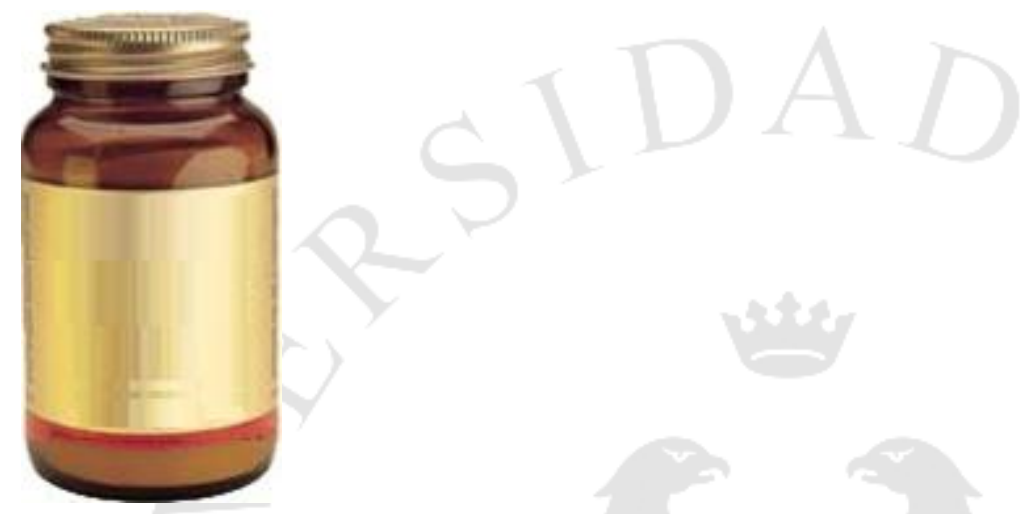

Elaboración propia

Asimismo, una estrategia de venta será que el frasco lleve el slogan de "Marca Perú" para así poder promover su consumo logrando que el peruano se sienta identificado con un producto elaborado en el país.

\subsubsection{Regulaciones técnicas del producto}

Las regulaciones técnicas que se tienen para los alimentos son muy estrictas ya que al ser un alimento para consumo humano directo, deben guardar todas las medidas de inocuidad para que no cause algún malestar, por ello se deben hacer bajo las medidas establecidas por la Organización de las Naciones Unidas para la alimentación y la agricultura (FAO por sus siglas en inglés), la Organización Mundial de la Salud (OMS), las normas del Codex Alimentarius y la Legislación Nacional Vigente establecida por el Ministerio de Salud

Por ello, la cantidad minina que ofrezca el complemento alimenticio deberá ser equivalente al 15\% de la ingesta diaria recomendada, siendo el consumo de hierro diario recomendado entre 8 a $11 \mathrm{mg} /$ día. Así mismo el envase deberá proteger la higiene y las características del producto. 
Asimismo, se debe indicar en la etiqueta el valor nutricional en forma numérica, la modalidad de uso y la dosis diaria recomendada.

\subsection{Tecnologías existentes y procesos de producción}

\subsubsection{Naturaleza de la tecnología requerida}

\subsubsection{Descripción de la tecnología existente}

Los complementos vitamínicos más comercializados actualmente en el mercado son los complejos de vitaminas B, C, D K, Zn, entre otros. En este estudio se buscará comercializar un complejo vitamínico en base a la harina de sangre de pollo mezclada con cacao para el consumo humano directo. A continuación se describirán las diversas tecnologías utilizadas para elaborar complejos vitamínicos diversos:

\section{a) Elaboración artesanal:}

Tipo de elaboración utilizada cuando la demanda de productos es baja. El proceso inicia cuando se recibe la materia prima, la cual pasa por procesos como horneado, secado, tamizado, en los que se tiene que separar la vitamina sin perder su continuidad y eliminando elementos patógenos presentes.

\section{b) Elaboración semi-industrial:}

Tipo de elaboración utilizada cuando la demanda de productos es medianamente elevada. Este proceso es similar al anterior a diferencia que se usa una mayor cantidad de maquinaria y más líneas de trabajo.

\section{c) Elaboración industrial:}

Tipo de elaboración utilizada cuando la demanda de productos es elevada, El proceso a difiere de los anteriores ya que optimiza la extracción de vitaminas de la materia prima mediante una síntesis química inorgánica, que consiste en generar compuestos químicos a partir de otros, para posteriormente mezclarse con otros componentes.

\section{d) Elaboración automática:}

Tipo de elaboración utilizada cuando la demanda de productos es muy elevada. Similar a la anterior mencionada solo que empleando una menor cantidad de operarios y automatizando la mayor cantidad de procesos. 
Para el proyecto se decidió trabajar con una elaboración de tipo artesanal porque la demanda a cubrir no es muy alta y el uso de maquinaria con grandes capacidades generaría demasiado tiempo ocioso.

\subsubsection{Selección de la tecnología}

Para el proyecto se seleccionó la tecnología del tipo de elaboración artesanal, por el tamaño de la demanda, por lo consecuente no se requería de una gran cantidad de maquinaria ni mano de obra, ni automatización.

\subsubsection{Proceso de producción}

\subsubsection{Descripción del proceso}

El proceso de producción comienza con la adquisición de los insumos principales. Una vez que se obtienen la sangre y el cacao pasan por sus respectivos procesos que se detallarán a continuación. Cabe señalar que a lo largo de toda la cadena alimentaria, que incluye los insumos, se aplicará las Buenas Prácticas de Manipulación de Alimentos y otras exigencias establecidas por la autoridad sanitaria, con la finalidad de asegurar la inocuidad de este producto

La sangre de pollo al ser un insumo orgánico animal, es altamente perecible, por ello debe tenerse especial cuidado en su manipuleo, por lo que se trabajara conservando la cadena de frio (refrigeración) hasta llegar a la etapa de procesamiento. La sangre se recogerá de nuestro principal abastecedor (San Fernando) en contenedores refrigerantes para que el insumo no sufra alteraciones durante su traslado a temperatura promedio de $3^{\circ} \mathrm{C}$. Ésta pasa a la zona de tratamiento térmico donde se procede a cocinarlo de forma lenta y agitando constantemente por un tiempo no mayor a 150 minutos a una temperatura mínima de $82^{\circ} \mathrm{C} \mathrm{y}$ no mayor a $95{ }^{\circ} \mathrm{C}$ para evitar destruir la lisina que es un aminoácido muy importante para la construcción de todas las proteínas del organismo, durante ese tiempo se tiene que estar controlando que el proceso no se encuentre por debajo de la temperatura indicada. La cocción sirve para destruir a los microorganismos patógenos que se encuentran presente en el producto.

Una vez que la sangre sale del horno industrial pasa por un proceso de secado para eliminar la humedad que se genera al cocinarse. En el proceso de secado la sangre ya cocida 
reduce su tamaño porque pierde humedad y se pierde aproximadamente $5 \%$ de lo que entra al inicio. Una vez que la sangre esté cocida y seca, pasa al molino donde se reducirá el tamaño a finas partículas ya que a esta altura del proceso la sangre se encuentra en estado sólido. Una vez que la sangre esta molida pasa a la tamizadora donde por medio de una malla (mesh) y las vibraciones de la máquina se obtendrá solo las partículas del tamaño deseado para el producto final, después de ella se hace una inspección para ver que el tamaño sea el deseado.

Por su parte, el cacao una vez que llega a la planta se pesa en la balanza, es inspeccionado para ver si que las semillas están en buen estado o para que no se encuentren golpeadas ya que ello podría generar cierto sabor amargo al producto final.

Luego de la inspección pasan a ser lavadas y luego a ser secadas. Las semillas seleccionadas pasan al proceso de molienda y seguidamente al tamizado para obtener las partículas de cacao necesarias para el producto final.

Una vez que se tiene la harina de pollo y de cacao tamizados pasan a una mezcladora donde adicionalmente se agregan aditivos como el fósforo y el magnesio que brindarán ciertas propiedades al producto.

Finalizado el proceso de mezclado, un operario se encargará del envasado del producto y del etiquetado para su disposición final.

\subsubsection{Diagrama del proceso}

A continuación se presenta el Diagrama de operaciones del proceso de elaboración de un complemento alimenticio a base de harina sangre de pollo y cacao. 


\section{Figura 5.2}

\section{Diagrama de operaciones del proceso}

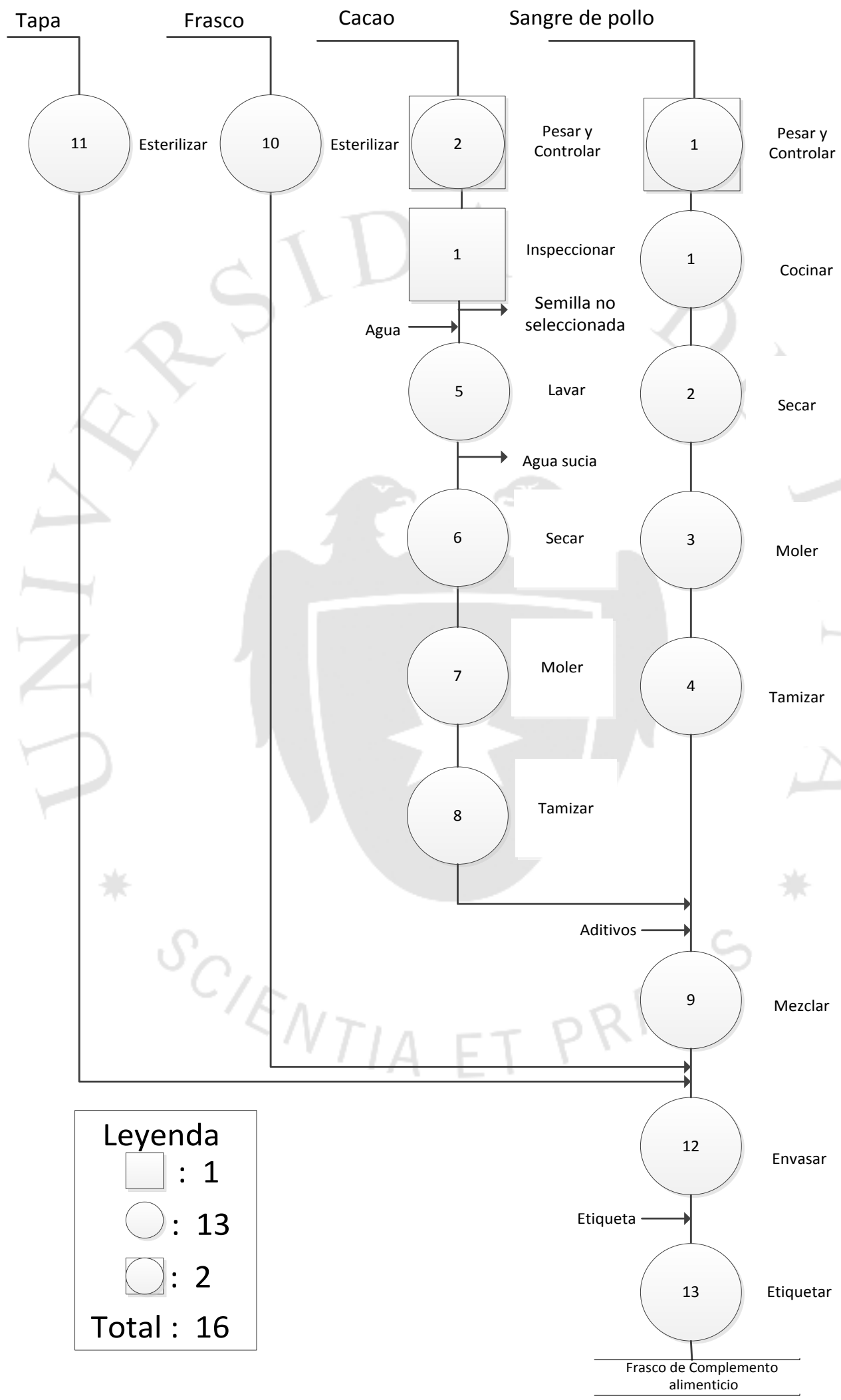

Elaboración propia 


\subsubsection{Balance de materia: Diagrama de bloques}

A continuación se detalla el proceso de producción a través de un diagrama de bloques en que cual es indica las cantidades que ingresa a cada proceso por unidad de producto, dando como resultado final 250 gramos de harina que es el peso de un frasco.

\section{Figura 5.3}

\section{Diagrama de bloques del proceso}

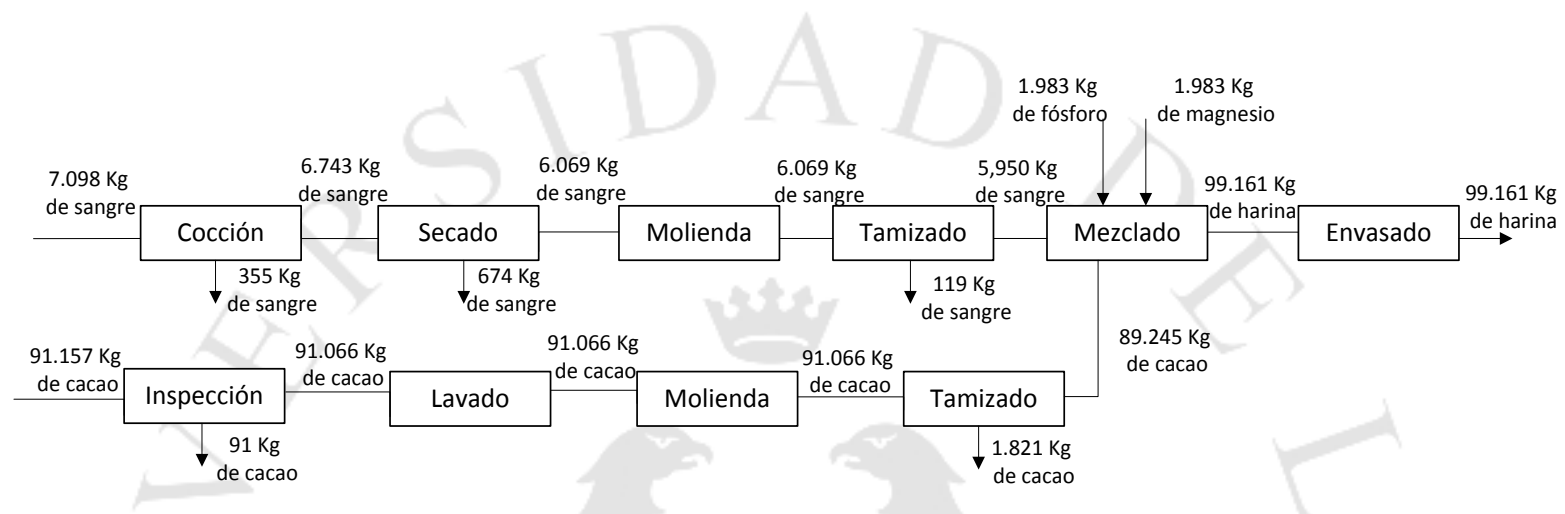

Elaboración propia

\subsection{Características de las instalaciones y equipos}

\subsubsection{Selección de la maquinaria y equipos}

Para el proceso de elaboración de un complemento alimenticio a base de sangre de pollo y cacao se decidió por elegir un proceso sencillo para la producción, es por eso que las máquinas que se eligieron son:

- Lavadora cilíndrica: Se empleará para eliminar el polvo, suciedad e incluso pequeños animales que se puedan encontrar cuando se compre el cacao.

- Horno industrial con chaqueta: Se empleará para cocinar la sangre y así eliminar los microorganismos patógenos que puedan encontrarse para evitar la contaminación del producto final.

- Secadora de platos: Se empleará para eliminar la humedad que se genere en el proceso de cocción de la sangre.

- Molino coloidal con esmeriles: Se usará para reducir el tamaño de las semillas de cacao y la sangre que después del proceso de secado queda en estado sólido. 
- Tamizadora vibratoria: Se usará como un filtro por el cual a través de las vibraciones de la máquina funcionara como un colador por el que solo pasarán las partículas de polvo requeridas para el producto final.

- Mezcladora de polvos en V: Se usará para combinar la harina de cacao y la de sangre de pollo con los aditivos adicionales.

\subsubsection{Especificaciones de la maquinaria}

Las máquinas a emplear en el proceso productivo, como ya se mencionó anteriormente son:

- Lavadora

- Horno industrial

- Mezclador

- Tamizador

- Molino

- Secadora

Adicionalmente, se emplearán instrumentos como balanza, un esterilizador de frasco que es fundamental para mantener la inocuidad de los recipientes y un etiquetador.

A continuación se describirá las especificaciones técnicas de cada una de los equipos a emplear, detallando en ella la potencia que consuma el equipo, la energía que consuma por tiempo de operación para determinar así los costos a los que se incurren, las dimensiones (largo, ancho y altura) para determinar el requerimiento de espacio dentro de la planta.

Tabla 5.2

Especificaciones técnicas por cada máquina

\begin{tabular}{|c|l|c|c|}
\hline Máquina & \multicolumn{2}{|c|}{ Especificaciones técnicas } & Imágenes de la maquinaria \\
\hline \multirow{5}{*}{ Lavadora } & Potencia & $2 \mathrm{HP}$ \\
\cline { 2 - 4 } & Energía consumida & $2 \mathrm{KW} / \mathrm{h}$ \\
\cline { 2 - 3 } & Largo & $1,300 \mathrm{~m}$ \\
\cline { 2 - 3 } & Ancho & $1,000 \mathrm{~m}$ \\
\cline { 2 - 3 } & Altura & $1,250 \mathrm{~m}$ & \\
\end{tabular}


Tabla 5.3

Continuación especificaciones técnicas por cada máquina

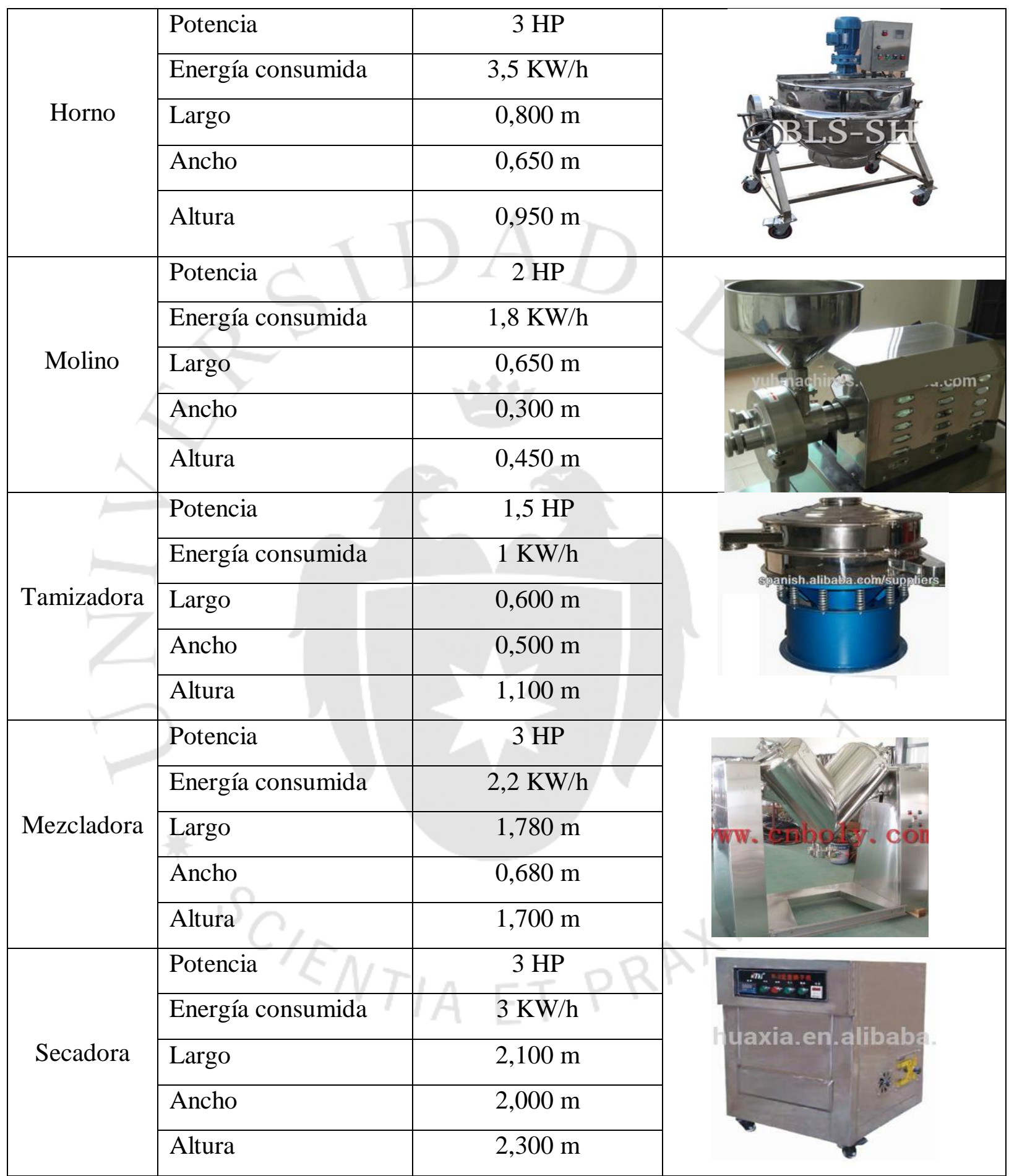

Fuente:Alibaba, 2014

Elaboración propia

\subsection{Capacidad instalada}




\subsubsection{Cálculo de la capacidad instalada}

El cálculo de la capacidad instalada es el volumen de producción de la planta tomando en consideración la capacidad de las máquinas que se tienen.

A continuación se hará el cálculo de la capacidad instalada, por tal motivo se considerará el factor de conversión como la cantidad de kilogramos por unidad que ingresa a cada máquina:

\section{Tabla 5.4}

Capacidad instalada de la planta

\begin{tabular}{|l|c|c|c|c|c|c|c|c|c|}
\hline Máquina & $\begin{array}{c}* \text { Capacidad } \\
\text { Real (kg) }\end{array}$ & $\begin{array}{c}\mathrm{N}^{\circ} \\
\text { Máq }\end{array}$ & Horas & Días & Semanas & Meses & $\begin{array}{c}\text { Conversión } \\
\text { (kg /und) }\end{array}$ & $\begin{array}{c}\text { Factor de } \\
\text { ajuste (**) }\end{array}$ & $\begin{array}{c}\text { Capacidad } \\
\text { Instalada } \\
\text { (unidades) }\end{array}$ \\
\hline Lavadora & 35,3 & 1 & 8 & 7 & 4,33 & 12 & 0,225 & 0,98 & 447.315 \\
\hline Secadora & 4,4 & 1 & 8 & 7 & 4,33 & 12 & 0,015 & 0,88 & 753.133 \\
\hline Horno & 8,8 & 1 & 8 & 7 & 4,33 & 12 & 0,015 & 0,84 & 1.437 .800 \\
\hline Molino & 35,3 & 1 & 8 & 7 & 4,33 & 12 & 0,240 & 0,98 & 419.358 \\
\hline Tamizadora & 52,9 & 1 & 8 & 7 & 4,33 & 12 & 0,240 & 0,98 & 629.037 \\
\hline Mezcladora & 35,3 & 1 & 8 & 7 & 4,33 & 12 & 0,250 & 1,00 & 410.800 \\
\hline
\end{tabular}

Elaboración propia

(*) La capacidad real se obtiene luego de aplicarle a la capacidad original de la máquina los factores de utilización y eficiencia.

(**) El factor de ajuste se calcula en base a lo que se requiere para el producto final entre lo que ingresa al proceso.

La capacidad instalada de la planta sería la capacidad del proceso que menos unidades puede producir, que en este caso es la mezcladora con una producción anual de 410.800 unidades.

\subsubsection{Cálculo detallado del número de máquinas requerido}

Para cumplir con el tamaño de planta planteado por el proyecto, se necesita calcular la cantidad de máquinas a usar en cada operación, por lo que se realizará el análisis para saber cuántas máquinas de cada tipo se necesitaran. 
Para calcular el número de máquinas se empleará la siguiente fórmula:

$$
N \text { o Máquinas }=\frac{(\text { Tiempo de la operación }) x(\text { demanda anual })}{N^{0} \text { Total de horas disponibles al año }}
$$

Para el tiempo de trabajo en la planta, se definió que sería un tiempo efectivo 8 horas de trabajo, otorgando a los operarios media hora para que puedan almorzar o realizar otro tipo de actividades, como por ejemplo, hacer uso de los servicios higiénicos, completando una jornada total de 8.5 horas reales.

Para el cálculo de número de máquinas se debe hallar el factor de utilización, que es la desviación que existe entre las horas productivas y las horas reales de la planta, se simboliza con una $\mathrm{U}$, y se calcula de la siguiente manera:

U=Número de Horas Productivas / Número de Horas Reales $\mathrm{U}=8 / 8,5=0,9412$

Asimismo, se calculara el valor del factor de eficiencia que representa la desviación que existe entre las horas estándar y las horas productivas para realizar una misma cantidad de producto, este valor se representa con la letra E, por lo tanto:

E = Número de Horas Estándar / Número de Horas Productivas

$\mathrm{E}=7,5 / 8=0,9375$

Con los valores hallados, se procede a calcular la cantidad de máquinas a emplear para la elaboración de un complemento vitamínico a base de sangre de pollo y cacao:

\section{- Lavadora}

$$
\text { № Máq }=\frac{\left(\frac{1}{40} \frac{H-M}{K g}\right) \times\left(91.066 \frac{K g}{a \tilde{n} o}\right)}{8 \frac{H}{\text { día }} \times 7 \frac{\text { día }}{\text { semana }} \times 4.33 \frac{\text { semana }}{\text { mes }} \times 12 \frac{\text { mes }}{\text { año }} \times 0,9412 \times 0,9375}=0.89
$$

Se requerirá un total de 1 lavadora. 
- Secadora

$$
N^{\circ} \text { Máq }=\frac{\left(\frac{1}{5} \frac{H-M}{K g}\right) \times\left(6.743 \frac{K g}{a \tilde{n} o}\right)}{8 \frac{H}{\text { turno }} \times 7 \frac{\text { día }}{\text { semana }} \times 4.33 \frac{\text { semana }}{\text { mes }} \times 12 \frac{\text { mes }}{\text { año }} \times 0,9412 \times 0,9375}=0,53
$$

Se requerirá un total de 1 secadora.

- Horno

$$
N^{\text {o }} \text { Máq }=\frac{\left(\frac{1}{10} \frac{H-M}{K g}\right) \times\left(7.098 \frac{K g}{a \tilde{n} o}\right)}{8 \frac{H}{\text { turno }} \times 7 \frac{\text { día }}{\text { semana }} \times 4.33 \frac{\text { semana }}{\text { mes }} \times 12 \frac{\text { mes }}{\text { año }} \times 0,9412 \times 0,9375}=0.28
$$

Se requerirá un total de 1 horno.

- Molino

$$
\text { No Máq }=\frac{\left(\frac{1}{40} \frac{H-M}{K g}\right) \times\left(97.135 \frac{K g}{a \tilde{n} o}\right)}{8 \frac{H}{\text { turno }} \times 7 \frac{\text { día }}{\text { semana }} \times 4.33 \frac{\text { semana }}{\text { mes }} \times 12 \frac{\text { mes }}{\text { año }} \times 0,9412 \times 0,9375}=0.95
$$

Se requerirá un total de 1 molino.

\section{- Tamizadora}

$$
\text { No Máq }=\frac{\left(\frac{1}{60} \frac{H-M}{K g}\right) \times\left(97.135 \frac{K g}{a \tilde{n} o}\right)}{8 \frac{H}{\text { turno }} \times 7 \frac{\text { día }}{\text { semana }} \times 4.33 \frac{\text { semana }}{\text { mes }} \times 12 \frac{\text { mes }}{\text { año }} \times 0,9412 \times 0,9375}=0,63
$$

Se requerirá un total de 1 tamizadora.

\section{- Mezcladora}

$$
N^{\text {o }} \text { Máq }=\frac{\left(\frac{1}{40} \frac{H-M}{K g}\right) \times\left(99.161 \frac{K g}{a \tilde{n} o}\right)}{8 \frac{H}{\text { turno }} \times 7 \frac{\text { día }}{\text { semana }} \times 4.33 \frac{\text { semana }}{\text { mes }} \times 12 \frac{\text { mes }}{\text { año }} \times 0,9412 \times 0,9375}=0,97
$$

Se requerirá un total de 1 mezcladora. 
Después de hacer el cálculo de cada una de las máquinas, se llega a la conclusión que se requerirá un total de 6 máquinas, una de cada tipo.

\subsection{Aseguramiento de la calidad e inocuidad del producto}

\subsubsection{Calidad de la materia prima, de los insumos, del proceso y del producto}

Con la finalidad de obtener un producto final que satisfaga las necesidades de los clientes, tanto en aspectos de calidad e inocuidad, se debe controlar todas las etapas que constituyen o forman parte de la cadena alimentaria, desde la compra de insumos hasta la entrega del producto al cliente. Aplicando las Buenas Prácticas de Manipulación de Alimentos, y la legislación exigida por la autoridad sanitaria, para el caso de alimentos envasados, como es el caso del HACCP, con la finalidad de contar con un sistema de Gestión de la Inocuidad. Así mismo cumplir con las especificaciones establecidas, aplicando un Sistema de Gestión de Calidad.

\section{Figura 5.4}

Circulo de Deming. Sistema de mejora continua

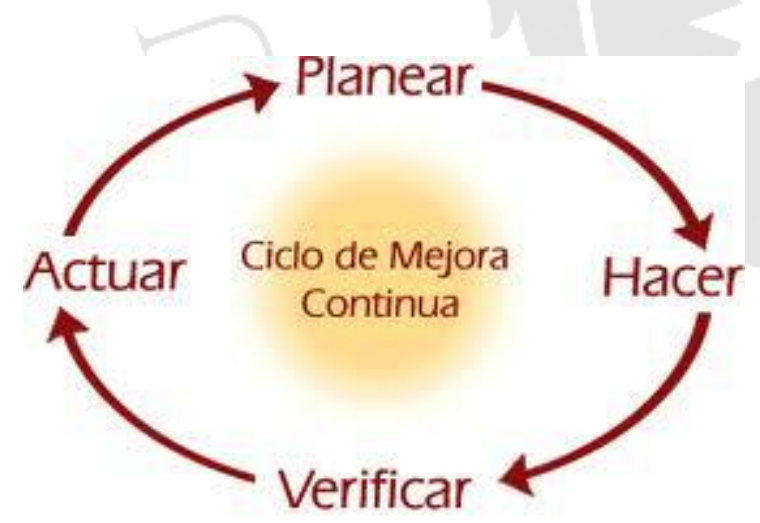

Fuente: Nafarroa Gestión, 2014

El círculo de Deming es una herramienta muy útil en los procesos de gestión de calidad ya que permite integrar todo el proceso de forma continua, desde el planeamiento en la obtención de materias primas e insumos hasta la verificación y retroalimentación de todo el proceso. 


\section{Materia prima}

La sangre de pollo, es un insumo, que por sus composición es altamente perecible, quiere decir que puede ser atacado por microorganismos patógenos y sufrir otras reacciones bioquímicas indeseables que pueden poner en riesgo la calidad e inocuidad del producto final. Por lo que debe ser manipulado de manera adecuada.

De igual forma se debe cuidar que la semilla de cacao que se adquiera encuentre en buen estado de conservación, libre de insectos o daños físicos y químicos.

\section{Proceso}

El proceso crítico de la elaboración del complemento alimenticio es la cocción, durante este punto del proceso se tiene que cuidar que la sangre no esté por debajo de los $82^{\circ} \mathrm{C}$ ya que la materia puede no eliminar completamente los microorganismos que este posee, asimismo se debe cuidar que la temperatura no esté por encima de los $100{ }^{\circ} \mathrm{C}$ porque de lo contrario podría perder sus propiedades nutricionales. Este proceso debe estar en un cuidado permanente durante los 10 minutos que dura, ya que es de vital importancia para la continuidad y la calidad del producto final.

\section{Producto}

La calidad del producto final estará en función de las especificaciones del producto. Este debe cumplir con el peso establecido; color y sabor agradables y textura fina del polvo.

\section{Tabla 5.5}

\section{Especificaciones técnicas del producto}

\begin{tabular}{|c|c|c|c|c|c|}
\hline \multicolumn{6}{|c|}{$\begin{array}{l}\text { Nombre del producto: Complemento vitamínico } \\
\text { Función: Complementar la alimentación } \\
\text { Tamaño y apariencia: } 250 \text { gramos } \\
\text { Insumos requeridos: Sangre de pollo y cacao } \\
\text { Costo del producto: } 8,00 \text { soles }\end{array}$} \\
\hline Características & Tipo & $\mathrm{VN}+/-\mathrm{g}$. & $\begin{array}{c}\text { Medio de } \\
\text { control }\end{array}$ & Tipo de inspección & NCA \\
\hline Color & Variable/crítico & - & Sensorial & Muestreo & $0 \%$ \\
\hline Olor & Variable/crítico & - & Sensorial & Muestreo & $0 \%$ \\
\hline Sabor & Variable/crítico & - & Sensorial & Muestreo & $0 \%$ \\
\hline Humedad & Variable crítico & $7 \%+/-1 \&$ & Higrómetro & Muestreo & $0 \%$ \\
\hline Índ. de Fosforo & Variable/crítico & $7,50+/-10$ & Balanza & Muestreo & $0 \%$ \\
\hline Ind.de Magnesio & Variable/crítico & $7,50+/-10$ & Balanza & Muestreo & $0 \%$ \\
\hline Volumen neto & Variable/crítico & $250+/-5$ & Balanza & Muestreo & $0 \%$ \\
\hline
\end{tabular}


Elaboración propia

\subsubsection{Estrategias de mejora}

Para el proceso de producción, se aplicará el sistema de análisis de puntos críticos de control HACCP, el cual nos permitirá recopilar información sobre los peligros y las condiciones que permiten determinar qué puntos son importantes para mantener la inocuidad en los alimentos y así garantizar su calidad.

A continuación se presenta la información de los procesos y los peligros a los que se pueden estar expuestos y además se determinan aquellos considerados como puntos críticos del proceso:

\section{Figura 5.5}

\section{Peligros y determinación de puntos críticos de control del proceso}

\begin{tabular}{|c|c|c|c|c|c|}
\hline ETAPA DE PROCESO & PELIGROS & $\begin{array}{l}\text { ¿El PEIGRO ES } \\
\text { SIGNIFICATIVO? }\end{array}$ & JUSTIFICACIÓN & $\begin{array}{l}\text { ¿QUÉ MEDIDAS PREVENTIV AS } \\
\text { PUEDER SER APLICADAS? }\end{array}$ & $\begin{array}{l}\text { ¿ES ESTA ETAPA } \\
\text { UN PCC? }\end{array}$ \\
\hline $\begin{array}{l}\text { Selección de materia } \\
\text { prima }\end{array}$ & $\begin{array}{c}\text { Componentes químicos } \\
\text { Descomposición }\end{array}$ & SI & \begin{tabular}{|} 
La sangre de pollo \\
puede estar \\
descompuesta \\
Las semillas \\
pueden no estar en \\
buen estado
\end{tabular} & $\begin{array}{l}\text { Usar sangre fresca y de un } \\
\text { proveedor seguro } \\
\text { Lavar y desinfectar antes de } \\
\text { usar }\end{array}$ & 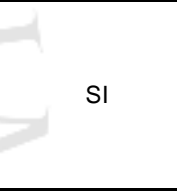 \\
\hline Lavado & $\begin{array}{l}\text { Contaminacion de } \\
\text { microorganismos y } \\
\text { polvo } \\
\text { Descomposición }\end{array}$ & NO & $\begin{array}{l}\text { Compuestos } \\
\text { químicos en las } \\
\text { semillas }\end{array}$ & $\begin{array}{l}\text { Contar con un sistema de } \\
\text { agua potable que garantice la } \\
\text { inocuidad del proceso }\end{array}$ & NO \\
\hline Cocción & $\begin{array}{c}\text { Presencia bacteriana } \\
\text { Descomposición }\end{array}$ & SI & $\begin{array}{l}\text { Supervivencia de } \\
\text { microorganismos } \\
\text { bacterianos }\end{array}$ & $\begin{array}{l}\text { Monitoreo continuo del } \\
\text { proceso }\end{array}$ & SI \\
\hline Secado & $\begin{array}{l}\text { Supervivencia de } \\
\text { microorganismos }\end{array}$ & NO & $\begin{array}{c}\text { Elimina la húmedad } \\
\text { del proceso de } \\
\text { cocción }\end{array}$ & Verificar la húmedad del polvo & NO \\
\hline Molienda & $\begin{array}{l}\text { Supervivencia de } \\
\text { microorganismos }\end{array}$ & NO & $\begin{array}{l}\text { Reduce el tamaño } \\
\text { del material }\end{array}$ & $\begin{array}{l}\text { Verificar la homogeniedad del } \\
\text { proceso }\end{array}$ & NO \\
\hline Tamizado & $\begin{array}{l}\text { Supervivencia de } \\
\text { microorganismos }\end{array}$ & NO & $\begin{array}{c}\text { Filtra el tamaño del } \\
\text { polvo necesario }\end{array}$ & Verificar el tamaño del polvo & NO \\
\hline Mezclado & $\begin{array}{l}\text { Supervivencia de } \\
\text { microorganismos }\end{array}$ & NO & $\begin{array}{c}\text { Combina todos los } \\
\text { materiales }\end{array}$ & $\begin{array}{l}\text { Verificar la homogeniedad del } \\
\text { proceso y las cantidades } \\
\text { necesarias }\end{array}$ & NO \\
\hline Envasado & $\begin{array}{c}\text { Contaminación por } \\
\text { parte del operario }\end{array}$ & NO & $\begin{array}{c}\text { Posible } \\
\text { contaminacion del } \\
\text { producto final }\end{array}$ & $\begin{array}{l}\text { Uso de equipos de } \\
\text { protección como guantes, } \\
\text { mascarillas y gorros. }\end{array}$ & NO \\
\hline Almacenamieto & $\begin{array}{c}\text { Supervivencia de } \\
\text { microorganismos } \\
\text { Contaminacion del } \\
\text { ambiente del almacén }\end{array}$ & NO & $\begin{array}{c}\text { Podría haber un } \\
\text { descuido de higiene } \\
\text { y limpieza }\end{array}$ & $\begin{array}{l}\text { Mantener la limpieza en las } \\
\text { áreas de almacenamiento }\end{array}$ & NO \\
\hline
\end{tabular}

Elaboración propia 
A continuación, se establece la tabla de puntos críticos para determinar cómo se hará el monitoreo y control para determinar la calidad del proceso:

\section{Figura 5.6}

\section{Puntos críticos de control}

\begin{tabular}{|c|c|c|c|c|c|c|}
\hline \multirow{2}{*}{$\begin{array}{l}\text { Puntos } \\
\text { críticos de } \\
\text { control }\end{array}$} & \multirow{2}{*}{$\begin{array}{c}\text { Peligros } \\
\text { significativos }\end{array}$} & \multirow{2}{*}{$\begin{array}{c}\text { Limites criticos para } \\
\text { cada medida } \\
\text { preventiva }\end{array}$} & \multicolumn{4}{|c|}{ Monitoreo } \\
\hline & & & Qué & Cómo & Frecuencia & Quién \\
\hline $\begin{array}{l}\text { Selección de } \\
\text { materia prima }\end{array}$ & $\begin{array}{c}\text { Materia en } \\
\text { descomposición } \\
\text { Componentes } \\
\text { químicos }\end{array}$ & $\begin{array}{c}\text { Revisar que la materia } \\
\text { prima esté en buen } \\
\text { estado }\end{array}$ & $\begin{array}{c}\text { Estado de los } \\
\text { materiales }\end{array}$ & $\begin{array}{l}\text { Muestreo } \\
\text { Revisión de } \\
\text { propiedades } \\
\text { organolépticas }\end{array}$ & En la recepción & Operario \\
\hline Cocción & $\begin{array}{c}\text { Supervivencia de } \\
\text { microorganismos } \\
\text { patógenos. } \\
\text { Eliminar los } \\
\text { nutrientes del } \\
\text { compuesto }\end{array}$ & $\begin{array}{c}\text { Temperatura entre } 82^{\circ} \\
\text { C a } 100^{\circ} \mathrm{C} \\
\text { Tiempo no mayor a } 10 \\
\text { minutos }\end{array}$ & $\begin{array}{c}\text { Temperatura } \\
\text { Tiempo }\end{array}$ & $\begin{array}{l}\text { Termómetro } \\
\text { Cronómetro con } \\
\text { alarmas }\end{array}$ & $\begin{array}{l}\text { Durante todo el } \\
\text { proceso }\end{array}$ & Operario \\
\hline
\end{tabular}

Elaboración propia

\subsection{Estudio de impacto ambiental}

La industria alimentaria se caracteriza por utilizar una gran variabilidad de materias primas, tecnologías y procesos que generan una gran cantidad de desechos sólidos, líquidos y gaseosos. En gran parte de los procesos, estos desechos son de origen biológico y con una carga microbiana pueden contaminar el ambiente de las zonas de trabajo, por ello se han creado una legislación para el control y fiscalización de estos desechos para mitigar el impacto que las industrias puedan causar al ambiente y a las personas. 
Tabla 5.6

Identificación de aspectos e impactos ambientales

\begin{tabular}{|c|c|c|c|c|}
\hline $\begin{array}{c}\text { Etapas del } \\
\text { Proceso }\end{array}$ & Salidas & Aspecto Ambiental & Impacto Ambiental & $\begin{array}{c}\text { Medidas } \\
\text { Correctoras }\end{array}$ \\
\hline $\begin{array}{l}\text { Selección de } \\
\text { materia prima }\end{array}$ & -Residuos & $\begin{array}{l}\text { Residuos sólidos y } \\
\text { líquidos }\end{array}$ & $\begin{array}{l}\text { Potencial } \\
\text { contaminación del } \\
\text { agua y suelo }\end{array}$ & $\begin{array}{l}\text { Manejo adecuado } \\
\text { de residuos. }\end{array}$ \\
\hline Lavado & $\begin{array}{l}\text { - Aguas } \\
\text { residuales }\end{array}$ & $\begin{array}{l}\text { Agua contaminada } \\
\text { por polvo y químicos }\end{array}$ & $\begin{array}{l}\text { Potencial } \\
\text { contaminación del } \\
\text { agua }\end{array}$ & $\begin{array}{l}\text { Tratamiento del } \\
\text { agua } \\
\text { contaminada }\end{array}$ \\
\hline Cocción & $\begin{array}{l}\text {-Vapores } \\
\text {-Calor }\end{array}$ & $\begin{array}{l}\text {-Emisión de vapores } \\
\text {-Energía liberada en } \\
\text { forma de calor }\end{array}$ & $\begin{array}{l}\text {-Afectación a la } \\
\text { salud de los } \\
\text { trabajadores. } \\
\text {-Potencial } \\
\text { contaminación del } \\
\text { aire }\end{array}$ & $\begin{array}{l}\text { Uso de mascarilla } \\
\text { Manejo de los } \\
\text { vapores } \\
\text { emanados }\end{array}$ \\
\hline Secado & -Vapores & $\begin{array}{l}\text { Excesivo consumo } \\
\text { de energía }\end{array}$ & $\begin{array}{l}\text { Potencial } \\
\text { agotamiento del } \\
\text { recurso }\end{array}$ & $\begin{array}{l}\text { Uso racional de } \\
\text { la energía }\end{array}$ \\
\hline Molienda & $\begin{array}{l}\text {-Polvos } \\
\text {-Ruido }\end{array}$ & $\begin{array}{l}\text { Ruido generado por } \\
\text { el molino }\end{array}$ & $\begin{array}{l}\text { Afectación a la salud } \\
\text { de los trabajadores } \\
\text { por ruido y polvo. }\end{array}$ & $\begin{array}{lr}\text { Uso } & \text { de } \\
\text { mascarillas } & \text { y } \\
\text { audífonos } & \end{array}$ \\
\hline Mezclado & $\begin{array}{l}\text {-Polvos } \\
\text {-Ruido }\end{array}$ & $\begin{array}{l}\text { Ruido generado por } \\
\text { el molino }\end{array}$ & $\begin{array}{l}\text { Afectación a la salud } \\
\text { de los trabajadores } \\
\text { por ruido y polvo. }\end{array}$ & $\begin{array}{lr}\text { Uso } & \text { de } \\
\text { mascarillas } & \text { y } \\
\text { audífonos } & \end{array}$ \\
\hline Tamizado & $\begin{array}{l}\text {-Polvos } \\
\text {-Ruido }\end{array}$ & $\begin{array}{l}\text { Ruido generado por } \\
\text { la tamizadora }\end{array}$ & $\begin{array}{l}\text { Afectación a la salud } \\
\text { de los trabajadores } \\
\text { por ruido y polvo. }\end{array}$ & $\begin{array}{lr}\text { Uso } & \mathrm{de} \\
\text { mascarillas } & \mathrm{y} \\
\text { audífonos } & \end{array}$ \\
\hline Envasado & $\begin{array}{l}\text {-Polvos } \\
\text {-Envases } \\
\text { restos } \\
\text { aceptados }\end{array}$ & $\begin{array}{l}\text {-Posible aspiración } \\
\text { del polvo } \\
\text {-Manejo de residuos }\end{array}$ & Manejo de residuos & $\begin{array}{l}\text { Uso } \\
\text { mascarillas }\end{array}$ \\
\hline
\end{tabular}




\section{Figura 5.7}

Matriz de Identificación y evaluación de impactos ambientales

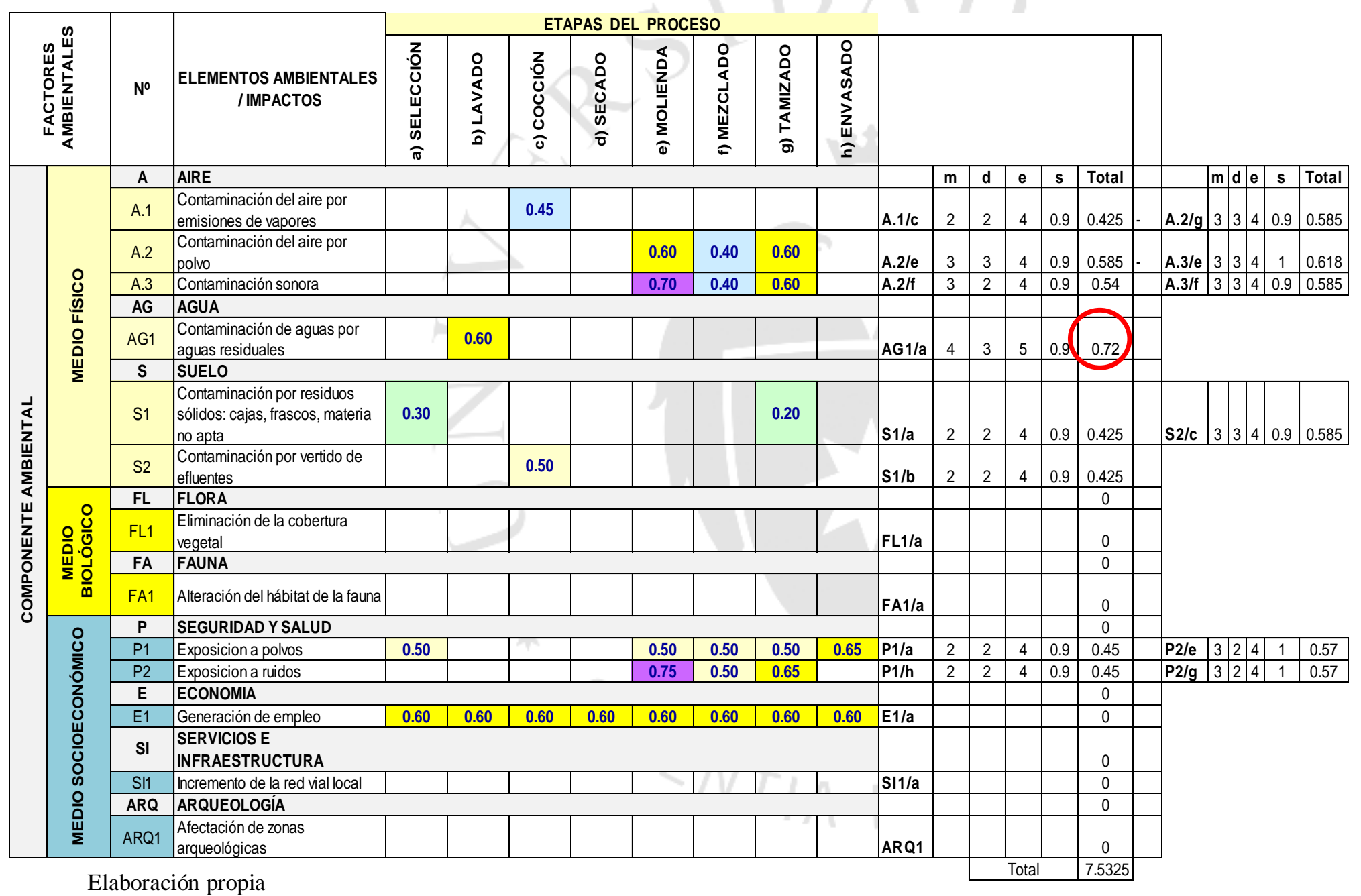

\begin{tabular}{|c|c|}
\hline SIGNIFICANCIA & VALORACION \\
\hline $\begin{array}{c}\text { Muy poco } \\
\text { significativo (1) }\end{array}$ & $0.10-<0.39$ \\
\hline $\begin{array}{c}\text { Poco } \\
\text { significativo (2) }\end{array}$ & $0.40-<0.49$ \\
\hline $\begin{array}{r}\text { Moderadamente } \\
\text { significativo (3) } \\
\end{array}$ & $0.50-<0.59$ \\
\hline \begin{tabular}{|c} 
Muy significativo \\
$(4)$ \\
\end{tabular} & $0.60-<0.69$ \\
\hline $\begin{array}{c}\text { Altamente } \\
\text { sianificativo (5) }\end{array}$ & $0.70-1.0$ \\
\hline
\end{tabular}

\begin{tabular}{|c|c|c|c|c|c|}
\hline Rangos & Magnitud (m) & Duración (d) & Extensión (e) & \multicolumn{2}{|c|}{ Sensibilidad } \\
\hline \multirow[b]{2}{*}{1} & Muy pequeña & Días & Puntual & \multirow[b]{2}{*}{0.80} & \multirow[b]{2}{*}{ Nula } \\
\hline & Casi Imperceptible & $1-7$ días & $\begin{array}{l}\text { En un punto del } \\
\text { proyecto }\end{array}$ & & \\
\hline \multirow[b]{2}{*}{2} & Pequeña & Semanas & Local & \multirow[b]{2}{*}{0.85} & \multirow[b]{2}{*}{ Baja } \\
\hline & Leve alteración & $\begin{array}{c}1-4 \\
\text { semanas }\end{array}$ & $\begin{array}{c}\text { En una sección del } \\
\text { proyecto. }\end{array}$ & & \\
\hline \multirow[b]{2}{*}{3} & Mediana & Meses & Área del proyecto & \multirow[b]{2}{*}{0.90} & \multirow[b]{2}{*}{ Media } \\
\hline & $\begin{array}{l}\text { Moderada } \\
\text { alteración }\end{array}$ & $1-12$ meses & En el área del proyecto & & \\
\hline \multirow[b]{2}{*}{4} & Alta & Años & Más allá del proyecto & \multirow[b]{2}{*}{0.95} & \multirow[b]{2}{*}{ Alta } \\
\hline & $\begin{array}{l}\text { Se produce } \\
\text { modificación }\end{array}$ & $1-10$ años & $\begin{array}{l}\text { Dentro del área de } \\
\text { influencia }\end{array}$ & & \\
\hline \multirow[b]{2}{*}{5} & Muy Alta & Permanente & Distrital & \multirow[b]{2}{*}{1.00} & \multirow[b]{2}{*}{$\begin{array}{c}\text { Extrer } \\
\text { a }\end{array}$} \\
\hline & $\begin{array}{l}\text { Modificación } \\
\text { sustancial }\end{array}$ & $\begin{array}{l}\text { Más de } 10 \\
\text { años }\end{array}$ & $\begin{array}{l}\text { Fuera del área de } \\
\text { influencia }\end{array}$ & & \\
\hline
\end{tabular}


El cálculo del impacto total se obtiene de la siguiente fórmula:

$$
\text { IS: }[(2 \mathrm{~m}+\mathrm{d}+\mathrm{e}) / 20) * \mathrm{~S}
$$

Con los valores totales, se puede determinar que los impactos ambientales que deberán estar en un continuo control para evitar mayores consecuencias son: contaminación por polvo, exposición a ruidos y contaminación por aguas residuales, siendo el de mayor impacto contaminación de aguas residuales con una valoración de 0.72

\subsection{Seguridad y salud ocupacional}

Para determinar los posibles, riesgos y peligros en el proceso productivo anteriormente mencionado, se hizo uso de la herramienta IPER (Identificación de peligros y evaluación de riesgos), la cual nos ayudara a planificar el sistema de gestión priorizando los riesgos de acuerdo a un nivel de riesgo previamente establecido y los controles a tomar respecto a los riesgos encontrados. 


\section{Figura 5.8}

Identificación de peligros y evaluación de riesgos del proceso productivo

\begin{tabular}{|c|c|c|c|c|c|c|c|c|c|c|c|c|c|c|}
\hline \multirow[b]{2}{*}{ Actividades } & \multicolumn{2}{|c|}{ Peligro } & \multirow[b]{2}{*}{ Riesgo } & \multirow[b]{2}{*}{ Consecuencias } & \multirow[b]{2}{*}{ Causas } & \multirow[b]{2}{*}{$\begin{array}{l}\text { Cumplimiento } \\
\text { legal }\end{array}$} & \multicolumn{2}{|c|}{ Afecta } & \multicolumn{3}{|c|}{ Controles existentes } & \multicolumn{3}{|c|}{ Evaluación del riesgo } \\
\hline & $\begin{array}{l}\text { Tipo de } \\
\text { Peligro }\end{array}$ & $\begin{array}{l}\text { Descripción } \\
\text { del peligro }\end{array}$ & & & & & $\begin{array}{l}n \\
0 \\
\frac{0}{0} \\
\vdots \\
0\end{array}$ & $\begin{array}{l}n \\
0 \\
0 \\
d \\
0 \\
0 \\
0 \\
-1\end{array}$ & Ingeniería & Administración & EPPs & NC & NP & NR \\
\hline Inspección & Ergonómico & $\begin{array}{l}\text { Fatiga } \\
\text { muscular }\end{array}$ & \begin{tabular}{|c|} 
Probabilidad de \\
Fatiga muscular \\
debido a la \\
mala postura
\end{tabular} & Fatiga muscular & $\begin{array}{c}\text { Por mala postura al } \\
\text { ejecutar la labor }\end{array}$ & \begin{tabular}{|c|} 
Ley № 29783 \\
DS № 005-2012-TR
\end{tabular} & $x$ & & $\begin{array}{c}\text { Capacitación sobre } \\
\text { ergonomía }\end{array}$ & & & $\begin{array}{l}\text { Ligeramente } \\
\text { dan̂ino }\end{array}$ & Baja & TRIVIAL \\
\hline Lavado & Físico & $\begin{array}{l}\text { Descarga } \\
\text { eléctrica }\end{array}$ & $\begin{array}{l}\text { Probabilidad de } \\
\text { electrocución }\end{array}$ & $\begin{array}{c}\text { Electrocución, } \\
\text { Quemaduras } \\
\text { eléctricas }\end{array}$ & Falla de lavadora & \begin{tabular}{|c|} 
Ley № 29783 \\
DS № $005-2012-\mathrm{TR}$
\end{tabular} & $x$ & & $\begin{array}{c}\text { Comprobar estado de } \\
\text { maquinaria }\end{array}$ & & & $\begin{array}{c}\text { Extremadamente } \\
\text { dañino }\end{array}$ & Baja & MODERADO \\
\hline \multirow{2}{*}{ Cocción } & Locativo & $\begin{array}{l}\text { Quemadura } \\
\text { por vapores }\end{array}$ & $\begin{array}{c}\text { Probabilidad de } \\
\text { quemadura }\end{array}$ & $\begin{array}{c}\text { Quemaduras de } \\
\text { 1er, 2do o 3er } \\
\text { grado }\end{array}$ & $\begin{array}{c}\text { Malas prácticas en } \\
\text { el procedimiento } \\
\text { de trabajo }\end{array}$ & \begin{tabular}{|c|} 
Ley № 29783 \\
DS № $005-2012-\mathrm{TR}$ \\
\end{tabular} & $x$ & & $\begin{array}{c}\text { Capacitación sobre } \\
\text { cocción }\end{array}$ & & & Dañino & Media & MODERADO \\
\hline & Locativo & $\begin{array}{c}\text { Aspiración de } \\
\text { vapores }\end{array}$ & $\begin{array}{c}\text { Probabilidad de } \\
\text { aspiración }\end{array}$ & $\begin{array}{c}\text { Enfermedades } \\
\text { pulmonares }\end{array}$ & $\begin{array}{l}\text { Por no usar } \\
\text { mascarilla }\end{array}$ & $\begin{array}{c}\text { Ley № } 29783 \\
\text { DS № 005-2012-TR }\end{array}$ & $x$ & & & & $\begin{array}{c}\text { Uso de } \\
\text { mascarillas }\end{array}$ & Dañino & Alta & IMPORTANTE \\
\hline Secado & Físico & $\begin{array}{l}\text { Descarga } \\
\text { eléctrica }\end{array}$ & $\begin{array}{c}\text { Probabilidad de } \\
\text { electrocución }\end{array}$ & $\begin{array}{c}\text { Electrocución, } \\
\text { Quemaduras } \\
\text { eléctricas }\end{array}$ & Falla de secadora & \begin{tabular}{|c|} 
Ley № 29783 \\
DS № $005-2012-\mathrm{TR}$
\end{tabular} & $x$ & & $\begin{array}{c}\text { Comprobar estado de } \\
\text { maquinaria }\end{array}$ & & & $\begin{array}{c}\text { Extremadamente } \\
\text { dañino }\end{array}$ & Baja & MODERADO \\
\hline
\end{tabular}

Elaboración propia 


\section{Figura 5.9}

\section{Continuación de Identificación de peligros y evaluación de riesgos del proceso productivo}

Elaboración propia

\begin{tabular}{|c|c|c|c|c|c|c|c|c|c|c|c|}
\hline \multirow{2}{*}{ Molido } & Locativo & Atrapamiento & $\begin{array}{c}\text { Probabilidad de } \\
\text { atrapamiento }\end{array}$ & $\begin{array}{c}\text { Fracturas, } \\
\text { Cercenamiento }\end{array}$ & $\begin{array}{l}\text { Descuido del } \\
\text { operario }\end{array}$ & $\mid \begin{array}{c}\text { Ley № } 29783 \\
\text { DS № } 005-2012-\operatorname{TR}\end{array}$ & $x$ & $\begin{array}{c}\text { Instalación de guardas } \\
\text { de seguridad en } \\
\text { Molino }\end{array}$ & $\begin{array}{c}\text { Extremadamente } \\
\text { dañino }\end{array}$ & Baja & MODERADO \\
\hline & Físico & $\begin{array}{l}\text { Descarga } \\
\text { eléctrica }\end{array}$ & $\begin{array}{c}\text { Probabilidad de } \\
\text { electrocución }\end{array}$ & \begin{tabular}{c|}
$\begin{array}{c}\text { Electrocución, } \\
\text { Quemaduras } \\
\text { eléctricas }\end{array}$ \\
\end{tabular} & Falla de molino & $\begin{array}{c}\text { Ley № } 29783 \\
\text { DS № 005-2012-TR }\end{array}$ & $x$ & $\begin{array}{c}\text { Comprobar estado de } \\
\text { maquinaria }\end{array}$ & $\begin{array}{c}\text { Extremadamente } \\
\text { dañino }\end{array}$ & Baja & MODERADO \\
\hline $\begin{array}{l}\text { Tamizado y } \\
\text { Verificación }\end{array}$ & Físico & $\begin{array}{l}\text { Descarga } \\
\text { eléctrica }\end{array}$ & $\begin{array}{c}\text { Probabilidad de } \\
\text { electrocución }\end{array}$ & $\begin{array}{c}\text { Electrocución, } \\
\text { Quemaduras } \\
\text { eléctricas }\end{array}$ & Falla de lavadora & $\begin{array}{c}\text { Ley № } 29783 \\
\text { DS № 005-2012-TR }\end{array}$ & $x$ & $\begin{array}{c}\text { Comprobar estado de } \\
\text { maquinaria }\end{array}$ & $\begin{array}{c}\text { Extremadamente } \\
\text { dañino }\end{array}$ & Baja & MODERADO \\
\hline Mezclado & Físico & $\begin{array}{l}\text { Descarga } \\
\text { eléctrica }\end{array}$ & $\begin{array}{c}\text { Probabilidad de } \\
\text { electrocución }\end{array}$ & $\begin{array}{c}\text { Electrocución, } \\
\text { Quemaduras } \\
\text { eléctricas }\end{array}$ & Falla de lavadora & $\mid \begin{array}{c}\text { Ley № } 29783 \\
\text { DS № } 005-2012-\operatorname{TR}\end{array}$ & $x$ & $\begin{array}{c}\text { Comprobar estado de } \\
\text { maquinaria }\end{array}$ & $\begin{array}{c}\text { Extremadamente } \\
\text { dañino }\end{array}$ & Baja & MODERADO \\
\hline \multirow{2}{*}{$\begin{array}{l}\text { Envasado e } \\
\text { inspección }\end{array}$} & Locativo & $\begin{array}{l}\text { Caída de } \\
\text { frascos }\end{array}$ & $\begin{array}{c}\text { Probabilidad de } \\
\text { caída }\end{array}$ & $\begin{array}{l}\text { Golpes,Hemato } \\
\text { mas }\end{array}$ & $\begin{array}{l}\text { Desorden en área } \\
\text { de trabajo }\end{array}$ & $\mid \begin{array}{l}\text { Ley № } 29783 \\
\text { DS № 005-2012-TR }\end{array}$ & $x$ & $\begin{array}{l}\text { Capacitación sobre } \\
\text { orden en el área de } \\
\text { trabajo }\end{array}$ & $\begin{array}{l}\text { Ligeramente } \\
\text { dañino }\end{array}$ & Media & TOLERABLE \\
\hline & Ergonómico & $\begin{array}{l}\text { Fatiga } \\
\text { muscular }\end{array}$ & $\begin{array}{l}\text { Probabilidad de } \\
\text { Fatiga muscular }\end{array}$ & Fatiga muscular & \begin{tabular}{|c} 
Por mala postura al \\
ejecutar la labor
\end{tabular} & \begin{tabular}{|c|} 
Ley № 29783 \\
DS № $005-2012-\mathrm{TR}$ \\
\end{tabular} & $x$ & $\begin{array}{c}\text { Capacitación sobre } \\
\text { ergonomía }\end{array}$ & $\begin{array}{l}\text { Ligeramente } \\
\text { dañino }\end{array}$ & Media & TOLERABLE \\
\hline
\end{tabular}

\begin{tabular}{|c|c|}
\hline \multicolumn{2}{|c|}{ Leyenda } \\
\hline NC & Nivel de Consecuencia \\
\hline NP & Nivel de Probabilidad \\
\hline NR & Nivel de Riesgo \\
\hline
\end{tabular}

\begin{tabular}{|c|c|c|c|}
\cline { 2 - 4 } \multicolumn{1}{c|}{} & \multicolumn{3}{c|}{ CONSECUENCIA } \\
\hline PROBABILIDAD & $\begin{array}{c}\text { LIGERAMENTE } \\
\text { DAÑINO }\end{array}$ & DAÑINO & $\begin{array}{c}\text { EXTREMADAMENTE } \\
\text { DAÑINO }\end{array}$ \\
\hline BAIA & TRIVIAL & TOLERABLE & MODERADO \\
\hline MEDIA & TOLERABLE & MODERADO & IMPORTANTE \\
\hline ALTA & MODERADO & IMPORTANTE & INTOLERABLE \\
\hline
\end{tabular}


Asimismo, para garantizar que la seguridad se cumpla en las instalaciones de la empresa, se impondrán medidas de recompensa (reconocimientos no monetarios) y castigo para los que cumplan o no con las indicaciones establecidas.

\subsection{Sistema de mantenimiento}

El mantenimiento es un aspecto fundamental para la industria, entre las actividades necesarias para efectuarlo de forma correcta, se encuentran:

- Elaborar un presupuesto anual enfocado al área de mantenimiento.

- Ejecutar el Plan de Mantenimiento.

- Mantener un registro de los mantenimientos efectuados.

- Hacer una lista de los repuestos críticos de cada máquina.

Es por esto, que debe existir una implementación de mantenimiento en todas las líneas de producción para evitar las posibles paradas de maquinaria por fallas y alargar la vida útil de estas, a fin de aumentar la productividad de la empresa.

Entre los tipos de mantenimientos existentes, se seguirán:

- Mantenimiento preventivo: Ya que este evitaría gastos innecesarios a la empresa, como los generados por la paralización de la producción. Se programará un mantenimiento de este tipo en la empresa ya que la producción será continua

Al mismo tiempo se consideró, implantar un mantenimiento productivo total (TPM), ya que esta clase de mantenimiento engloba mantenimientos del tipo predictivo, preventivo, correctivo, Just in Time y Trabajo en Equipo, la implantación de este mantenimiento se da en un largo plazo.

El Plan de Mantenimiento a seguir por la planta será el siguiente: 


\section{Tabla 5.7}

\section{Plan de Mantenimiento}

\begin{tabular}{|l|l|c|}
\hline \multicolumn{1}{|c|}{$\begin{array}{c}\text { Máquinas y } \\
\text { Equipos }\end{array}$} & \multicolumn{1}{|c|}{ Trabajo de Mantenimiento } & Periodicidad \\
\hline Lavadora & $\begin{array}{l}\text { Limpiar y retirar restos de } \\
\text { cáscaras de cacao }\end{array}$ & Diario \\
\hline Horno & $\begin{array}{l}\text { Limpiar restos de sangre, } \\
\text { Verificar que la humedad no } \\
\text { genera corrosión. }\end{array}$ & Diario \\
\hline Secadora & Limpiar restos de sangre & Diario \\
\hline Molino & $\begin{array}{l}\text { Limpiar y retirar partículas } \\
\text { sobrantes en el tornillo }\end{array}$ & Diario \\
\hline Tamizadora & $\begin{array}{l}\text { Limpiar partículas sobrantes } \\
\text { sobre la criba }\end{array}$ & Diario \\
\hline Mezcladora & $\begin{array}{l}\text { Limpiar y retirar partículas } \\
\text { sobrantes }\end{array}$ \\
\hline
\end{tabular}

Elaboración propia

\subsection{Programa de producción}

\subsubsection{Factores para la programación de la producción}

Para la programación de la producción se tomará en cuenta el factor clima, ya que en invierno es cuando la gente suele enfermarse por las bajas temperaturas y ello conlleva a que las personas consuman complementos alimenticios, por eso, la producción en invierno deberá ser mayor.

\subsubsection{Programa de producción}

El programa de producción de la planta estará en función de la demanda del mercado ya que esta fue elegida como el tamaño de planta del proyecto, por ende la producción anual será de la siguiente manera: 
Tabla 5.8

Producción anual de la planta

\begin{tabular}{|c|c|}
\hline Año & $\begin{array}{c}\text { Producción anual } \\
\text { (unidades) }\end{array}$ \\
\hline 1 & 211.112 \\
\hline 2 & 283.676 \\
\hline 3 & 329.908 \\
\hline 4 & 365.868 \\
\hline 5 & 396.644 \\
\hline
\end{tabular}

Elaboración propia

El factor tecnología no será un impedimento en la producción durante el ciclo de vida del proyecto ya que con el cuello de botella del proceso de fabricación, la producción sería de unidades

Dado que la esencia del producto es complementar la alimentación de la población, se estableció que los meses de invierno sería la temporada con un ligero incremento en la producción en comparación con otras, ya que en invierno es cuando la gente tiende a enfermarse por el descenso de temperatura y el incremento de lluvias y con ello la humedad, por eso requiere mayores opciones de ingesta de alimentos que le brinden soporte para conservar una buena salud, ya que la mala alimentación es una de las principales causas de que las personas se enfermen.

A continuación se presenta la distribución anual de la producción por meses en porcentaje y en cantidad: 


\section{Figura 5.10}

\section{Producción mensual del proyecto en unidades}

\begin{tabular}{|c|c|c|c|c|c|c|c|c|c|c|c|c|}
\hline Mes & Enero & Febrero & Marzo & Abril & Mayo & Junio & Julio & Agosto & Septiembre & Octubre & Noviembre & Diciembre \\
\hline Distribución & $7 \%$ & $7 \%$ & $7 \%$ & $8 \%$ & $8 \%$ & $9 \%$ & $10 \%$ & $10 \%$ & $10 \%$ & $9 \%$ & $8 \%$ & $7 \%$ \\
\hline Año 1 & 14,778 & 14,778 & 14,778 & 16,889 & 16,889 & 19,000 & 21,111 & 21,111 & 21,111 & 19,000 & 16,889 & 14,778 \\
\hline Año 2 & 19,857 & 19,857 & 19,857 & 22,694 & 22,694 & 25,531 & 28,368 & 28,368 & 28,368 & 25,531 & 22,694 & 19,857 \\
\hline Año 3 & 23,094 & 23,094 & 23,094 & 26,393 & 26,393 & 29,692 & 32,991 & 32,991 & 32,991 & 29,692 & 26,393 & 23,094 \\
\hline Año 4 & 25,611 & 25,611 & 25,611 & 29,269 & 29,269 & 32,928 & 36,587 & 36,587 & 36,587 & 32,928 & 29,269 & 25,611 \\
\hline Año 5 & 27,765 & 27,765 & 27,765 & 31,732 & 31,732 & 35,698 & 39,664 & 39,664 & 39,664 & 35,698 & 31,732 & 27,765 \\
\hline
\end{tabular}

Elaboración propia

A continuación se muestra una tabla con la utilización de la planta a lo largo de los 5 años, como se puede apreciar, al ir aumentando la demanda la utilización ira incrementado hasta llegar a $97 \%$ para el último año del proyecto.

\section{Tabla 5.9}

\section{Utilización de la capacidad de planta}

\begin{tabular}{|c|c|c|c|c|}
\hline Año & Demanda & Producción & Capacidad & Utilización \\
\hline 1 & 211.112 & 211.112 & 410.800 & $51 \%$ \\
\hline 2 & 283.676 & 283.676 & 410.800 & $69 \%$ \\
\hline 3 & 329.908 & 329.908 & 410.800 & $80 \%$ \\
\hline 4 & 365.868 & 365.868 & 410.800 & $89 \%$ \\
\hline 5 & 396.644 & 396.644 & 410.800 & $97 \%$ \\
\hline
\end{tabular}

Elaboración propia

\subsection{Requerimiento de insumos, servicios y personal}

\subsubsection{Materia prima, insumos y otros materiales}

Según el balance de materia presentado anteriormente en la figura 5.3, en la siguiente tabla se presenta los requerimientos del factor material, que incluyen las materias primas e insumos del producto, tomados en base al último año de producción. 
Tabla 5.10

\section{Requerimientos del factor material}

\begin{tabular}{|l|c|c|}
\hline Materia Prima/ Insumos & Cantidad & Unidades \\
\hline Sangre & 0.31 & $\mathrm{Lts} / \mathrm{h}$ \\
\hline Cacao & 27.6 & $\mathrm{~kg} / \mathrm{h}$ \\
\hline Fósforo & 0.68 & $\mathrm{~kg} / \mathrm{h}$ \\
\hline Magnesio & 0.68 & $\mathrm{~kg} / \mathrm{h}$ \\
\hline Tapa & 137 & $\mathrm{Unid} / \mathrm{h}$ \\
\hline Frasco & 137 & $\mathrm{Unid} / \mathrm{h}$ \\
\hline Etiquetas & 137 & Unid/h \\
\hline
\end{tabular}

Elaboración propia

Tomando en cuenta la relación en la que se encuentra la materia prima y los insumos del producto, se pudo calcular el requerimiento por hora que se requería de cada uno de estos. A continuación se presenta la planificación de los requerimientos de materiales (MRP) en kilogramos para el año 5, que es el que determina la demanda y por ende el tamaño de planta. 


\section{Figura 5.11}

\section{Planificación de los requerimientos de materiales al año 5 en kilogramos}

\begin{tabular}{|c|c|c|c|c|c|c|c|c|c|c|c|c|}
\hline Producto final & Ene & Feb & Mar & Abr & May & Jun & Jul & Ago & Sep & Oct & Nov & Dic \\
\hline Requerimientos bruto & 6,941 & 6,941 & 6,941 & 7,933 & 7,933 & 8,924 & 9,916 & 9,916 & 9,916 & 8,924 & 7,933 & 6,941 \\
\hline Requerimiento Neto & 4,883 & 4,760 & 4,760 & 5,751 & 5,751 & 6,743 & 7,735 & 7,735 & 7,735 & 6,743 & 5,751 & 4,760 \\
\hline Inventario Inicial & 2,058 & 2,182 & 2,182 & 2,181 & 2,181 & 2,182 & 2,181 & 2,181 & 2,181 & 2,182 & 2,181 & 2,182 \\
\hline Lanzamiento de pedido & 4,883 & 4,760 & 4,760 & 5,751 & 5,751 & 6,743 & 7,735 & 7,735 & 7,735 & 6,743 & 5,751 & 4,760 \\
\hline Sangre & Ene & Feb & Mar & $\mathrm{Abr}$ & May & Jun & Jul & Ago & Sep & Oct & Nov & Dic \\
\hline Requerimientos bruto & 293 & 286 & 286 & 345 & 345 & 405 & 464 & 464 & 464 & 405 & 345 & 286 \\
\hline Requerimiento Neto & 169 & 155 & 155 & 214 & 214 & 274 & 333 & 333 & 333 & 274 & 214 & 155 \\
\hline Inventario Inicial & 124 & 131 & 131 & 131 & 131 & 131 & 131 & 131 & 131 & 131 & 131 & 131 \\
\hline Lanzamiento de pedido & 562 & 513 & 513 & 711 & 711 & 908 & 1,106 & 1,106 & 1,106 & 908 & 711 & 513 \\
\hline Cacao & Ene & Feb & Mar & Abr & May & Jun & Jul & Ago & Sep & Oct & Nov & Dic \\
\hline Requerimientos bruto & 4,395 & 4,284 & 4,284 & 5,176 & 5,176 & 6,069 & 6,961 & 6,961 & 6,961 & 6,069 & 5,176 & 4,284 \\
\hline Requerimiento Neto & 2,542 & 2,320 & 2,320 & 3,213 & 3,213 & 4,105 & 4,998 & 4,998 & 4,998 & 4,105 & 3,213 & 2,320 \\
\hline Inventario Inicial & 1,853 & 1,963 & 1,963 & 1,963 & 1,963 & 1,963 & 1,963 & 1,963 & 1,963 & 1,963 & 1,963 & 1,963 \\
\hline Lanzamiento de pedido & 365 & 333 & 333 & 461 & 461 & 590 & 718 & 718 & 718 & 590 & 461 & 333 \\
\hline Magnesio & Ene & Feb & Mar & Abr & May & Jun & Jul & Ago & Sep & Oct & Nov & Dic \\
\hline Requerimientos bruto & 98 & 95 & 95 & 115 & 115 & 135 & 155 & 155 & 155 & 135 & 115 & 95 \\
\hline Requerimiento Neto & 56 & 52 & 52 & 71 & 71 & 91 & 111 & 111 & 111 & 91 & 71 & 52 \\
\hline Inventario Inicial & 41 & 44 & 44 & 44 & 44 & 44 & 44 & 44 & 44 & 44 & 44 & 44 \\
\hline Lanzamiento de pedido & 30 & 27 & 27 & 37 & 37 & 48 & 58 & 58 & 58 & 48 & 37 & 27 \\
\hline & & & & & & & & & & & & \\
\hline Fósforo & Ene & Feb & Mar & Abr & May & Jun & Jul & Ago & Sep & Oct & Nov & Dic \\
\hline Requerimientos bruto & 98 & 95 & 95 & 115 & 115 & 135 & 155 & 155 & 155 & 135 & 115 & 95 \\
\hline Requerimiento Neto & 56 & 52 & 52 & 71 & 71 & 91 & 111 & 111 & 111 & 91 & 71 & 52 \\
\hline Inventario Inicial & 41 & 44 & 44 & 44 & 44 & 44 & 44 & 44 & 44 & 44 & 44 & 44 \\
\hline Lanzamiento de pedido & 30 & 27 & 27 & 37 & 37 & 48 & 58 & 58 & 58 & 48 & 37 & 27 \\
\hline
\end{tabular}

Elaboración propia

\subsubsection{Servicios: energía eléctrica, agua, vapor, combustible, etc.}

La empresa requerirá de los servicios básicos de agua y de luz, los cuales debido a la ubicación de la planta y por mayor conveniencia serán los siguientes: 
Tabla 5.11

Otros servicios

\begin{tabular}{|l|l|}
\hline Servicio & Empresa \\
\hline Agua & Sedapal \\
\hline Luz & Edelnor \\
\hline Telefonía e Internet & Telefónica \\
\hline
\end{tabular}

Elaboración propia

\subsubsection{Determinación del número de operarios y trabajadores indirectos}

Para el cálculo aproximado del número de operarios y trabajadores indirectos, se hizo uso de los cálculos estimados anteriormente para el punto de equilibrio.

La plantara contará con el siguiente número de operarios para las áreas del proceso productivo:

-Inspección y selección (2)

-Lavado (1)

-Horneado (1)

-Tamizado y Mezclado (1)

- Envasado, etiquetado y sellado (2)

\subsubsection{Servicio de terceros}

Entre los servicios de terceros que requerirá la planta se encontrarán Seguridad, Limpieza y Comedor.

\subsection{Disposición de planta}

\subsubsection{Características físicas del proyecto}

El diseño de la planta debe ser de tal forma que no interfiera con el proceso de producción, por ello esta debe tener una buena infraestructura y una correcta distribución que minimice tiempos de traslado entre zonas y permita la mejor circulación de los materiales o productos en proceso, brinde satisfacción y seguridad a los trabajadores y contribuya a la minimización de costo de fabricación, al aumento de la productividad, al uso eficiente de la maquinaria y 
optimice el área de la planta. Se tomará en cuenta la regulación alimentaria referida a la inocuidad en las plantas y establecimientos que procesan alimentos, que incluye al personal.

La planta será de un solo piso ya que dentro de las ventajas que esta elección puede brindar son:

- Buena ventilación

- Mejor esparcimiento de luz,

- Menores costos en el manejo de los materiales

- Facilidad de movimiento, tanto de equipo como de personal.

Es importante definir el tipo de piso con el que contará la planta ya que esta será la superficie de trabajo y además en ella se trasladarán tanto los operarios como las máquinas de acarreo, por ello el piso será de concreto armado (piedra chancada, arena, fierro y cemento) en las áreas en las que se encuentre las máquinas y de concreto simple en las demás áreas en las que hay tránsito de personal y medios de acarreo. Se tomará en cuenta las exigencias sanitarias para techo, piso, instalaciones sanitarias, ventanas, puertas, instrumentos, equipo, personal entre otros.

El techo de la planta permitirá que la producción no permanezca a la intemperie y se ofrezca la seguridad tanto del producto como de los bienes dentro de la planta, por ello, este será de concreto aislante y tendrá una altura no menor de 3 metros desde el nivel del piso.

Las áreas requeridas para una la distribución de la planta serán: patio de maniobras, almacén de materia prima y productos terminados, áreas que involucren el proceso productivo, área de control de calidad, depósito de herramientas, servicios higiénicos, comedor y oficinas

En cuanto a las dimensiones de la infraestructura, las puertas de las oficinas deberán tener un ancho de $90 \mathrm{~cm}$ y las puertas de los sanitarios serán de $80 \mathrm{~cm}$ de ancho, ambas puertas se ubicaran en una esquina para que puedan abrirse con un arco de $90^{\circ}$. Para las puertas exteriores, el ancho será de 1.2 metros como mínimo para el paso de operarios, mientras que para el caso de las puertas de ingreso de vehículos, estas tendrán un ancho mínimo de 3 metros y una altura de 4.20 metros. 
Las puertas se abrirán hacia afuera de los corredores y del edificio para mayor seguridad, se preferirán puertas sólidas porque brindan mayor protección contra el ruido que otro tipo de puertas y son más seguras.

Para mantener una cultura de seguridad dentro de la organización, se contará con carteles de aviso y señales en caso de una emergencia o requerimiento para entrar a algún área en específico, dentro de lo mencionado estará:

- Salidas de seguridad y vías de evacuación en caso de un sismo, un incendio o cualquier otro tipo de eventualidad.

- Servicios higiénicos.

- Advertencia de riesgo eléctrico y poder recibir una descarga.

- Presencia de extintor y de manguera.

- Uso obligatorio de protección.

- Advertencia sobre el paso de vehículos.

- Prohibido fumar dentro de la planta.

\subsubsection{Determinación de las zonas físicas requeridas}

Se determinará las zonas físicas requeridas en base al análisis desde 3 puntos de vista: enfocado al personal, al material y a las máquinas.

Relativo al personal: Se deberán considerar las condiciones apropiadas para que realicen su trabajo, dentro de ello se puede analizar las vías de acceso, instalaciones sanitarias, servicio de alimentación e iluminación.

Las vías de acceso del operario a la planta serán independientes del ingreso de la materia prima y/o productos terminados y además los pasajes tendrán un ancho mínimo de 1,20 metros para que el operario no tenga problemas de caminar por la planta.

La cantidad de instalaciones sanitarias necesarias en la planta, según las especificaciones de la OSHA, es de 1 baño, sin embargo se establecerá 2 baños (uno para varones y otro para damas). Estos estarán debidamente iluminados y ventilados. Contarán con jabón, papel higiénico, papel toalla, urinarios, espejo y un basurero. 
Tabla 5.12

Instalación de servicios higiénicos

\begin{tabular}{|c|c|}
\hline Número de empleados & Número mínimo de baños \\
\hline $1-15$ & 1 \\
\hline $16-35$ & 2 \\
\hline $36-55$ & 3 \\
\hline
\end{tabular}

Fuente: United States Department of Labor, s.f

Elaboración propia

La planta contará con un área destinada como comedor para que los operarios puedan calentar sus alimentos y sentarse a comer. El comedor tendrá que tener una puerta que permita separar el comedor del resto de la planta para así evitar que ciertos olores se propaguen.

Para cada área se contará con la correcta iluminación para así los trabajadores puedan estar más cómodos, seguros y evitar errores por forzar su vista. La iluminación será natural y artificial, ya que habrá ventanas en las paredes que permitan el paso de la luz solar; el techo será de color blanco, las paredes de color claro y el piso de color oscuro. Asimismo, para respetar el Reglamento Nacional de Edificaciones del Ministerio de Vivienda, las áreas en las que haya algún proceso de producción tendrá 750 lux, el área administrativa tendrá 500 lux, los almacenes 300 lux y el baño 200 lux.

Tabla 5.13

Iluminación por zonas

\begin{tabular}{|c|c|}
\hline Zona & Iluminación (Lux) \\
\hline Producción & 750 \\
\hline Áreas administrativas & 500 \\
\hline Almacenes & 300 \\
\hline Baños & 200 \\
\hline
\end{tabular}

Fuente: Instituto de la construcción y gerencia, s.f

Elaboración propia

Relativo al material: Con respecto al material, los servicios que se realizan sobre el control de calidad y los análisis de laboratorio.

Los controles de calidad de la materia prima se hacen a la llegada a la planta donde se revisa si es que las semillas se encuentran malogradas o la sangre se encuentra en buen estado, así como la temperatura de refrigeración. Asimismo, durante el proceso de producción se va 
controlando ciertos parámetros que garanticen que el producto es de buena calidad en el laboratorio. Al concluir el proceso de producción, se realiza un muestreo y se hace los análisis necesarios para determinar que efectivamente el producto tiene la calidad que se ofrece.

Relativo a la maquinaria: Para las máquinas se deben tener en cuenta las instalaciones eléctricas y depósito de herramientas.

Las instalaciones eléctricas deben instalarse de acuerdo a las necesidades de la planta, verificando siempre que no se vaya a producir sobrecargas que generen una probabilidad de incendio o explosión, por ello se utilizará el Código Nacional de Electricidad para reducir al mínimo cualquier riesgo existente, asimismo se instalarán equipos de protección eléctrica como lo son interruptores diferenciales.

Se contará con un depósito de herramientas donde se manejara un inventario de estas para poder emplearlas cuando tenga que realizarse algún mantenimiento o en algún momento dado. Las acciones de mantenimiento se realizarán en la misma ubicación de la máquina, por ello no se necesitará un taller para realizar reparaciones. Las herramientas estarán en compartimientos debidamente señalizados para facilitar su ubicación al operario que lo requiera.

\subsubsection{Cálculo de áreas para cada zona}

Para determinar el área de cada zona se realizará el análisis de determinación de espacios con el método de Guerchet, se tomará en cuenta los elementos fijos y elementos móviles. Además, se debe determinar qué áreas tendrán puntos de espera, los cuales también deben ser considerados: 
Tabla 5.14

\section{Análisis de punto de espera}

\begin{tabular}{|c|c|c|c|c|}
\hline Actividad & $\begin{array}{c}\text { Cantidad } \\
\text { procesada por día } \\
(\mathrm{Kg})\end{array}$ & $\begin{array}{c}\mathrm{N}^{\circ} \text { de sacos, } \\
\text { bolsas o cajas } \\
(25 \mathrm{~kg} \text { c/u })\end{array}$ & $\begin{array}{c}\mathrm{N}^{\circ} \text { de parihuelas } \\
(18 \mathrm{sacos} \text { c/u })\end{array}$ & $\begin{array}{c}\mathrm{N}^{\circ} \text { de Monta } \\
\text { Carga o carritos }\end{array}$ \\
\hline $\begin{array}{c}\text { Selección } \\
\text { no aptas) }\end{array}$ & 250,62 & 10 & 1 & Monta carga 1 \\
\hline $\begin{array}{c}\text { Lavado } \\
\text { (semillas aptas) }\end{array}$ & 250,37 & 1 & 1 & Monta carga 1 \\
\hline $\begin{array}{c}\text { Cocción } \\
\text { Secado }\end{array}$ & 19,52 & 1 & 1 & Carrito 1 \\
\hline $\begin{array}{c}\text { Molienda } \\
\text { (18,54 }\end{array}$ & 267,06 & 11 & 1 & Carrito 1 \\
\hline $\begin{array}{c}\text { Mezclado } \\
\text { producto final) }\end{array}$ & 272,63 & 11 & 1 & Carrito 2 \\
\hline $\begin{array}{c}\text { Tamizado } \\
\text { Envasado }\end{array}$ & 267,06 & 11 & 1 & Carrito 2 \\
\hline con frascos & 272,63 & 11 & 1 & Carrito 3 \\
\hline
\end{tabular}

Elaboración propia

Una caja de frascos vacíos contiene 24 unidades y el peso unitario de cada frasco es de 224 gramos.

Con estos datos, se determinó las áreas que se necesita para cada punto de espera y se comparó con el 30\% del área gravitacional de su área de trabajo. 
Tabla 5.15

Análisis de punto de espera para Guerchet

\begin{tabular}{|c|c|c|c|c|c|}
\hline $\mathbf{N}^{\circ}$ & Punto de espera & Área por unidad & Área total & $\begin{array}{c}\text { 30\% del área } \\
\text { gravitacional } \\
\text { de trabajo }\end{array}$ & $\begin{array}{c}\text { iNecesita } \\
\text { incluirse en } \\
\text { Guerchet? }\end{array}$ \\
\hline 1 & Selección & 1 Parihuela: $1,2 \mathrm{~m} 2$ & $2,4 \mathrm{~m}^{2}$ & $3,10 \mathrm{~m} 2$ & SI \\
\hline 2 & Lavado & 1 Parihuela: $1,2 \mathrm{~m} 2$ & $1,2 \mathrm{~m}^{2}$ & $1,30 \mathrm{~m} 2$ & SI \\
\hline 3 & Cocción & 1 Parihuela: $1,2 \mathrm{~m} 2$ & $1,2 \mathrm{~m}^{2}$ & $1,04 \mathrm{~m} 2$ & SI \\
\hline 4 & Secado & 1 Parihuela: $1,2 \mathrm{~m} 2$ & $1,2 \mathrm{~m}^{2}$ & $4,2 \mathrm{~m} 2$ & NO \\
\hline 8 & Molienda & 1 Parihuela: $1,2 \mathrm{~m} 2$ & $1,2 \mathrm{~m}^{2}$ & $4,84 \mathrm{~m} 2$ & NO \\
\hline 6 & Tamizado & 1 Parihuela: $1,2 \mathrm{~m} 2$ & $1,2 \mathrm{~m}^{2}$ & $0,30 \mathrm{~m} 2$ & SI \\
\hline 7 & Mezclado & 1 Parihuela: $1,2 \mathrm{~m} 2$ & $1,2 \mathrm{~m}^{2}$ & $4,84 \mathrm{~m} 2$ & NO \\
\hline
\end{tabular}

Elaboración propia

A continuación se presenta el Tabla con el cálculo de superficies con el método de Guerchet: 


\section{Figura 5.12}

\section{Cálculo de superficies por el método de Guerchet}

\begin{tabular}{|c|c|c|c|c|c|c|c|c|c|c|c|c|}
\hline ELEMENTO FIJOS & $\mathrm{L}$ & A & $\mathrm{h}$ & $\mathrm{N}$ & $\mathrm{n}$ & Ss & $\mathrm{Sg}$ & $\mathrm{Se}$ & ST & Ssxn & Ssxnxh & Ajuste \\
\hline \multicolumn{13}{|l|}{ AREA DE SELECCIÓN } \\
\hline MESA DE SELECCIÓN & 1.55 & 1.00 & 1.20 & 2 & 1 & 1.55 & 3.10 & 3.01 & 7.66 & 1.55 & 1.86 & \multirow{3}{*}{$5 \times 3$} \\
\hline BALANZA & 0.40 & 0.61 & 0.95 & 1 & 1 & 0.24 & 0.24 & 0.32 & 0.80 & 0.24 & 0.23 & \\
\hline PUNTO DE ESPERA 1 & 1.20 & 1.00 & 1.00 & 0 & 2 & 1.20 & 0.00 & 0.78 & 3.95 & 2.40 & 2.40 & \\
\hline \multicolumn{13}{|l|}{ AREA DE LAVADO } \\
\hline LAVADORA & 1.30 & 1.00 & 1.25 & 1 & 1 & 1.30 & 1.30 & 1.68 & 4.28 & 1.30 & 1.63 & \multirow{2}{*}{$3 \times 3$} \\
\hline PUNTO DE ESPERA 2 & 1.20 & 1.00 & 1.00 & 0 & 1 & 1.20 & 0.00 & 0.78 & 1.98 & 1.20 & 1.20 & \\
\hline \multicolumn{13}{|l|}{ AREA DE COCCIÓN } \\
\hline HORNO & 0.80 & 0.65 & 0.95 & 2 & 1 & 0.52 & 1.04 & 1.01 & 2.57 & 0.52 & 0.49 & \multirow{2}{*}{$2 \times 3$} \\
\hline PUNTO DE ESPERA 3 & 1.20 & 1.00 & 1.00 & 0 & 1 & 1.20 & 0.00 & 0.78 & 1.98 & 1.20 & 1.20 & \\
\hline \multicolumn{13}{|l|}{ AREA DE SECADO } \\
\hline SECADORA & 1.35 & 0.70 & 0.90 & 1 & 1 & 0.95 & 0.95 & \begin{tabular}{l|l|}
1.22 \\
\end{tabular} & 3.11 & 0.95 & 0.85 & $1 \times 3$ \\
\hline \multicolumn{13}{|l|}{ AREA DE MOLIENDA } \\
\hline MOLINO & 0.65 & 0.30 & 0.45 & 4 & 1 & 0.20 & 0.78 & \begin{tabular}{l|l}
0.63 \\
\end{tabular} & 1.61 & 0.20 & 0.09 & $1 \times 3$ \\
\hline \multicolumn{13}{|l|}{ AREA DE MEZCLADO } \\
\hline MEZCLADORA & 1.78 & 0.68 & 1.70 & 4 & 1 & 1.21 & 4.84 & 3.91 & 9.97 & 1.21 & 2.06 & $4 \times 3$ \\
\hline \multicolumn{13}{|l|}{ AREA DE TAMIZADO } \\
\hline TAMIZADORA & 0.60 & 0.50 & 1.10 & 1 & 1 & 0.30 & 0.30 & 0.39 & 0.99 & 0.30 & 0.33 & \multirow{2}{*}{$2 \times 3$} \\
\hline PUNTO DE ESPERA 4 & 1.20 & 1.00 & 1.00 & 0 & 2 & 1.20 & 0.00 & 0.78 & 3.95 & 2.40 & 2.40 & \\
\hline \multicolumn{9}{|l|}{ AREA DE ENVASADO } & \multicolumn{4}{|c|}{ 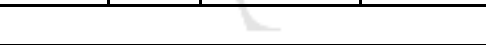 } \\
\hline MESAS DE ENVASADO & 1.55 & 1.00 & 1.20 & 4 & 1 & 1.55 & 6.20 & 5.01 & 12.76 & 1.55 & 1.86 & \multirow{2}{*}{$5 \times 4$} \\
\hline PUNTO DE ESPERA 5 & 1.20 & 1.00 & 1.00 & 0 & 2 & 1.20 & 0.00 & 0.78 & 3.95 & 2.40 & 2.40 & \\
\hline \multicolumn{9}{|c|}{ MÍNIMO $\left(\mathrm{m}^{2}\right)$} & \multirow{2}{*}{\multicolumn{3}{|c|}{\begin{tabular}{l|l|l|l}
59.55 & 17.41 & 19.00 \\
\end{tabular}}} & \\
\hline ELEMENTOS MÓVILES & $\mathrm{L}$ & $A$ & $\mathrm{~h}$ & $\mathrm{~N}$ & $\mathrm{n}$ & Ss & $\mathrm{Sg}$ & $\mathrm{Se}$ & & & & \\
\hline MONTACARGA & 1.61 & 1.00 & 1.50 & - & 2 & 1.61 & - & - & - & 3.22 & 4.83 & \\
\hline OPERARIOS & - & - & 1.65 & - & 7 & 0.50 & - & - & - & 3.50 & 5.78 & \\
\hline ELEMENTOS DE ACARREO & 0.60 & 1.05 & 0.66 & - & 3 & 0.50 & - & - & - & 1.50 & 0.99 & \\
\hline 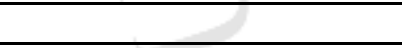 & & & & & & & & & & 8.22 & 11.60 & \\
\hline hEM & 1.41 & & & & & & & & & & & \\
\hline $\mathrm{hEE}$ & 1.09 & & & & & & & & & & & \\
\hline $\mathrm{K}$ & 0.65 & & & & & & & & & & & \\
\hline
\end{tabular}

Elaboración propia

Dónde:

L : Largo

Ss :Superficie estática

A : Ancho

$\mathrm{Sg} \quad$ : Superficie gravitacional

$\mathrm{H}$ : Altura

Se : Superficie evolutiva

$\mathrm{N} \quad$ : Número de lados que puede utilizarse

St : Superficie total

$\mathrm{N} \quad$ : número de elementos

Una vez hallada la superficie total, podemos establecer que el espacio mínimo para el área de producción es de $59,55 \mathrm{~m}^{2}$, sin embargo, realizando un ajuste a la superficie de cada área se podría obtener un tamaño de $86 \mathrm{~m}^{2}$. 
Aplicando la siguiente fórmula, se obtendrá las dimensiones del área:

$$
A=L x \frac{L}{2}
$$

Siendo el área de $86 \mathrm{~m}^{2}$, las dimensiones son las siguientes:

$\begin{array}{lll}\mathrm{L} & : \text { Largo } & =13,11 \mathrm{~m} \\ \mathrm{~L} / 2 & : \text { Ancho } & =6,56 \mathrm{~m}\end{array}$

Otras áreas que también deben dimensionarse son: almacén de materia prima, almacén de productos terminados, depósito de herramientas, área administrativa, comedor, laboratorio, servicios higiénicos y el patio de maniobras.

\section{Almacén de materia prima}

El almacén de materias primas deberá contar con un espacio refrigerado para poder almacenar la sangre de pollo, ya que este al ser un compuesto orgánico debe almacenarse a temperaturas por debajo de los $0^{\circ} \mathrm{C}$; el cacao, el fósforo y el magnesio serán guardados en sacos de 25 Kilogramos (0,5 m de largo x 0,4 metros de ancho x 0,125 metros de alto) y los frascos serán almacenados en cajas $(0,32 \mathrm{~m}$ de largo x 0,27 metros de ancho x 0,21 metros de alto). La programación del almacenamiento será semanal y tendrá que soportar las siguientes capacidades:

\section{Tabla 5.16}

\section{Requerimiento semanal de materiales al año 5}

\begin{tabular}{|l|c|c|c|c|}
\cline { 2 - 5 } \multicolumn{1}{c|}{} & Unidades & $\begin{array}{c}\text { Requerimiento } \\
\text { anual }\end{array}$ & $\begin{array}{c}\text { Requerimiento } \\
\text { mensual }\end{array}$ & $\begin{array}{c}\text { Requerimiento } \\
\text { semanal }\end{array}$ \\
\hline Sangre de pollo & $\mathrm{Kg}$ & 7.098 & 592 & 137 \\
\hline Cacao & $\mathrm{Kg}$ & 91.157 & 7.596 & 1.754 \\
\hline Fósforo & $\mathrm{Kg}$ & 1.983 & 165 & 38 \\
\hline Magnesio & $\mathrm{Kg}$ & 1.983 & 165 & 38 \\
\hline Frascos & Unidad & 396.644 & 33.054 & 7.634 \\
\hline Etiquetas & Unidad & 396.644 & 33.054 & 7.634 \\
\hline
\end{tabular}

Elaboración propia

La sangre de pollo se almacenará en una congeladora con una capacidad aproximada de 500 kilogramos. Los sacos y las cajas se apilarán en parihuelas, cuya medida estándar es de 
1,20 $\mathrm{m}^{2}$, con capacidad para 24 sacos de $25 \mathrm{Kg}$ apilados en una base de 6 sacos y 4 niveles, o 39 cajas apiladas con capacidad para 24 unidades, en una base de 13 cajas y 3 niveles, por ello se hará el cálculo de parihuelas necesarias:

Tabla 5.17

Requerimiento de parihuelas para almacén de Materia Prima al año 5

\begin{tabular}{|l|c|c|c|c|c|c|}
\cline { 2 - 7 } \multicolumn{1}{c|}{} & $\begin{array}{c}\text { Requerimiento } \\
\text { semanal }\end{array}$ & Unidades & \multicolumn{2}{|c|}{ \# sacos o cajas } & \# parihuelas & $\begin{array}{c}\text { Requerimiento } \\
\text { final de } \\
\text { parihuelas }\end{array}$ \\
\hline sangre de pollo & 137 & $\mathrm{Kg}$ & - & - & - & \\
\hline cacao & 1.754 & $\mathrm{Kg}$ & 71 & sacos & 2,92 & 3 \\
\hline Fósforo & 38 & $\mathrm{Kg}$ & 2 & sacos & 0,06 & 1 \\
\hline magnesio & 38 & $\mathrm{Kg}$ & 2 & sacos & 0,06 & 1 \\
\hline frascos & 7.634 & Unidad & 318 & cajas & 8,2 & 9 \\
\hline etiquetas & 7.634 & Unidad & 318 & cajas & 8,2 & 9 \\
\hline
\end{tabular}

Elaboración propia

El almacén de materias primas tendrá que abarcar 23 parihuelas de $1,2 \mathrm{~m}^{2}$ y un congelador. Las dimensiones del congelador son 3 metros de largo por 1,5 metros de ancho por 1,5 metros de alto.

Por lo tanto, el área mínimo del almacén de materias primas será igual a:

$$
\left(23 \times 1,2 \mathrm{~m}^{2}\right)+\left(4,5 \mathrm{~m}^{2}\right)=32.1 \mathrm{~m}^{2}
$$

\section{Almacén de producto terminado}

En el almacén de productos terminados, como su nombre lo indica, se hará el almacenamiento del producto final, este tendrá una programación de 2 días, por lo que se realizará el cálculo de cuantas parihuelas se necesitaran para el almacenamiento: 
Tabla 5.18

Requerimiento de parihuelas para almacén de Productos Terminados al año 5

\begin{tabular}{|c|c|c|c|c|c|c|c|}
\cline { 2 - 7 } \multicolumn{1}{c|}{} & $\begin{array}{c}\text { Requerimiento } \\
\text { anual }(\mathrm{Kg})\end{array}$ & $\begin{array}{c}\text { Requerimiento } \\
\text { mensual(Kg) }\end{array}$ & $\begin{array}{c}\text { Requerimiento } \\
\text { semanal(Kg) }\end{array}$ & $\begin{array}{c}\text { Requerimiento } \\
\text { para 2 días(Kg) }\end{array}$ & $\begin{array}{c}\# \\
\text { unidades }\end{array}$ & $\begin{array}{c}\# \text { cajas } \\
\text { necesarias }\end{array}$ & $\begin{array}{c}\# \\
\text { parihuelas }\end{array}$ \\
\hline $\begin{array}{c}\text { Producto } \\
\text { terminado }\end{array}$ & 396.644 & 33.054 & 7.634 & 2.181 & 8.724 & 364 & 10 \\
\hline
\end{tabular}

Elaboración propia

El almacén de productos terminados tendrá que tener en su disposición de cuatro parihuelas.

$$
10 \times 1,2 \mathrm{~m}^{2}=12 \mathrm{~m}^{2}
$$

Por lo tanto, el área mínima del almacén de productos terminados será de $12 \mathrm{~m}^{2}$

\section{Depósito de herramientas}

En esta área se usarán armarios para guardar las herramientas necesarias para realizar algún tipo de mantenimiento o reparación a las máquinas, también se guardaran otros instrumentos de trabajo como guantes de seguridad, guantes, mandiles, entre otros.

\section{Administración}

En esta área se encontraran el gerente general, jefe de planta, jefe comercial y la secretaria, por ello debe estar acondicionada de tal forma que permita a cada uno desempeñar sus funciones cómodamente, por lo que se contará con una sala de reuniones para que se pueda coordinar temas en equipo y además con mobiliarios como sillas, sofás y mesas para cualquier tipo de actividad o visita de algún cliente o invitado.

A continuación se muestra un Tabla con la suma de las áreas mínimas para las estaciones de trabajo obtenidas del libro de Konz, Diseño de sistemas de trabajo: 
Tabla 5.19

Determinación de los espacios administrativos

\begin{tabular}{|l|c|}
\hline \multicolumn{1}{|c|}{ Puesto } & Área mínima $\left(\mathrm{m}^{2}\right)$ \\
\hline Gerente general & 18,00 \\
\hline Jefe de planta & 10,00 \\
\hline Jefe comercial & 10,00 \\
\hline Secretaria & 4,50 \\
\hline Total & 42,50 \\
\hline
\end{tabular}

Fuente: Konz, 1994

Elaboración propia

El espacio mínimo requerido para el área administrativa es de $42.50 \mathrm{~m}^{2}$.

\section{Comedor}

En esta área, el personal dispondrá de un espacio para ingerir sus alimentos, estará equipada de:

- Cocina

- Fregaderos y lavavajillas para lavar los platos y/o recipientes

- Zona de microondas

- Una mesa y sillas

- Tacho de basura

En el comedor tendrá una mesa donde se encontrarán ubicadas 6 personas y adicionalmente habrá 2 cocineros. Por ello, el área mínima para el comedor será:

$$
8 \times 1,58 m^{2}=12,64 m^{2}
$$

El requerimiento mínimo para el comedor será de $12,64 \mathrm{~m}^{2}$

\section{Laboratorio de calidad}

Está área contará con el equipo necesario para poder realizar las pruebas y así se pueda elaborar los documentos necesarios para acreditar la calidad del producto, es por ellos que tendrá principalmente una mesa de trabajo y un lavatorio para lavarse las manos antes de realizar cualquier prueba. El área mínima para esta área será de $4 \mathrm{~m}^{2}$ 


\section{Servicios higiénicos}

Se contará con inodoros, urinarios para el caso de los hombres, espejos, dispensadores de jabón y de papel. La cantidad de inodoros y lavabos se establecerá de acuerdo a los estándares de OSHA, que dice que para empresas de 1 a 15 trabajadores se debe contar por lo menos con un baño, sin embargo, para el caso del proyecto se instalará 2 baños ( 1 de varones y 1 de damas) con 2 inodoros cada uno.

\section{Patio de maniobras}

Esta área se encuentra en el frontis de la planta, en él se encontrará la puerta de acceso, la entrada de vehículos de proveedores, clientes y personal, estacionamientos y una gaceta de seguridad.

\subsubsection{Dispositivos de seguridad industrial y señalización}

Como dispositivos de seguridad se emplearán extintores para poder usarlo como primer medio de desactivación de un posible incendio, asimismo se podrá hacer uso de una manguera. Se capacitará a los trabajadores para prevenir cualquier evento de esta naturaleza ya que esta manera se minimiza el riesgo.

A continuación se presenta una tabla en el cual se muestra los tipos de extintores que se usarán en la empresa:

Tabla 5.20

Selección de tipo de extintor

\begin{tabular}{|c|c|c|}
\hline Material & Tipo de fuego & Agente extintor \\
\hline Papel, trapos, cartón & A & Agua \\
Pesinfectantes & $\mathrm{B}$ & Polvo químico seco químico seco \\
\hline $\begin{array}{c}\text { Equipos eléctricos, cableado } \\
\text { y tableros }\end{array}$ & $\mathrm{C}$ & $\begin{array}{l}\text { Polvo químico seco } \\
\text { Dióxido de carbono }\end{array}$ \\
\hline Metales combustibles & $\mathrm{D}$ & $\begin{array}{l}\text { Dióxido de carbono } \\
\text { Polvo químico seco }\end{array}$ \\
\hline Grasas de cocina & $\mathrm{K}$ & Acetato de potasio \\
\hline
\end{tabular}

Fuente: Asfahl, C. Ray, 2000

Elaboración propia 
Se colocarán diferenciales térmicos para evitar que existan sobrecargas de energía, además se hará la instalación de un panel eléctrico de donde se controlará el fluido de corriente.

En el piso se marcará por donde deberán pasar los equipos de acarreo, es decir que por los obreros o algún otro miembro de la organización deberá pasar por la zona marcada.

Finalmente, se colocarán carteles en los cuales se señalará las salidas de emergencia, los equipos de protección necesarios para entrar a cada zona como gorro, guantes, zapatos con punta de metal o mascarillas.

\section{Figura 5.13}

\section{Señales que indican uso de equipos obligatorios}

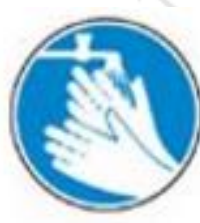

1

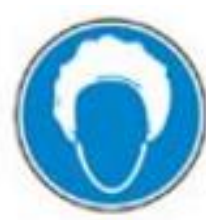

2

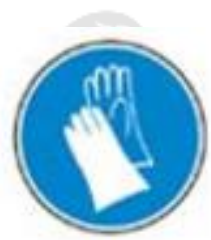

3

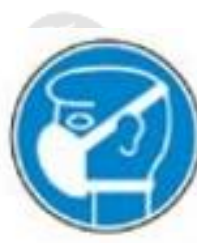

4

Fuente: Seton, s.f

Elaboración propia

Dónde:

1: Obligatorio lavarse las manos

2: Obligatorio el uso de gorro

3: Obligatorio el uso de guantes

4: Obligatorio el uso de mascarilla

\subsubsection{Disposición general}

A continuación se realizará el diagrama relacional de actividades, en el cual se determinará qué áreas deberían estar cerca y cuáles no. La lista de motivas por la cual se explica su cercanía es la siguiente:

1. Secuencia del proceso

2. Evitar ruidos

3. Acceso a herramientas para el proceso 
4. Acceso a servicios higiénicos

5. Facilitar el control de ingresos y salidas a la planta

6. Evitar la contaminación del producto

Además se consideró que toda la línea del proceso debería estar necesariamente cerca para evitar pérdida de tiempo y un mayor esfuerzo de los operarios, asimismo, las actividades productivas del proceso no deberían estar próximas a las oficinas.

Con la información mencionada, se establecen los pares ordenados de la tabla relacional:

Tabla 5.21

Pares ordenados de la tabla relacional

\begin{tabular}{|l|c|c|c|}
\hline \multicolumn{5}{|c|}{ Pares Ordenados } \\
\hline \multicolumn{1}{|c|}{ A } & E & \multicolumn{1}{c|}{ I } & X \\
\hline$(1,2)$ & $(10,11)$ & $(15,16)$ & $(5,16)$ \\
\hline$(2,3)$ & & & $(6,16)$ \\
\hline$(3,4)$ & & & $(7,16)$ \\
\hline$(4,5)$ & & & $(8,16)$ \\
\hline$(5,6)$ & & & $(9,16)$ \\
\hline$(6,7)$ & & & $(12,15)$ \\
\hline$(7,8)$ & & & \\
\hline$(8,9)$ & & & \\
\hline$(9,10)$ & & & \\
\hline$(1,13)$ & & & \\
\hline$(10,13)$ & & & \\
\hline$(11,13)$ & & & \\
\hline
\end{tabular}

Elaboración propia

Con los pares ordenados establecidos, se procede a desarrollar la tabla relacional de actividades y el diagrama relacional de actividades, para ello se usará la siguiente leyenda: 


\section{Figura 5.14}

\section{Leyenda para la tabla y diagrama relacional de actividades}

\begin{tabular}{|c|c|c|c|}
\hline CODIGO & PROXIMIDAD & COLOR & No DE LINEAS \\
\hline A & Absolutamente necesario & Rojo & 4 rectas \\
\hline $\mathrm{E}$ & Especialmente necesario & Amarillo & 3 rectas \\
\hline 1 & Importante & Verde & 2 rectas \\
\hline $\mathrm{O}$ & Normal & Azul & 1 recta \\
\hline $\mathrm{U}$ & Sin importancia & & \\
\hline$x$ & No deseable & Plomo & 1 zig-zag \\
\hline$x x$ & Altamente no deseable & Negro & $2 z i g-z a g$ \\
\hline
\end{tabular}

Fuente: Díaz, B., Jarufe, B., \& Noriega, M., 2007

\section{Figura 5.15}

Tabla relacional de actividades

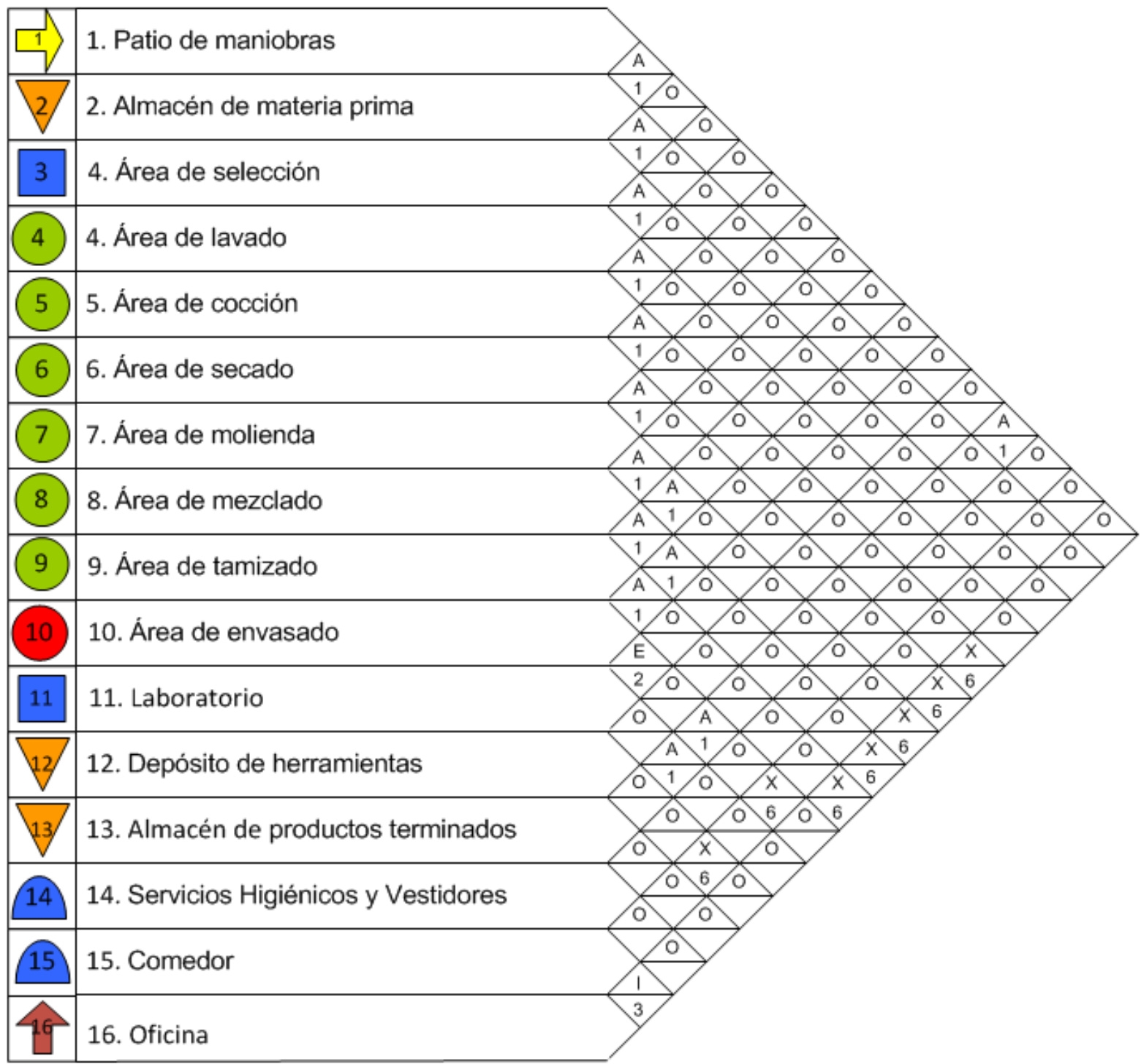

Elaboración propia 
Figura 5.16

Diagrama relacional de actividades

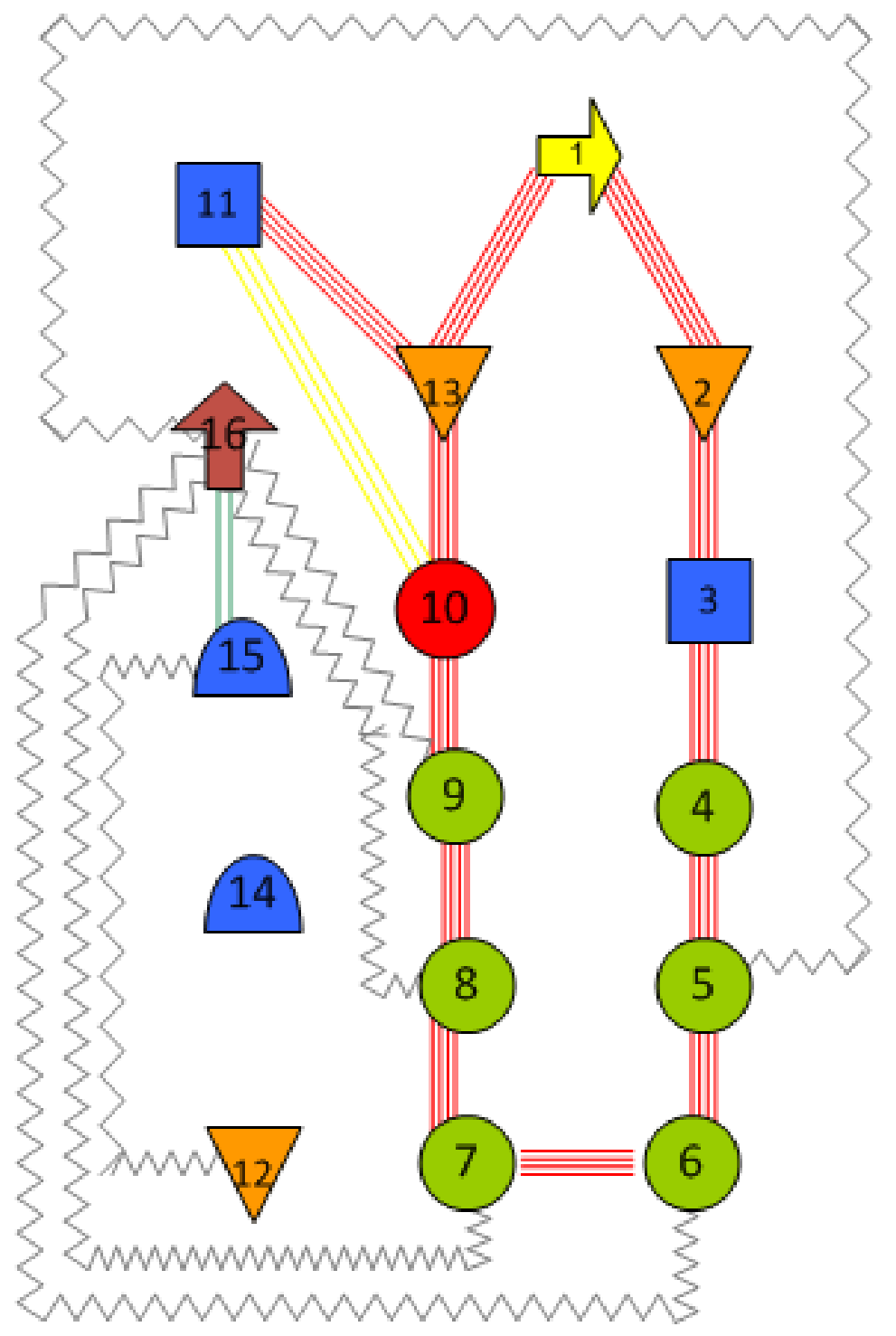

Elaboración propia 
Figura 5.17

\section{Diagrama relacional de espacios}

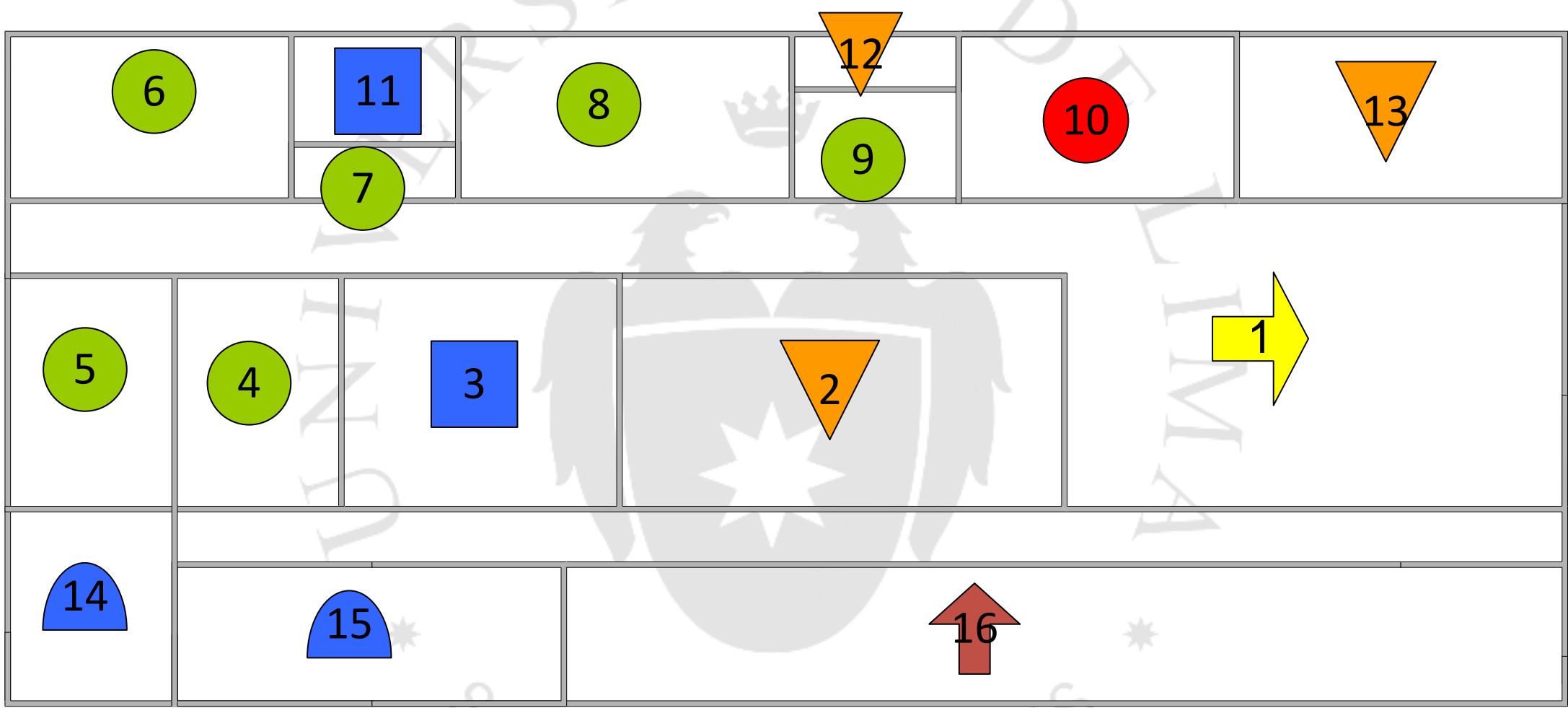

Elaboración propia 


\subsubsection{Disposición de detalle}

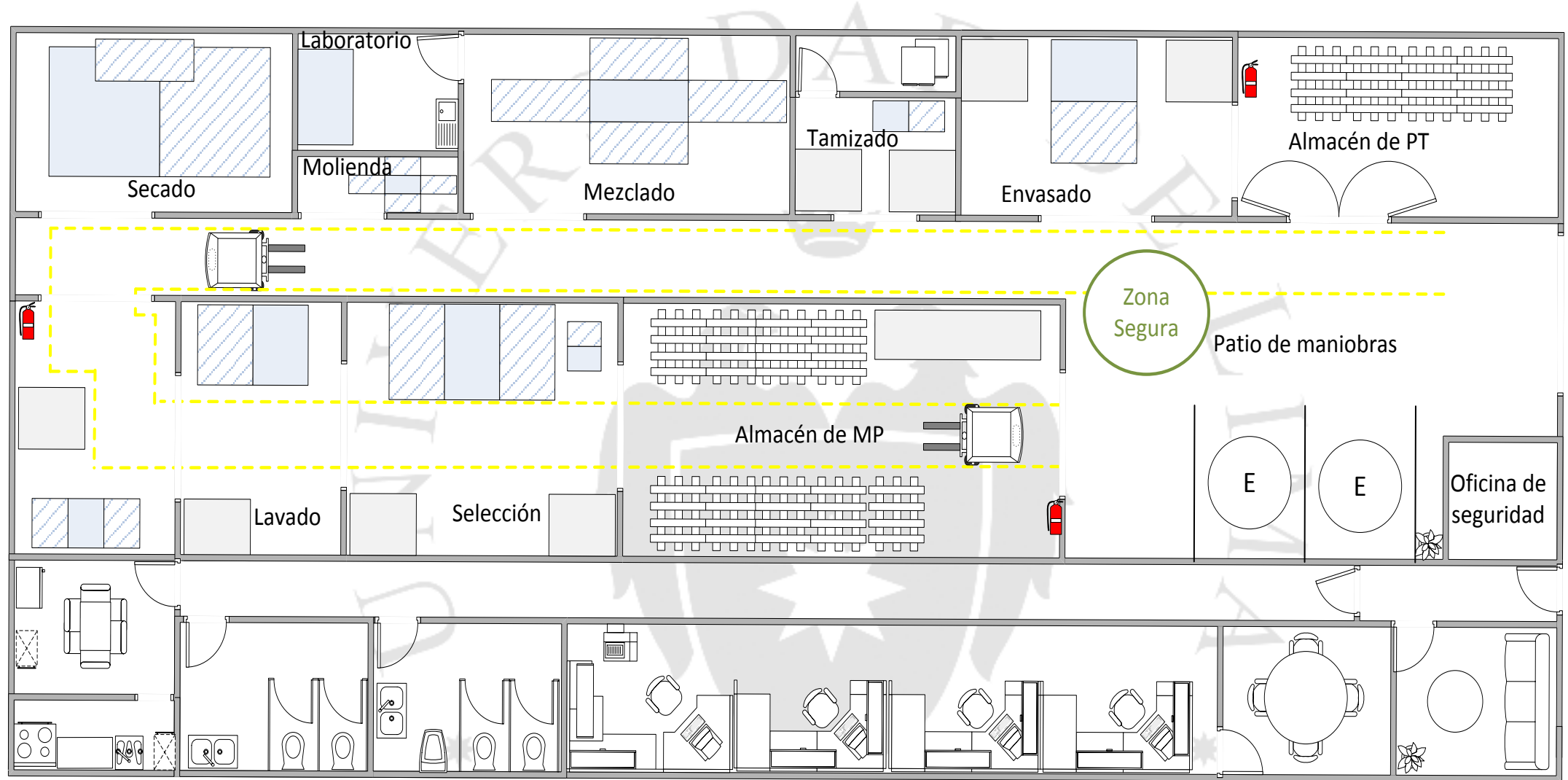

$\Leftrightarrow \quad$ UNIVERSIDAD DE LIMA $\quad$ PLANO DE PLANTA DE PRODUCCIÓN DE COMPLEMENTO VITAMÍNICO ELABORADO POR: Renato López y Renzo Urrelo CURSO: Seminario de Investigación II

Elaboración propia 


\subsection{Cronograma de implementación del proyecto}

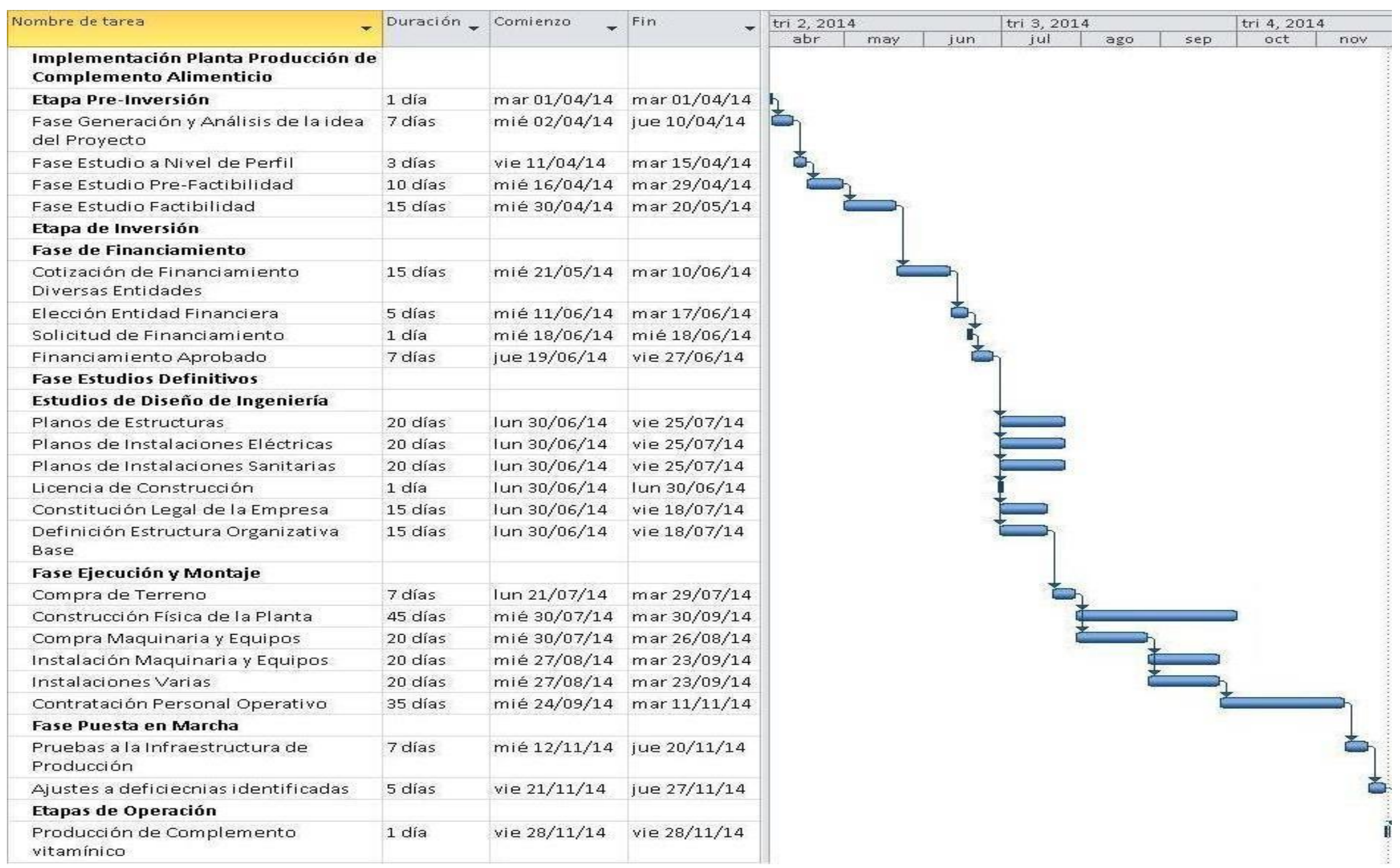

Elaboración propia 


\section{CAPÍTULO VI. ORGANIZACIÓN Y ADMINISTRACIÓN}

\subsection{Formación de la organización empresarial}

La organización se constituirá como Sociedad Anónima Cerrada (S.A.C), en donde el capital se encontrará representado por acciones y se pueda separar la gestión de la empresa de los bienes individuales de cada individuo.

\subsection{Requerimiento de personal directivo, administrativo y de servicios}

El personal dentro de la organización deberá cumplir con ciertas funciones, por ello, a continuación se mencionará el puesto y se detallará sus respectivas funciones:

\section{Gerente general}

Es el encargado de manejar, ordenar, coordinar y gestionar las actividades para que el negocio vaya por buen camino. Deberá desarrollar las metas y objetivos a corto y largo plazo, ello conlleva a que realice evaluaciones periódicas para hacer corregir los errores en lo que respecta producción, mercadeo y ventas. Es el responsable de la empresa frente a cualquier situación legal que pueda afrontar.

Asimismo, al ser una organización de pocos trabajadores, el gerente general se encargará de las funciones de contratación, capacitaciones, entre otros.

\section{Jefe de planta}

Es el encargado de planificar, controlar y programar el correcto proceso productivo, es decir, de la totalidad de las operaciones en planta. Además, es el encargado de velar por la seguridad de los obreros y de reportar al gerente general el registro de incidencias.

\section{Jefe comercial}

Es en encargado de supervisar todo lo referido a las ventas del producto, es decir, supervisa como van las ventas, coordina con los puntos de venta la llegada del producto, se encarga de las cobranzas, con la finalidad de mantener y aumentar las ventas. 


\section{Inspector de calidad}

Es el encargado de examinar el producto fabricado y el proceso productivo para corroborar y garantizar que se cumpla con todos los estándares establecidos.

\section{Secretaria}

Es el encargado de llevar la agenda del gerente general, apoyarlo con la recepción y redacción de cartas, contestar correos electrónicos y atender y realizar llamadas.

\section{Obreros}

Es el encargado del manejo de materiales necesarios para la transformación en el producto final. Trabaja en la línea productiva y está a cargo del jefe de planta.

\subsection{Estructura organizacional}

La estructura organizacional de la empresa será como se muestra a continuación:

\section{Figura 6.1}

\section{Organigrama}

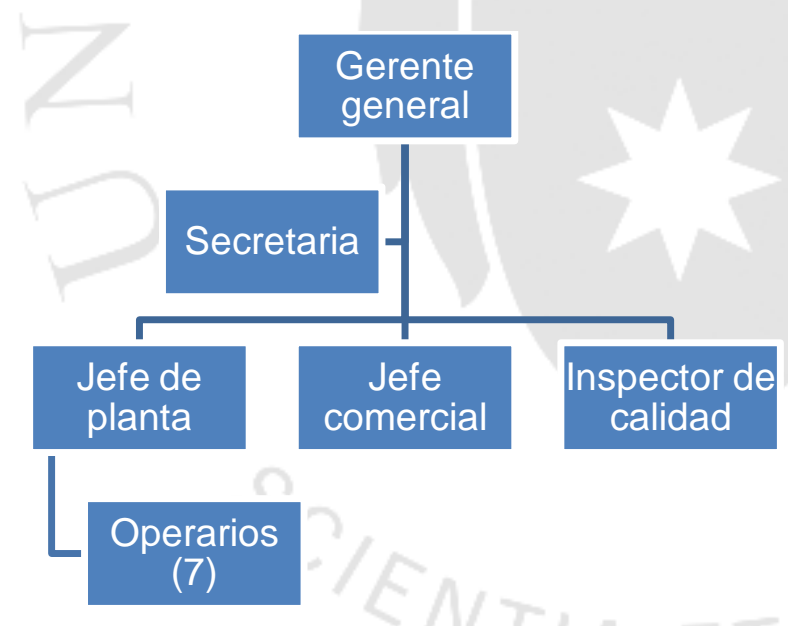

Elaboración propia

En la figura 6.1 se puede apreciar que el jefe de planta, el jefe comercial y el inspector de calidad le reportarán directamente al gerente general sobre los acontecimientos que ocurran en sus respectivas áreas.

No se consideró tener un encargado de recursos humanos, ya que al ser una organización con pocas personas (12), quien se encargará de ese rol será el gerente general. 


\section{CAPÍTULO VII. ASPECTOS ECONÓMICOS Y FINANCIEROS}

\subsection{Inversiones}

\subsubsection{Estimación de las inversiones de largo plazo (tangibles e intangibles)}

Para la estimación del capital de trabajo, se empleará la metodología de prorrateo de gastos diarios del primer año de funcionamiento del proyecto, para ello se empleó los siguientes datos:

Tabla 7.1

Prorrateo de gastos diarios

\begin{tabular}{|c|c|}
\hline Rubro & Monto en soles (S/.) \\
\hline Materia prima & 606.736 \\
\hline Salarios & 214.500 \\
\hline Sueldos & 213.000 \\
\hline Gastos fijos & 18.043 \\
\hline Total & $\mathbf{1 . 0 5 2 . 2 7 9}$ \\
\hline
\end{tabular}

Elaboración: Propia

Los costos de materia prima incluyen los costos de la materia prima, insumos y materiales para la elaboración del producto. Asimismo, el salario hace referencia al sueldo que recibe las áreas administrativas, por otra parte los salarios corresponden a la gente encargada de la producción.

El valor obtenido de 1.052.279 corresponde al gasto anual del primer año, pero para calcular el capital de trabajo se requiere el costo diario, que vendría a ser:

$$
\text { Gasto diario }=\frac{1.052 .279}{365}=2.883 \mathrm{~S} /
$$




\subsubsection{Estimación de las inversiones de corto plazo (Capital de trabajo)}

Del punto 7.1.1, se obtuvo que el valor de los gastos diarios es 2.883 soles. Para el cálculo del capital de trabajo se consideró lo siguiente:

- Periodo promedio de cobro (PPC) : 30 días

- Periodo promedio de ingresos (PPI): 45 días

- Periodo promedio de pago (PPP): 30 días

Con los datos anteriores se estimará el ciclo de caja de la siguiente manera:

$$
\text { Ciclo de caja }=P P C+P P I-P P P=45 \text { días }
$$

Con 45 días de ciclo de caja se procede a hallar el capital de trabajo:

$$
\text { Capital de trabajo }=\text { Gastos diarios } x \text { Ciclo de caja } \text {. }
$$

$$
\text { Capital de trabajo }=2.883 \times 45=129.733 \mathrm{~S} / \text {. }
$$

Con la estimación se obtiene un valor de S/. 129.733 como capital de trabajo.

\subsection{Costos de producción}

\subsubsection{Costos de las materias primas}

Dado nuestros programas de producción a continuación se presentan los requerimientos de insumos en soles.

Tabla 7.2

Costos de Materias primas e insumos

\begin{tabular}{|c|c|c|c|c|c|c|}
\hline Costos MP & S/. /Kg & Año 2014 & Año 2015 & Año 2016 & Año 2017 & Año 2018 \\
\hline Sangre de pollo & 3 & 9.500 & 12.765 & 14.846 & 16.464 & 17.849 \\
\hline Cacao & 8 & 380.002 & 510.617 & 593.834 & 658.561 & 713.957 \\
\hline Magnesio & 15,4 & 16.256 & 21.843 & 25.403 & 28.172 & 30.542 \\
\hline Fósforo & 22,4 & 23.645 & 31.772 & 36.950 & 40.977 & 44.424 \\
\hline \multicolumn{2}{|r|}{ TOTAL } & $\mathbf{4 2 9 . 4 0 2}$ & $\mathbf{5 7 6 . 9 9 7}$ & $\mathbf{6 7 1 . 0 3 3}$ & $\mathbf{7 4 4 . 1 7 3}$ & $\mathbf{8 0 6 . 7 7 2}$ \\
\hline
\end{tabular}

Elaboración propia 


\subsubsection{Costos de la mano de obra directa}

La mano de obra directa, que participa en la fabricación y elaboración del producto, está conformada por los operarios, Jefe de planta e Inspector de calidad, los cuales se les considero un total de 14 salarios al año, además de 1 salario más por CTS.

\section{Tabla 7.3}

\section{Mano de Obra Directa}

\begin{tabular}{|l|c|c|c|c|}
\hline \multicolumn{1}{|c|}{ Personal } & Cantidad & $\begin{array}{c}\text { Sueldo } \\
\text { Unitario(S/.) }\end{array}$ & $\begin{array}{c}\text { Sueldo/Mes } \\
\text { (S/.) }\end{array}$ & $\begin{array}{c}\text { Sueldo Anual } \\
(\mathbf{S} / .)\end{array}$ \\
\hline Operarios & 7 & 900 & 6.300 & 94.500 \\
\hline Jefe de Planta & 1 & 5.000 & 5.000 & 75.000 \\
\hline Inspector Calidad & 1 & 3.000 & 3.000 & 45.000 \\
\hline \multicolumn{4}{|c|}{ Total } & $\mathbf{2 1 4 . 5 0 0}$ \\
\hline
\end{tabular}

Elaboración propia

Se consideró el inspector de calidad, dentro de la mano de obra directa ya que es indispensable que el producto sea revisado y aprobado por este, antes de llegar a manos de nuestros consumidores.

\subsubsection{Costo indirecto de fabricación (materiales indirectos, mano de obra indirecta y costos generales de planta)}

Dado el nivel de producción, se presentan el costo de los materiales indirectos de fabricación:

\section{Tabla 7.4}

Costos de los materiales indirectos de fabricación

\begin{tabular}{|c|c|c|c|c|c|c|}
\hline $\begin{array}{c}\text { Costos } \\
\text { Materiales }\end{array}$ & S/. Unid & Año 2014 & Año 2015 & Año 2016 & Año 2017 & Año 2018 \\
\hline Frasco & 0,57 & 120.334 & 161.695 & 188.048 & 208.544 & 226,087 \\
\hline Etiquetado & 0,27 & 57.000 & 76.593 & 89.075 & 98.784 & 107,094 \\
\hline \multicolumn{2}{|c|}{ TOTAL } & $\mathbf{1 7 7 . 3 3 4}$ & $\mathbf{2 3 8 . 2 8 8}$ & $\mathbf{2 7 7 . 1 2 3}$ & $\mathbf{3 0 7 . 3 2 8}$ & $\mathbf{3 3 3 . 1 8 0}$ \\
\hline
\end{tabular}

Elaboración propia 
La mano de obra indirecta se encuentra conformada por los empleados que no participan directamente en la fabricación del producto. Está conformada por el Gerente general, Secretaria y Jefe Comercial, los cuales se les considero un total de 14 salarios al año, además de 1 salario más por CTS.

\section{Tabla 7.5}

\section{Mano de Obra Indirecta}

\begin{tabular}{|l|c|c|c|c|}
\hline \multicolumn{1}{|c|}{ Personal } & Cantidad & $\begin{array}{c}\text { Sueldo } \\
\text { Unitario(S/.) }\end{array}$ & $\begin{array}{c}\text { Sueldo/Mes } \\
(\mathbf{S} / \text {.) }\end{array}$ & $\begin{array}{c}\text { Sueldo Anual } \\
(\mathbf{S} / \text {.) }\end{array}$ \\
\hline Gerente General & 1 & 8.000 & 8.000 & 120.000 \\
\hline Secretaria & 1 & 1.200 & 1.200 & 18.000 \\
\hline Jefe Comercial & 1 & 5.000 & 5.000 & 75.000 \\
\hline \multicolumn{4}{|c|}{ Total } \\
\hline
\end{tabular}

Elaboración propia

Dado el nivel de producción y los consumos de las máquinas que se emplearán en el proceso productivo, a continuación se presentan los costos de los siguientes servicios.

\section{Tabla 7.6}

\section{Costos de servicio eléctrico}

\begin{tabular}{|l|c|c|c|c|c|}
\hline \multicolumn{1}{|c|}{ Equipos } & $\mathrm{kwh}$ & $\mathrm{S} / . / \mathrm{kwh}$ & $\mathrm{h} / \mathrm{año}$ & $\begin{array}{c}\text { cargo } \\
\text { fijo(s/./año) }\end{array}$ & Total(S/.) \\
\hline Lavadora & 2 & 0,378 & 2.910 & 29.00 & 2.229 \\
\hline Moledora & 2 & 0,378 & 2.910 & 29.00 & 2.249 \\
\hline Mezcladora & 2 & 0,378 & 2.910 & 29.00 & 2.249 \\
\hline Tamizadora & 1 & 0,378 & 2.910 & 29.00 & 1.115 \\
\hline Secadora & 2 & 0,378 & 2.910 & 29.00 & 2.229 \\
\hline Horno & 4 & 0,378 & 2.910 & 29.00 & 4.458 \\
\hline Esterilizador & 2 & 0.378 & 2.910 & 29.00 & 2.429 \\
\hline & & Total & $\mathbf{1 6 . 9 5 8}$ \\
\hline
\end{tabular}

Elaboración propia 


\section{Tabla 7.7}

\section{Costos de servicio de Agua Potable}

\begin{tabular}{|l|c|c|c|c|c|c|c|}
\hline Equipos & lt/min & m3/año & h/año & $\begin{array}{c}\text { cargo } \\
\text { fijo(s/./año) }\end{array}$ & $\begin{array}{c}\text { Volumen de } \\
\text { agua(s/./m3) }\end{array}$ & $\begin{array}{c}\text { cargo } \\
\text { fijo(s/./m3) }\end{array}$ & Total(S/.) \\
\hline Lavadora & 15 & 175 & 2.910 & 57 & 716 & 312 & $\mathbf{1 . 0 8 5}$ \\
\hline
\end{tabular}

Elaboración propia

El total del costo por estos servicios sería de 18.043 soles al año, trabajando en un turno de 8 horas, 7 días a la semana.

\subsection{Presupuestos operativos}

\subsubsection{Presupuesto de ingreso por ventas}

A continuación se presenta el presupuesto de ingresos que se tiene por la venta de los productos año a año:

Tabla 7.8

Presupuestos de ingresos

\begin{tabular}{|c|c|c|c|c|c|}
\cline { 2 - 6 } \multicolumn{1}{c|}{} & Año 2014 & Año 2015 & Año 2016 & Año 2017 & Año 2018 \\
\hline Ventas & 211.112 & 283.676 & 329.908 & 365.867 & 396.643 \\
\hline P. Venta & 8,0 & 8,0 & 8,0 & 8,0 & 8,0 \\
\hline Ingreso por ventas & $\mathbf{1 . 6 8 8 . 8 9 6}$ & $\mathbf{2 . 2 6 9 . 4 0 8}$ & $\mathbf{2 . 6 3 9 . 2 6 4}$ & $\mathbf{2 . 9 2 6 . 9 3 6}$ & $\mathbf{3 . 1 7 3 . 1 4 4}$ \\
\hline
\end{tabular}

Elaboración propia

\subsubsection{Presupuesto operativo de costos}

En el presupuesto operativo de costos de materias primas, se determinó el costo total anual de producción considerando los costos variables, costos fijos, costos de mano de obra directa y los costos indirectos de fabricación que incluyen los servicios generales. 
Tabla 7.9

Costos variables de producción

\begin{tabular}{|c|c|c|c|c|c|}
\cline { 2 - 6 } \multicolumn{1}{c|}{} & Año 2014 & Año 2015 & Año 2016 & Año 2017 & Año 2018 \\
\hline Ventas & 211.112 & 283.676 & 329.908 & 365.867 & 396.643 \\
\hline C. Variable Unitario & 2,87 & 2,87 & 2,87 & 2,87 & 2,87 \\
\hline Costo Variable total & $\mathbf{6 0 5 . 8 9 1}$ & $\mathbf{8 1 4 . 1 5 0}$ & $\mathbf{9 4 6 . 8 3 6}$ & $\mathbf{1 . 0 5 0 . 0 3 8}$ & $\mathbf{1 . 1 3 8 . 3 6 5}$ \\
\hline
\end{tabular}

Elaboración propia

Tabla 7.10

Presupuesto operativo de costos de materia prima

\begin{tabular}{|l|c|c|c|c|c|}
\cline { 2 - 6 } \multicolumn{1}{c|}{} & Año 2014 & Año 2015 & Año 2016 & Año 2017 & Año 2018 \\
\hline Costo variable & 605.891 & 814.150 & 946.836 & 1.050 .038 & 1.138 .365 \\
\hline MOD & 214.500 & 214.500 & 214.500 & 214.500 & 214.500 \\
\hline CIF (agua, electricidad) & 18.043 & 18.043 & 18.043 & 18.043 & 18.043 \\
\hline Depreciación & 17.819 & 17.819 & 17.819 & 17.819 & 17.819 \\
\hline Costo operativo de MP total & $\mathbf{8 5 6 . 2 5 3}$ & $\mathbf{1 . 0 6 4 . 5 1 2}$ & $\mathbf{1 . 1 9 7 . 1 9 8}$ & $\mathbf{1 . 3 0 0 . 4 0 0}$ & $\mathbf{1 . 3 8 8 . 7 2 7}$ \\
\hline
\end{tabular}

Elaboración propia 
Tabla 7.11

Depreciación de activos fijos tangibles en producción

\begin{tabular}{|l|c|c|c|c|c|c|c|}
\hline \multicolumn{1}{|c|}{ Equipos } & $\begin{array}{c}\text { Precio } \\
\text { unitario } \\
(\mathrm{S} / .)\end{array}$ & $\begin{array}{c}\text { Vida útil } \\
(\text { Años })\end{array}$ & Año 2014 & Año 2015 & Año 2016 & Año 2017 & Año 2018 \\
\hline Lavadora & 4.170 & 5 & 834 & 834 & 834 & 834 & 834 \\
\hline Moledora & 3.900 & 5 & 780 & 780 & 780 & 780 & 780 \\
\hline Mezcladora & 8.340 & 5 & 1.668 & 1.668 & 1.668 & 1.668 & 1.668 \\
\hline Tamizadora & 5.560 & 5 & 1.112 & 1.112 & 1.112 & 1.112 & 1.112 \\
\hline Secadora & 2.688 & 5 & 538 & 538 & 538 & 538 & 538 \\
\hline Horno & 5.560 & 5 & 1.112 & 1.112 & 1.112 & 1.112 & 1.112 \\
\hline Balanza & 840 & 5 & 168 & 168 & 168 & 168 & 168 \\
\hline Esterilizador & 1.350 & 5 & 270 & 270 & 270 & 270 & 270 \\
\hline Etiquetador & 750 & 5 & 150 & 150 & 150 & 150 & 150 \\
\hline & Total (S/.) & & $\mathbf{6 . 6 3 2}$ & $\mathbf{6 . 6 3 2}$ & $\mathbf{6 . 6 3 2}$ & $\mathbf{6 . 6 3 2}$ & $\mathbf{6 . 6 3 2}$ \\
\hline
\end{tabular}

Elaboración propia

La depreciación del edificio será de 32 años y de los activos intangibles será de 10 años.

Tabla 7.12

\section{Depreciación de otros activos}

\begin{tabular}{|l|c|c|c|}
\hline \multicolumn{1}{|c|}{ Equipos } & Valor (S/.) & $\begin{array}{c}\text { Años de } \\
\text { depreciación }\end{array}$ & $\begin{array}{c}\text { Valor de } \\
\text { depreciación (S/.) }\end{array}$ \\
\hline Edificio & 70.000 & 32 & 2187,5 \\
\hline Activos intangibles & 30.000 & 10 & 3.000 \\
\hline
\end{tabular}

Elaboración propia 


\subsubsection{Presupuesto operativo de gastos}

Para el presupuesto operativo de gastos, se consideró los gastos relacionados a ventas, distribución, marketing y servicios tercerizados, además de la mano de obra indirecta.

Tabla 7.13

Presupuesto operativo de gastos de ventas

\begin{tabular}{|c|c|c|c|c|c|c|}
\hline & $\begin{array}{c}\% \text { sobre los } \\
\text { ingresos }\end{array}$ & 2014 & 2015 & 2016 & 2017 & 2018 \\
\hline Ventas & $7 \%$ & 118.223 & 158.859 & 184.748 & 204.886 & 222,120 \\
\hline Distribución & $8 \%$ & 135.112 & 181.553 & 211.141 & 234.155 & 253,852 \\
\hline Marketing & $8 \%$ & 135.112 & 181.553 & 211.141 & 234.155 & 253,852 \\
\hline Atención al cliente & - & 43.200 & 43.200 & 43.200 & 43.200 & 43,200 \\
\hline $\begin{array}{l}\text { Concesionario } \\
\text { alimentos }\end{array}$ & - & 72.000 & 72.000 & 72.000 & 72.000 & 72,000 \\
\hline Seguridad & - & 65.000 & 65.000 & 65.000 & 65.000 & 65,000 \\
\hline Total & 4 & 568,646 & 702.164 & 787.231 & 853.395 & 910.023 \\
\hline
\end{tabular}

Elaboración propia

De la tabla 7.5 y del 7.13 se procedió a calcular los gastos administrativos totales:

Tabla 7.14

Presupuesto operativo de gastos administrativos

\begin{tabular}{|l|c|c|c|c|c|}
\cline { 2 - 6 } \multicolumn{1}{c|}{} & Año 2014 & Año 2015 & Año 2016 & Año 2017 & Año 2018 \\
\hline Gasto de Ventas & 568.646 & 702.164 & 787.231 & 853.395 & 910.023 \\
\hline Administración y Ventas & 213.000 & 213.000 & 213.000 & 213.000 & 213.000 \\
\hline Gastos Administrativos Totales & $\mathbf{7 8 1 . 6 4 6}$ & $\mathbf{9 1 5 . 1 6 4}$ & $\mathbf{1 . 0 0 0 . 2 3 1}$ & $\mathbf{1 . 0 6 6 . 3 9 5}$ & $\mathbf{1 . 1 2 3 . 0 2 3}$ \\
\hline
\end{tabular}

Elaboración propia 
Tabla 7.15

Depreciación de activos fijos tangibles en oficina

\begin{tabular}{|c|c|c|c|c|c|c|c|}
\hline Equipos & $\begin{array}{c}\text { Precio } \\
\text { unitario } \\
(\mathrm{S} / .)\end{array}$ & $\begin{array}{l}\text { Vida útil } \\
\text { (Años) }\end{array}$ & Año 2014 & Año 2015 & Año 2016 & Año 2017 & Año 2018 \\
\hline $\begin{array}{l}\text { Mobiliario } \\
\text { de oficina }\end{array}$ & 30.000 & 5 & 6.000 & 6.000 & 6.000 & 6,000 & 6,000 \\
\hline \multicolumn{3}{|c|}{ Total (S/.) } & 6.000 & 6.000 & 6.000 & 6.000 & 6.000 \\
\hline
\end{tabular}

Elaboración propia

Los mobiliarios de oficina incluyen computadoras, sillas, escritorios, muebles y armarios.

\subsection{Presupuestos financieros}

\subsubsection{Presupuesto de servicio de deuda}

Para el proyecto, se consideró que el $40 \%$ de la inversión será financiada por capital propio de la empresa, mientras que el $60 \%$ será financiado por una entidad financiera. La TEA de esta entidad será de un $30 \%^{11}$, mientras que el COK será de $20 \%$.

Para el cálculo del rendimiento del inversionista (Ke), se hará uso del CAPM, donde se tendrán los siguientes valores:

- Tasa libre de riesgo Perú (Rf): 3,08\%

- $\quad$ Beta de mercado $(\beta): 1,21$

- Rendimiento de Mercado (Rm): 9,32\%

$$
\mathrm{Ke}: \mathrm{Rf}+\beta \mathrm{x}(\mathrm{Rm}-\mathrm{Rf})
$$

Aplicando la fórmula, se obtiene que el rendimiento del inversionista es $10,63 \%$. Sin embargo, en comparación con el COK, este valor resulta muy bajo, por lo que para efectos del cálculo se usará el mismo valor para el análisis económico y financiero (20\%).

\footnotetext{
${ }^{11}$ Tasa efectiva anual que ofrece el Banco de Crédito del Perú (2015).
} 
Se tuvo en cuenta que el préstamo obtenido por la entidad financiera se pagará en un periodo de 5 años, mediante un modelo de cuotas crecientes, lo cual permitirá tener menores gastos al proyecto en sus inicios.

Tabla 7.16

\section{Servicio a la deuda}

\begin{tabular}{|l|c|c|c|c|c|}
\cline { 2 - 6 } \multicolumn{1}{c|}{} & Año 2014 & Año 2015 & Año 2016 & Año 2017 & Año 2018 \\
\hline Deuda inicial & 316.855 & 295.731 & 253.484 & 190.113 & 105.618 \\
\hline Amortización & 21.124 & 42.247 & 63.371 & 84.495 & 105.618 \\
\hline Interés & 95.056 & 88.719 & 76.045 & 57.034 & 31.685 \\
\hline Cuota & 116.180 & 130.967 & 139.416 & 141.528 & 137.304 \\
\hline Saldo Final & $\mathbf{2 9 5 . 7 3 1}$ & $\mathbf{2 5 3 . 4 8 4}$ & $\mathbf{1 9 0 . 1 1 3}$ & $\mathbf{1 0 5 . 6 1 8}$ & $\mathbf{0}$ \\
\hline
\end{tabular}

Elaboración propia 
7.4.2 Presupuesto de estado de resultados

Tabla 7.17

Estado de resultados económico

\begin{tabular}{|l|c|c|c|c|c|c|}
\cline { 2 - 6 } \multicolumn{1}{c|}{} & $\begin{array}{c}\text { Inversión } \\
\text { Inicial }\end{array}$ & Año 2014 & Año 2015 & Año 2016 & Año 2017 & Año 2018 \\
\hline Ingreso por ventas & & 1.688 .896 & 2.269 .408 & 2.639 .264 & 2.926 .936 & 3.173 .144 \\
\hline (-) Costo de ventas & & & & & & \\
\hline MP e Insumos & & 606.736 & 815.285 & 948.156 & 1.051 .502 & 1.139 .952 \\
\hline MOD & & 214.500 & 214.500 & 214.500 & 214.500 & 214.500 \\
\hline CIF fijo & 18.043 & 18.043 & 18.043 & 18.043 & 18.043 \\
\hline Depreciación & & 17.819 & 17.819 & 17.819 & 17.819 & 17.819 \\
\hline Utilidad Bruta & & 831.798 & 1.203 .761 & 1.440 .746 & 1.625 .072 & 1.782 .830 \\
\hline $\begin{array}{l}\text { (-) Gastos } \\
\text { Operativos }\end{array}$ & & & & & \\
\hline $\begin{array}{l}\text { Administración y } \\
\text { Ventas }\end{array}$ & & 213.000 & 213.000 & 213.000 & 213.000 & 213.000 \\
\hline Publicidad & & 568.646 & 702.164 & 787.231 & 853.395 & 910.023 \\
\hline Utilidad Operativo & & 50.152 & 288.597 & 440.516 & 558.677 & 659.807 \\
\hline & & & & & & \\
\hline UAI & & 50.152 & 288.597 & 440.516 & 558.677 & 659.807 \\
\hline$(-)$ Impuesto & 15.046 & 86.579 & 132.155 & 167.603 & 197.942 \\
\hline Utilidad Neta & $\mathbf{- 5 2 8 . 0 9 1}$ & $\mathbf{5 0 . 1 5 2}$ & $\mathbf{2 0 2 . 0 1 8}$ & $\mathbf{3 0 8 . 3 6 1}$ & $\mathbf{3 9 1 . 0 7 4}$ & $\mathbf{4 6 1 . 8 6 5}$ \\
\hline
\end{tabular}

Elaboración propia 
7.4.3 Presupuesto de estado de situación financiera

Tabla 7.18

Estado de resultados financiero

\begin{tabular}{|l|c|c|c|c|c|c|}
\cline { 2 - 7 } \multicolumn{1}{c|}{} & $\begin{array}{c}\text { Inversión } \\
\text { Inicial }\end{array}$ & Año 2014 & Año 2015 & Año 2016 & Año 2017 & Año 2018 \\
\hline Ingreso por ventas & & 1.688 .896 & 2.269 .408 & 2.639 .264 & 2.926 .936 & 3.173 .144 \\
\hline (-) Costo de ventas & & & & & & \\
\hline MP e Insumos & & 606.736 & 815.285 & 948.156 & 1.051 .502 & 1.139 .952 \\
\hline MOD & & 214.500 & 214.5000 & 214.500 & 214.500 & 214.500 \\
\hline CIF fijo & 18.043 & 18.043 & 18.043 & 18.043 & 18.043 \\
\hline Depreciación & & 17.819 & 17.819 & 17.819 & 17.819 & 17.819 \\
\hline Utilidad Bruta & & 831.798 & 1.203 .761 & 1.440 .746 & 1.625 .072 & 1.782 .830 \\
\hline (-) Gastos Operativos & & & & & & \\
\hline $\begin{array}{l}\text { Administración y } \\
\text { Ventas }\end{array}$ & & 213.000 & 213.000 & 213.000 & 213.000 & 213.000 \\
\hline Gasto de Ventas & & 568.646 & 702.164 & 787.231 & 853.395 & 910.023 \\
\hline Utilidad Operativo & & 50.152 & 288.597 & 440.516 & 558.677 & 659.807 \\
\hline (-) Interés & & 95.056 & 88.719 & 76.045 & 57.034 & 31.685 \\
\hline UAI & & -44.904 & 199.878 & 364.470 & 501.643 & 628.121 \\
\hline (-) Impuesto & & 46.492 & 109.341 & 150.493 & 188.436 \\
\hline Utilidad Neta & $\mathbf{- 5 2 8 . 0 9 1}$ & $\mathbf{- 4 4 . 9 0 4}$ & $\mathbf{1 5 3 . 3 8 6}$ & $\mathbf{2 5 5 . 1 2 9}$ & $\mathbf{3 5 1 . 1 5 0}$ & $\mathbf{4 3 9 . 6 8 5}$ \\
\hline
\end{tabular}

Elaboración propia 


\subsubsection{Presupuesto de caja de corto plazo}

Tabla 7.19

Presupuesto de corto plazo o flujo de tesorería

\begin{tabular}{|l|c|c|c|c|c|c|}
\cline { 2 - 6 } \multicolumn{1}{c|}{} & Año 0 & Año 1 & Año 2 & Año 3 & Año 4 & Año 5 \\
\hline $\begin{array}{l}\text { (+) Aporte recibido de } \\
\text { accionistas }\end{array}$ & 211.236 & & & & & \\
\hline (+) Financiamiento recibido & 316.855 & & & & & \\
\hline (-) Equipos & -63.158 & & & & & \\
\hline (-)Edificio & -70.000 & & & & & \\
\hline (-)Terreno & -235.200 & & & & & \\
\hline (-)Activos intangibles & -30.000 & & & & & \\
\hline Utilidad Neta & & -44.904 & 153.386 & 255.129 & 351.150 & 439.685 \\
\hline (-) C x C final & & -42.222 & -56.735 & -65.982 & -73.173 & -79.329 \\
\hline (+) CXC inicial & & 0 & 42.222 & 56.735 & 65.982 & 73.173 \\
\hline (+) C x Pagar & & 15.168 & 20.382 & 23.704 & 26.288 & 28.499 \\
\hline (-) C x Pagar inicial & & 0 & -15.168 & -20.382 & -23.704 & -26.288 \\
\hline $\begin{array}{l}\text { (+) Depreciación y amortización } \\
\text { intangibles }\end{array}$ & & 17.819 & 17.819 & 17.819 & 17.819 & 17.819 \\
\hline (-) Amortización de la deuda & & -21.124 & -42.247 & -63.371 & -84.495 & -105.618 \\
\hline (+) Financiamiento a corto plazo & & 80.000 & -40.000 & -40.000 & & \\
\hline Flujo de Caja & $\mathbf{1 2 9 . 7 3 3}$ & $\mathbf{4 . 7 3 7}$ & $\mathbf{7 9 . 6 5 9}$ & $\mathbf{1 6 3 . 6 5 3}$ & $\mathbf{2 7 9 . 8 6 7}$ & $\mathbf{3 4 7 . 9 4 2}$ \\
\hline Balance de Caja & $\mathbf{1 2 9 . 7 3 3}$ & $\mathbf{1 3 4 . 4 7 0}$ & $\mathbf{2 1 4 . 1 2 9}$ & $\mathbf{3 7 7 . 7 8 2}$ & $\mathbf{6 5 7 . 6 4 8}$ & $\mathbf{1 . 0 0 5 . 5 9 0}$ \\
\hline
\end{tabular}

Elaboración propia

Dado los resultados del primer año, se deberá recurrir a un financiamiento de corto plazo de S/. 80.000 nuevos soles para tener un flujo de caja positivo y no operar en negativo. 


\subsection{Flujo de fondos netos}

\subsubsection{Flujo de fondos económicos}

Tabla 7.20

Flujo de fondos económicos del proyecto

\begin{tabular}{|l|c|c|c|c|c|c|}
\cline { 2 - 7 } \multicolumn{1}{c|}{} & Año 0 & Año 1 & Año 2 & Año 3 & Año 4 & Año 5 \\
\hline U. Neta & & 35.106 & 202.018 & 308.361 & 391.074 & 461.865 \\
\hline (+) Depreciación & & 17.819 & 17.819 & 17.819 & 17.819 & 17.819 \\
\hline (-) Terreno & 235.200 & & & & & \\
\hline (-) equipos & 33.158 & & & & & \\
\hline (-) Edificio & 70.000 & & & & & \\
\hline (-) Mobiliarios de oficina & 30.000 & & & & & \\
\hline (-) Activos intangibles & 30.000 & & & & & \\
\hline (-) Capital de trabajo & 129.733 & & & & & \\
\hline (+) recupera cap. de trabajo & & & & & & 129.733 \\
\hline Flujo Caja Neto ( Económico) & $\mathbf{- 5 2 8 . 0 9 1}$ & $\mathbf{5 2 . 9 2 5}$ & $\mathbf{2 1 9 . 8 3 7}$ & $\mathbf{3 2 6 . 1 8 0}$ & $\mathbf{4 0 8 . 8 9 3}$ & $\mathbf{6 0 9 . 4 1 7}$ \\
\hline
\end{tabular}

Elaboración propia

\subsubsection{Flujo de fondos financieros}

Tabla 7.21

Flujo de fondos financieros del proyecto

\begin{tabular}{|l|c|c|c|c|c|c|}
\cline { 2 - 7 } \multicolumn{1}{c|}{} & Año 0 & Año 1 & Año 2 & Año 3 & Año 4 & Año 5 \\
\hline U. Neta & & -44.904 & 153.386 & 255.129 & 351.150 & 439.685 \\
\hline (+) Depreciación & & 17.819 & 17.819 & 17.819 & 17.819 & 17.819 \\
\hline (-) Amort. de la deuda & 21.124 & 42.247 & 63.371 & 84.495 & 105.618 \\
\hline (-) Terreno & 235.200 & & & & & \\
\hline (-) Edificio & 70.000 & & & & & \\
\hline (-) equipos & 33.158 & & & & & \\
\hline (-) Mobiliarios de oficina & 30.000 & & & & & \\
\hline (-) Activos intangibles & 30.000 & & & & & \\
\hline (-) Capital de trabajo & 129.733 & & & & & \\
\hline (+) recupera cap. de trabajo & & & & & & 129.733 \\
\hline (+) Financiamiento Recibido & 316.855 & & & & & \\
\hline Flujo Caja Neto ( Financiero) & $\mathbf{- 2 1 1 . 2 3 6}$ & $\mathbf{- 4 8 . 2 0 9}$ & $\mathbf{1 2 8 . 9 5 8}$ & $\mathbf{2 0 9 . 5 7 8}$ & $\mathbf{2 8 4 . 4 7 5}$ & $\mathbf{4 8 1 . 6 1 9}$ \\
\hline
\end{tabular}

Elaboración propia 


\section{CAPÍTULO VIII. EVALUACIÓN ECONÓMICA Y FINANCIERA DEL PROYECTO}

8.1 Evaluación económica: VAN, TIR, B/C, PR

\section{Tabla 8.1}

Evaluación económica del proyecto

\begin{tabular}{|l|c|}
\hline VAN Económica & $299.540,65$ \\
\hline TIR Económica & $36.76 \%$ \\
\hline Relación B/c & S/. 1,881 \\
\hline Periodo de Recupero & 2,790 \\
\hline
\end{tabular}

Elaboración propia

8.2 Evaluación financiera: VAN, TIR, B/C, PR

Tabla 8.2

Evaluación financiera del proyecto

\begin{tabular}{|l|c|}
\hline VAN Financiero & $290.167,30$ \\
\hline TIR Financiero & $49.21 \%$ \\
\hline Relación B/c & S/. 2.848 \\
\hline Periodo de Recupero & 2,615 \\
\hline
\end{tabular}

Elaboración propia

8.3 Análisis de ratios (liquidez, solvencia, rentabilidad) e indicadores económicos y financieros del proyecto

Para poder hacer el análisis de los ratios de liquidez, solvencia y rentabilidad es necesario elaborar el balance general de los 5 años: 
Tabla 8.3

Balance general al 5 año de operación

\begin{tabular}{|l|c|c|c|c|c|c|}
\cline { 2 - 7 } \multicolumn{1}{l|}{} & Año 0 & Año 1 & Año 2 & Año 3 & Año 4 & Año 5 \\
\hline Activo & & & & & & \\
\hline Caja & 129.733 & 134.470 & 214.129 & 377.782 & 657.648 & 1.005 .590 \\
\hline Cuentas por cobrar & & 42.222 & 56.735 & 65.982 & 73.173 & 79.329 \\
\hline Activo fijo & 368.358 & 368.358 & 368.358 & 368.358 & 368.358 & 368.358 \\
\hline Intangibles & 30.000 & 30.000 & 30.000 & 30.000 & 30.000 & 30.000 \\
\hline Depreciación & & -17.819 & -35.638 & -53.457 & -71.276 & -89.096 \\
\hline Total Activos & $\mathbf{5 2 8 . 0 9 1}$ & $\mathbf{5 5 7 . 2 3 1}$ & $\mathbf{6 3 3 . 5 8 4}$ & $\mathbf{7 8 8 . 6 6 4}$ & $\mathbf{1 . 0 5 7 . 9 0 3}$ & $\mathbf{1 . 3 9 4 . 1 8 1}$ \\
\hline & & & & & & \\
\hline Pasivos & & & & & & \\
\hline Cuentas por pagar CP & & 15.168 & 20.382 & 23.704 & 26.288 & 28.499 \\
\hline Financiamiento CP & & 80.000 & 40.000 & 0 & 0 & 0 \\
\hline Financiamiento LP & 316.855 & 295.731 & 253.484 & 190.113 & 105.618 & 0 \\
\hline Total Pasivos & $\mathbf{3 1 6 . 8 5 5}$ & $\mathbf{3 9 0 . 8 9 9}$ & $\mathbf{3 1 3 . 8 6 6}$ & $\mathbf{2 1 3 . 8 1 7}$ & $\mathbf{1 3 1 . 9 0 6}$ & $\mathbf{2 8 . 4 9 9}$ \\
\hline & & & & & & \\
\hline Patrimonio & & & & & & \\
\hline Capital social & 211.236 & 211.236 & 211.236 & 211.236 & 211.236 & 211.236 \\
\hline Resultados acumulados & 0 & -44.904 & 108.491 & 363.611 & 714.761 & 1.154 .446 \\
\hline Total Patrimonio & $\mathbf{2 1 1 . 2 3 6}$ & $\mathbf{1 6 6 . 3 3 2}$ & $\mathbf{3 1 9 . 7 1 8}$ & $\mathbf{5 7 4 . 8 4 7}$ & $\mathbf{9 2 5 . 9 9 7}$ & $\mathbf{1 . 3 6 5 . 6 8 2}$ \\
\hline & & & & & & \\
\hline $\begin{array}{l}\text { Total Pasivo y } \\
\text { Patrimonio }\end{array}$ & $\mathbf{5 2 8 . 0 9 1}$ & $\mathbf{5 5 7 . 2 3 1}$ & $\mathbf{6 3 3 . 5 8 4}$ & $\mathbf{7 8 8 . 6 6 4}$ & $\mathbf{1 . 0 5 7 . 9 0 3}$ & $\mathbf{1 . 3 9 4 . 1 8 1}$ \\
\hline
\end{tabular}

Elaboración propia

Tabla 8.4

Análisis de ratios

\begin{tabular}{|l|c|c|c|c|c|c|}
\cline { 2 - 7 } \multicolumn{1}{c|}{} & Año 0 & Año 1 & Año 2 & Año 3 & Año 4 & Año 5 \\
\hline Liquidez & & & & & & \\
\hline Razón corriente & & 1,86 & 4,49 & 18,72 & 27,80 & 38,07 \\
\hline Razón de efectivo & & 8,87 & 10.51 & 15,94 & 25,02 & 35,29 \\
\hline Solvencia & & & & & & \\
\hline Razón deuda patrimonio & & 2,35 & 0,98 & 0,37 & 0,14 & 0,02 \\
\hline Razón de deuda & & 0,70 & 0,50 & 0,27 & 0,12 & 0,02 \\
\hline Rentabilidad & & & & & & \\
\hline ROA & & $-8,1 \%$ & $24,2 \%$ & $32,3 \%$ & $33,2 \%$ & $31,5 \%$ \\
\hline ROE & & $-27,0 \%$ & $48,0 \%$ & $44,4 \%$ & $37,9 \%$ & $32,2 \%$ \\
\hline
\end{tabular}

Elaboración propia 
Los ratios de liquidez muestran que a medida que avanzan los años, la empresa cuenta con mayores recursos para cubrir sus deudas a corto plazo.

Los ratios de solvencia o endeudamiento muestran que a inicios del proyecto hay un mayor grado de deuda y mayor involucramiento por parte de terceros, pero a medida que el proyecto continua, los ratios mejoran y la relación de deuda por cada sol invertido es mucho menor.

Los ratios de rentabilidad muestran que el primer año los resultados son pequeños ya que la inversión inicial impacta en los resultados del proyecto, sin embargo, a medida que van pasando los años, la rentabilidad de los activos aumenta, así como las utilidades que se generan con la inversión de los accionistas.

\section{Análisis de los indicadores económicos}

Los indicadores económicos previamente expuestos demuestran que el proyecto es viable y conveniente, con un valor actual neto de S/. 299.540,65, lo que determina que este proyecto generará un retorno de flujo a la actualidad. A su vez la TIR económica arroja un valor claramente superior al COK del proyecto. Adicionalmente, la relación B/C de 1,881. Finalmente se determinó que el periodo de recupero es de 2 años y 10 meses aproximadamente.

\section{Análisis de los indicadores financieros}

Los indicadores financieros al igual que los económicos, demuestran que el proyecto es viable con un valor actual neto de S/.290.167,30, lo que determina que este proyecto generará un retorno y ganancia a la actualidad. A su vez, la TIR financiera arroja un valor superior al rendimiento del inversionista del proyecto. Adicionalmente, existe una relación beneficio costo de S/. 2,848 nuevos soles. Finalmente se determinó un perdido de recupero de 2 años y 8 mes aproximadamente.

De acuerdo a los resultados mostrados, se concluye que se hará uso del financiamiento ya que en su mayoría los indicadores financieros son superiores al económico. 


\subsection{Análisis de sensibilidad del proyecto}

A continuación se hará un análisis de sensibilidad por si existe algún cambio que origine que el volumen del proyecto aumente o disminuye y como ello afecta los indicadores, por ello, se realizará el estudio para una variación de $10 \%$ anual:

\section{Tabla 8.5}

Análisis de sensibilidad por cambio en el volumen

\begin{tabular}{|c|c|c|c|}
\hline Indicador & $-10 \%$ Volumen & Propuesta original & $+10 \%$ volumen \\
\hline TIR & $28,97 \%$ & $49,21 \%$ & $87,87 \%$ \\
\hline VAN & $87.255,7$ & $290.167,3$ & $639.985,5$ \\
\hline
\end{tabular}

Elaboración propia

Con los resultados obtenidos, se observa que con una variación en el volumen genera una variación en el resultado de los indicadores, con lo cual convendría en un futuro aumentar el volumen de venta.

Por otro lado, si el volumen de ventas se mantuviera y lo que cambie sería el precio, se consideró un cambio de S/. 0,50 centavos, con lo cual el efecto sería el siguiente:

Tabla 8.6

Análisis de sensibilidad por cambio en el precio

\begin{tabular}{|c|c|c|c|}
\hline Indicador & $-\mathrm{S} / 0.50$ precio & Propuesta original & $+\mathrm{S} / 0.50$ precio \\
\hline TIR & $24,45 \%$ & $49,21 \%$ & $74,77 \%$ \\
\hline VAN & $44.315,5$ & $290.167,3$ & $536.019,1$ \\
\hline
\end{tabular}

Elaboración propia

Con los resultados obtenidos, podemos observar que un cambio de $\mathrm{S} / \mathrm{0,50}$ nuevos soles en el precio afectaría considerablemente el resultado de los indicadores financieros, por lo que se puede entender que el proyecto es muy sensible al cambio de precio del producto. 


\section{CAPÍTULO IX. EVALUACIÓN SOCIAL DEL PROYECTO}

\subsection{Identificación de las zonas y comunidades de influencia del proyecto}

El proyecto se establecerá en el Callao y se tratará de establecer en una zona industrial, que podría ser la avenida Argentina, cerca de la ciudad comercial Minka. Las comunidades aledañas a la zona son: Los pilares, Renovación palomino, Santa Rosa, Miguel Grau, Gambetta, Alfonso Aguilar y la urbanización Castilla, de estas comunidades se podría contratar al personal para que así ahorren tiempo y dinero para movilizarse.

Se tratará de colocar cerca de Minka, ya que permitiría abastecer de los insumos necesarios de una forma rápida y con poco costo de transporte.

\subsection{Análisis de indicadores sociales (valor agregado, densidad de capital, intensidad de} capital)

\section{Valor agregado}

Este indicador permitirá medir el valor generado por el proceso productivo, se incluyen los sueldos, salarios y el pago al capital. Para efectos de la tasa de descuento (TSD), se empleó como valor $12 \%$.

Valor agregado: Sueldos + Salarios + Pago al capital

\section{Tabla 9.1}

Valor agregado del proyecto

\begin{tabular}{|l|c|c|c|c|c|}
\cline { 2 - 6 } \multicolumn{1}{c|}{} & $\mathbf{2 0 1 4}$ & $\mathbf{2 0 1 5}$ & $\mathbf{2 0 1 6}$ & $\mathbf{2 0 1 7}$ & $\mathbf{2 0 1 8}$ \\
\hline Sueldos & 213,000 & 213,000 & 213,000 & 213,000 & 213,000 \\
\hline Salarios & 214,500 & 214,500 & 214,500 & 214,500 & 214,500 \\
\hline Depreciación & 17,819 & 17,819 & 17,819 & 17,819 & 17,819 \\
\hline Intereses & 95,056 & 88,719 & 76,045 & 57,034 & 31,685 \\
\hline impuestos & 0 & 103,640 & 147,446 & 192,751 & 234,249 \\
\hline $\begin{array}{l}\text { Valor } \\
\text { Agregado }\end{array}$ & $\mathbf{5 4 0 , 3 7 5}$ & $\mathbf{6 3 7 , 6 7 8}$ & $\mathbf{6 6 8 , 8 1 0}$ & $\mathbf{6 9 5 , 1 0 3}$ & $\mathbf{7 1 1 , 2 5 3}$ \\
\hline Actualizado & 482,478 & 508,353 & 476,046 & 441,751 & 403,584 \\
\hline Acumulado & $\mathbf{4 8 2 , 4 7 8}$ & $\mathbf{9 9 0 , 8 3 1}$ & $\mathbf{1 , 4 6 6 , 8 7 7}$ & $\mathbf{1 , 9 0 8 , 6 2 8}$ & $\mathbf{2 , 3 1 2 , 2 1 2}$ \\
\hline
\end{tabular}

Elaboración propia 
Con lo que se obtiene un valor agregado de S/. 2.312.212 soles.

\section{Densidad de capital}

La densidad de capital mide el grado de inversión por cada trabajador de la empresa.

$$
\begin{gathered}
\text { Densidad de capital }=\frac{\text { Inversión total }}{\# \text { de trabajadores }} \\
\text { Densidad de capital }=\frac{528.091}{12}
\end{gathered}
$$

Este indicador señala que por cada trabajador se hace una inversión de S/. 44,008 nuevos soles.

\section{Intensidad de capital}

$$
\begin{gathered}
\text { Intensidad de capital }=\frac{\text { Inversión total }}{\text { Valor agregado }} \\
\text { Intensidad de capital }=\frac{528.091}{2.312 .212}
\end{gathered}
$$

Este indicador nos muestra que se necesita invertir 0,23 soles para ganar un sol de valor agregado. 


\section{CONCLUSIONES}

- La instalación de una planta que produce un complemento alimenticio a base de harina de sangre de pollo y cacao es viable tecnológica, económica y financieramente viable.

- El producto tendrá aceptación ya que según las encuestas, el público objetivo NSE $\mathrm{C} / \mathrm{D}$ demuestra interés en el producto.

- El producto se diferenciara de las marcas actuales como Kiwigen, Sustagen, Enfagrow, Ensure y Forticao, mediante una estrategia de precios; ya que se ingresará con un precio inferior al de la competencia y empleará un insumo que es considerado como residuo del sacrificio del pollo..

- El mercado es el limitante de la capacidad de la planta, ya que por el lado de la maquinaria, esta tiene capacidad para producir más.

- La materia prima existente en el mercado local es la necesaria para satisfacer la demanda del proyecto.

- El proyecto generará nuevos puestos de trabajo que ayudara a la población y a la economía de las zonas aledañas. 


\section{RECOMENDACIONES}

- Ampliar el mercado local existente y posicionar la marca mediante alianzas con las principales cadenas de supermercados y bodegas.

- Implementado el proyecto se debe analizar la posibilidad de exportar al extranjero, con esto aumentando el mercado y usar la capacidad de los equipos al máximo o si se da el caso, expandir la planta.

- Poner en marcha el proyecto mediante financiamiento ya que los préstamos sirven como escudo fiscal.

- Llevar a cabo el proyecto teniendo en cuenta toda la normativa legal vigente, a fin de evitar costos por desinformación e incluso fuertes penalidades.

- Implementar en un futuro un sistema de gestión de la calidad e inocuidad (ISO 22000).

- Contar con la respectiva mano de obra calificada para poder realizar las labores de producción requeridas. 


\section{REFERENCIAS}

Agencia Agraria de Noticias. (Abril de 2014). Recuperado de Exportaciones peruanas en cacao en granose duplicaron: http://agraria.pe/noticia.php?url=exportacionesperuanas-de-cacao-en-grano-se-duplicaron \&id=2817

Alibaba. (2014). Recuperado de Mezclador: http://spanish.alibaba.com/p-detail/jbfarmac\%C3\%A9utico-mezclador-de-polvo-de-la-m\%C3\%A1quina300003588590.html

Alibaba. (2014). Recuperado de Horno: http://spanish.alibaba.com/p-detail/de-vaporindustrial-chaqueta-hervidor-de-agua-300002983965.html

Alibaba. (2014). Recuperado de Tamizador: http://spanish.alibaba.com/product-gs/floursieve-separator-machine-1689988628.html?s=p

Alibaba. (2014). Recuperado de Secador: http://www.alibaba.com/product-detail/Fabricanteprofesional-de-secadoras-industriales_1391862771.html

Alibaba. (2014). Recuperado de Mezclador: http://spanish.alibaba.com/p-detail/Des\%C3\%A9samo-amoladoras-moledoras-esmeriles-m\%C3\%A1quina-deman\% $3 \% \mathrm{AD}$-mantequilla-de-cacahuete-amoladoras-moledoras-esmeriles-molinocoloidal-300003082140.html

Alibaba. (2014). Recuperado de Lavadora: http://spanish.alibaba.com/p-detail/industrialwashing-machine-15kg-300kg-300000167743.html

Alibaba. (2014). Recuperado de Secador: http://spanish.alibaba.com/p-detail/Miniequipamiento-secadora-precio300007490021.html?spm=a2700.7725975.35.1.ndw2T5

Apoyo, I. (2014). IGM Estadística Poblacional 2014.

Asfahl, C. R. (2000). Seguridad Industrial y Salud. Mexico: Prentice Hall.

Banco Central de Reserva del Perú. (s.f.). Recuperado de Revista moneda. ¿Cúal es el retorno mínimo exigido para invertir en una entidad financiera peruana?: http://www.bcrp.gob.pe/docs/Publicaciones/Revista-Moneda/moneda-151/moneda151-04.pdf

Díaz, B., Jarufe, B., \& Noriega, M. (2007). Disposición de planta. Lima: Fondo Editorial.

Emapacopsa. (s.f.). Recuperado de Estructura tarifaria vigente del 01-07-2013-SUNASS. http://www.emapacopsa.com.pe/doc/tarifa2013.pdf

EPSMOYOBAMBA. (s.f.). Recuperado de Resolución de Gerencia General № 031-2012-EPSM/GG. http://epsmoyobamba.com.pe/gobernanza/doc/tarifas2012.pdf

Euromonitor . (2014). Recuperado de Vitamins and Dietary Supplements: http://www.portal.euromonitor.com/Portal/Pages/Search/SearchResultsList.aspx

Informática, I. N. (s.f.). INEI. Recuperado de Estadísticas: http://www.inei.gob.pe/estadisticas/indice-tematico/ocupacion-y-vivienda/

Instituto de la Contrucción y Gerencia. (s.f). Recuperado de Instalaciones eléctricas y mecánicas. Norma EM. 010.

http://www.construccion.org.pe/normas/rne2012/rne2006/files/titulo3/04_EM/RNE20 06_EM_010.pdf

Ipsos Apoyo. (2010). Recuperado de Perfiles Zonales de la Gran Lima 2010.

Ipsos Apoyo Opinión y Mercado. (2011). Recuperado de Liderazgo en productos comestibles 2011.

Konz, S. (1994). Diseño de sistemas de trabajo. México: Linusa. 
Ministerio de Energía y Minas, M. d. (s.f.). Guía de orientación para la selección de la tarifa eléctrica a usuarios finales en baja tensión. Recuperado de file:///C:/Users/R101617/Downloads/prepublicacion-z4wn17w0x26z77784cz.PDF

Ministerio Comercio Exterior y Turísmo. (s.f.). Recuperado de Región Ucayali: http://www.mincetur.gob.pe/newweb/Portals/0/UCAYALI.pdf

Ministerio de Agricultura y Riego. (s.f.). Recuperado de Principales productores: http://www.minag.gob.pe/portal/sector-agrario/pecuaria/principales-productores\#1

Ministerio de Comercio Exterior y Turismo. (s.f.). Recuperado de San Martín: http://www.mincetur.gob.pe/newweb/Portals/0/SAN_MARTIN.pdf

Nafarroa Gestión. (2014).Recuperado de Actuación en la ejecución de los planes de la calidad sanitaria. http://www.gruponafarroa.es/gestion/Html/calidad-productos-sanitarios.htm

Natural Nutrition. (2014). Recuperado de Forticao: http://naturalnutrition.com.pe/forticao.html

Sanchez, N. (2000). Los alimentos en el Perú. Recuperado de Revista peruana de Cardiología: http://sisbib.unmsm.edu.pe/bvrevistas/cardiologia/v26_n2/alimentos.htm

Sedapal. (s.f.). Recuperado de Ejemplos de aplicación de tarifa diferenciada por uso de la red de agua y desague publicada en el peruano el 05.06.2011 y vigente a partir del 06.06.2011. http://www.sedapal.com.pe/c/document_library/get_file?uuid=c0c0fcfe125c-4553-afa8-ccd10068ecd1 \&groupId=29544

Seton. (s.f.). Recuperado de Paneles de seguridad: http://www.seton.es/paneles-seguridadsenalizacion.html

Sunass. (2013). Recuperado de La EPS y su desarrollo: http://www.sunass.gob.pe/doc/eps_desarrollo_2013.pdf

United States Department of Labor (s.f). Recuperado de Occupational Safety \& Health Administration.

https://www.osha.gov/pls/oshaweb/owadisp.show_document?p_table=STANDARDS \&p_id=9790\#1910.141(c)(1)(i)

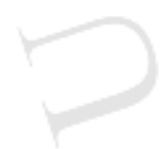




\section{BIBLIOGRAFÍA}

Acción contra el hambre. (2013). Recuperado de El Problema de la anemia en el Perú: http://www.accioncontraelhambre.org/files/file/informes/anemia_peru.pdf

$A D E X$ PERU. (s.f.). Recuperado de Kiwigen ingresa a competir con fuerza en canal tradicional.

http://www.adexperu.org.pe/BoletinesD/Prensa/BPrensa.asp?bol=2177\&cod=6

Aguirre, S. (2010). Estudio preliminar para la instalación de una planta productora de suplemento proteico a base de agua de cola de pescado en comprimidos. Lima.

Alimentación sana. (s.f.). Recuperado de La importancia del magnesio: http://www.alimentacion-sana.org/informaciones/novedades/magnesio2.htm

Armstrong, G., \& Kotler, P. (2008). Fundamentos de Marketing. Mexico: Pearson Educación.

Banco Central de Reserva del Perú. (s.f.). Recuperado de Análisis de la Avicultura nacional y regional 2013. http://www.bcrp.gob.pe/docs/Proyeccion-Institucional/EncuentrosRegionales/2013/la-libertad/eer-la-libertad-2013-medrano.pdf

Complejo Vitamínico. (s.f.). Recuperado de Producción industrial de un complejo vitaminico: http://www.complejovitaminico.com/produccion-industrial-de-un-complejovitaminico/produccin-industrial-de-un-complejo-vitamnico

Cottle Gray, J., \& Rodriguez Paiva, R. (2010). Estudio preliminar para la instalación de una planta de producción de un sustituto alimenticio en base a ingredientes naturales. Lima.

El Comercio. (s.f.). Recuperado de Producción nacional de pollo registró máximo histórico en mayo: http://elcomercio.pe/economia/peru/produccion-nacional-pollo-registromaximo-historico-mayo-noticia-1428307

El Comercio. (2013). Recuperado de El Perú se encuentra entre los 20 mayores productores avícolas del mundo: http://elcomercio.pe/economia/negocios/peru-se-encuentra-entre20-mayores-productores-avicolas-mundo-noticia-1592234

El Popular. (2014). Recuperado de Aquilina Palomino, La mamá del forticao. http://www.elpopular.pe/series/mujeres-batalla/2015-05-24-aquilina-palomino-lamama-del-forticao

Engormix. (2007). Recuperado de Proceso artesanal de producción de harina de sangre de bovino: http://www.engormix.com/MA-balanceados/formulacion/articulos/procesoartesanal-produccion-harina-t1833/800-p0.htm

Equilibrium. (s.f.). Recuperado de Informe de clasificación San Fernando: http://www.equilibrium.com.pe/SanFernando.pdf

FUNIBER. (2012). Recuperado de Fundación Universitaria Iberoamericana: http://composicionnutricional.com/alimentos/POLLO-SANGRE-CRUDA-DE-4

FUNIBER. (2012). Recuperado de Fundación Universitaria Iberoamericana: http://composicionnutricional.com/alimentos/POLLO-SANGRE-COCIDA-4

Guevara, Z. Z. (2006). Costo y efectividad de la ingesta de sangre de pollo en el tratamiento de anemia ferropénica en estudiantes de la EAP. de la facultad de obstetricia de la facultad de medicina de la UNMSM. Lima.

Gutierrez, A. G. (2002). Desarrollo de un alimento funcional a partir de hierro héminico y valuación de su biodisponibilidad, para la prevención y corrección de la deficiencia de hierro. Barcelona.

Machuca, O. M. (2012). Diseño y desarrollo de panes enriquecidos con proteinas y minerales, por incorporacion de harinas de sangre de pollo (Gallus domésticus) y de muña (Minthostachis mollis). Lima. 
Manual de espacios de oficinas por orden funcional. (Agosto de 2005). Recuperado de Manual de espacios de oficina por orden funcional.

$\mathrm{ftp} / / / \mathrm{ftp} 2$. sat.gob.mx/asistencia_ftp/publicaciones/normateca/documentos/acrm/Manua

1_Espacios_Orden_Funcional.pdf

Medline Plus. (Abril de 2014). Recuperado de Vitaminas.

http://www.nlm.nih.gov/medlineplus/spanish/vitamins.html

Ministerio de Finanzas, (s.f.). Recuperado de Directiva General del Sistema Nacional de Inversión Pública.

https://www.mef.gob.pe/contenidos/inv_publica/docs/normas/normasv/snip/Anexo_S NIP_10_modificado_por_la_RD003_2012.pdf

Ministerio de Salud. (2013). Recuperado de Instituto Nacional de Salud: http://www.ins.gob.pe/portal/noticias/noticia/0/989/la-sangrecita-economica-ynutritiva

Natursan. (2009). Recuperado de Los beneficios del cacao: http://www.natursan.net/losbeneficios-del-cacao/

Perufarma. (2014). Recuperado de Perufarma: http://www.perufarma.com.pe/pf_productosm.asp?marca=74\&division=1\&page=3

Producción de cacao en el Perú. (s.f.). Recuperado de Encuentro nacional de cacao http://www.appcacao.org/descargas/IX\%20ENCUENTRO\%20NACIONAL\%20DE\% 20CACAO\%20EXPOSICIONES/BLOQUE\%20I\%20EL\%20MERCADO $\% 20$ Y\% 20 LA\%20CALIDAD\%20DEL\%20CACAO\%20Y\%20CHOCOLATE/TEMA\%2002INOCUIDAD\%20EN\%20LA\%20CADENA\%20ALIMENTARIA\%20DE/Produccion $\% 20 \mathrm{de} \% 20$ Cacao $\% 20 \mathrm{en} \% 20 \mathrm{el} \%$

Real Académia Española. (Abril de 2014). Recuperado de http://www.rae.es/

RPP Noticias. (2013). Recuperado de Salud en RPP: http://www.rpp.com.pe/2013-09-20sangrecita-de-pollo-rica-en-hierro-y-combate-la-anemia-noticia_632944.html

RPP Noticias. (2013). Recuperado de Salud en RPP: http://www.rpp.com.pe/2013-01-07-dosde-cada-10-ninos-sufren-desnutricion-cronica-en-peru-noticia_555463.html

Sánchez, E. (2011). Estudio preliminar para la instalación de una planta procesadora de suplementos proteicos a base de quinua, kiwicha y tarwi. Lima.

Superintendencia Nacional de Tributos. (2014). Recuperado de SUNAT: http://www.sunat.gob.pe/cl-at-ittipcam/tcS01Alias

UNICEF . (2013). Recuperado de http://www.unicef.org/peru/spanish/Peru-600milninosdesnutridos.jpg

Universidad Autónoma Metropolitana Unidad Xochimilco. (s.f.). Recuperado de Densidad de la sangre en pollos de engorda con y sin síndrome ascítico:

http://bidi.xoc.uam.mx/resumen_articulo.php?id=7648\&archivo=5-536-

7648fyi.pdf\&titulo_articulo=Densidad $\% 20 \mathrm{de} \% 201 \mathrm{l} \% 20$ sangre $\% 20 \mathrm{en} \% 20$ pollos\%20d e $\% 20$ engorda\%20con $\% 20 \mathrm{y} \% 20 \sin \% 20$ s\%EDndrome\%20asc\%EDtico

Universidad de Zaragoza. (s.f.). Recuperado de Comisión ética asesora para la experimentación animal:

http://cea.unizar.es/Disenos_experimentales/Sangre/VOLUMEN\%20SANGRE\%20CI RCULANTE.pdf

Waala. (2013). Recuperado de Forticao: http://www.forticao.pe/quees.html

Zonadiet. (s.f.). Recuperado de El fósforo en la nutrición: http://www.zonadiet.com/nutricion/fosforo.htm

Zonadiet. (s.f.). Recuperado de Hierro en la nutricion. http://www.zonadiet.com/nutricion/hierro.htm 


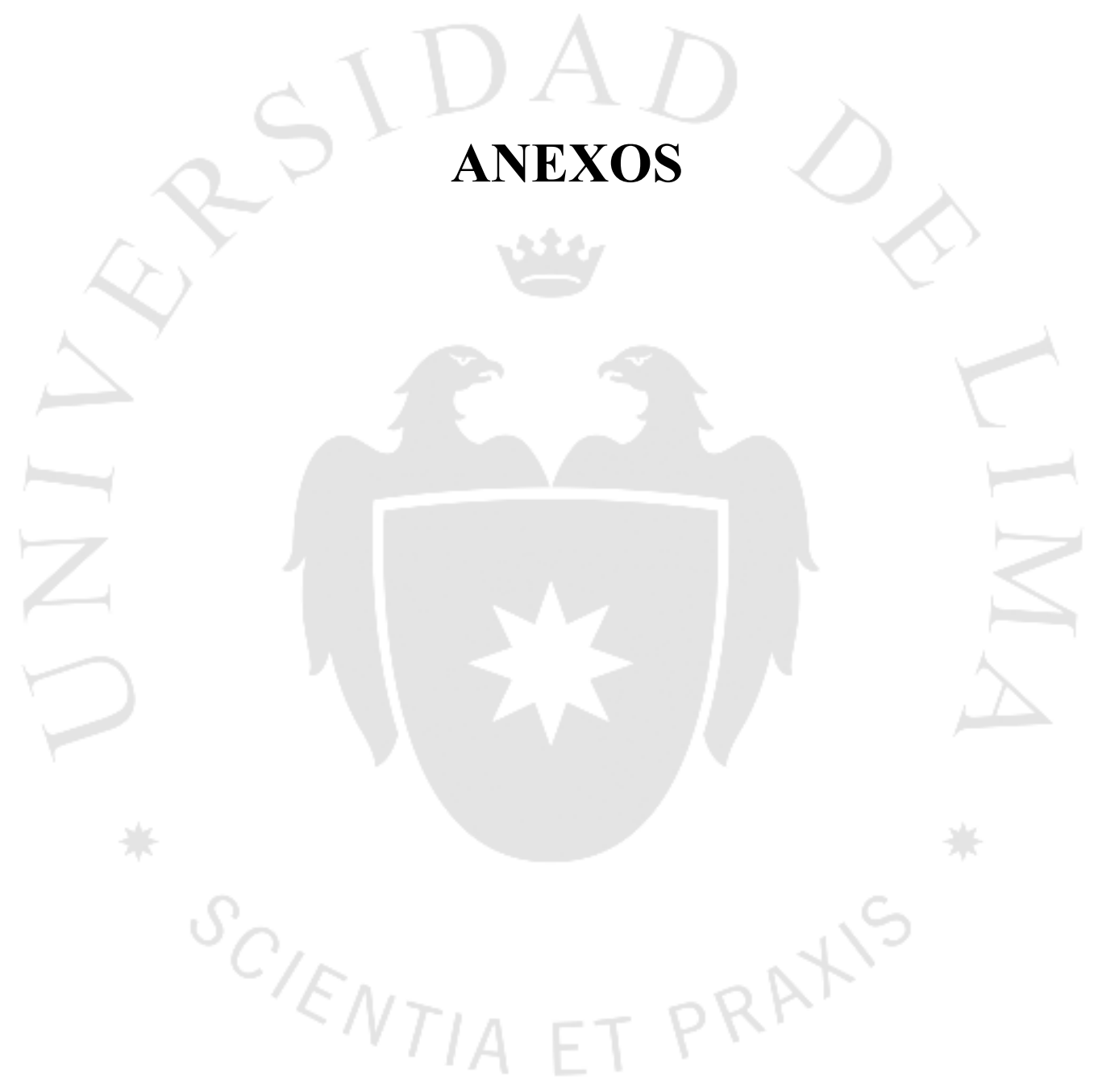




\section{ANEXO 1: ENCUESTA}

Un complemento alimenticio es un producto cuya finalidad es, como su nombre indica, es complementar la alimentación de las personas para obtener mayores beneficios en prevenir enfermedades y mejorar la salud. El producto en estudio está hecho a base de hierro hemínico, que es el hierro que se obtiene de sangre de animal.

1. ¿Consume complementos vitamínicos? (Sí la respuesta es NO, la encuesta concluye)

$$
\text { ( ) SI ( ) NO }
$$

2. ¿Lleva un estilo de vida saludable?

$$
\text { ( ) SI ( ) NO }
$$

3. ¿De qué forma le gusta consumir complementos vitamínicos?
a) Tabletas
b) Polvo
c) $\mathrm{Gel}$
d) Otro

4. ¿Con qué frecuencia consume complementos vitamínicos?
a) Diario
b) De 2 a 3 veces por semana
c) Una vez a la semana
d) Otro

5. ¿Qué es lo primero que se fija en el producto?

a) Precio

b) Presentación

c) Beneficios

d) Cantidad 
6. ¿Le gustaría consumir un complemento vitamínico natural a base de hierro hemínico? ( ) SI ( ) NO

7. ¿Cuál es el precio que estaría dispuesto a pagar?
a) De 10 a 15 soles
b) De 16 a 20 soles
c) De 21 a 25 soles
d) De 26 a 30 soles
e) Más de 30 soles

8. ¿En qué lugares preferiría comprar el producto?
a) Supermercados
b) Boticas
c) Bodegas
d) Otros puntos de venta

Gracias por su tiempo 
Conclusiones de la Encuesta

- De 30 personas entrevistadas, 15 manifestaron que les gustaría consumir un complemento vitamínico a base de hierro hemínico.

- EL $37 \%$ de las personas encuestadas manifestaron mantener un estilo de vida saludable.

- $\quad$ El $73 \%$ de los encuestados se fija primero en el precio.

- El precio que estarían dispuestos a pagar por un complemento alimenticio, en su gran mayoría, está en el rango de 5 a 10 soles.

- La frecuencia de consumo de los complementos vitamínicos, en un $87 \%$ de los encuestados es diario.

- El lugar preferido de compra son los supermercados con un $60 \%$ de los encuestados, es decir 18 personas. 